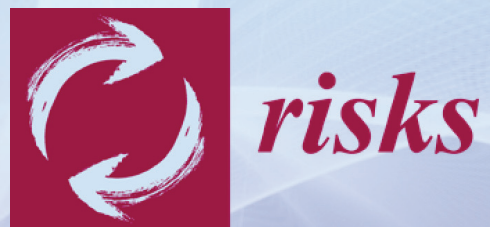

\title{
The Risk Landscape
}

within FinTech

and InsurTech

\section{Business Models}

Edited by

Ramona Rupeika-Apoga and Pierpaolo Marano

Printed Edition of the Special Issue Published in Risks 
The Risk Landscape within FinTech and InsurTech Business Models 



\section{The Risk Landscape within FinTech and InsurTech Business Models}

Editors

Ramona Rupeika-Apoga

Pierpaolo Marano 
Editors

$\begin{array}{ll}\text { Ramona Rupeika-Apoga } & \text { Pierpaolo Marano } \\ \text { University of Latvia } & \text { University of Latvia, Latvia } \\ \text { Latvia } & \text { Catholic University of the Sacred Heart, Italy } \\ & \text { University of Malta, Malta }\end{array}$

Editorial Office

MDPI

St. Alban-Anlage 66

4052 Basel, Switzerland

This is a reprint of articles from the Special Issue published online in the open access journal Risks (ISSN 2227-9091) (available at: https://www.mdpi.com/journal/risks/special_issues/Risk_ Landscape).

For citation purposes, cite each article independently as indicated on the article page online and as indicated below:

LastName, A.A.; LastName, B.B.; LastName, C.C. Article Title. Journal Name Year, Volume Number, Page Range.

ISBN 978-3-0365-2772-7 (Hbk)

ISBN 978-3-0365-2773-4 (PDF)

(C) 2021 by the authors. Articles in this book are Open Access and distributed under the Creative Commons Attribution (CC BY) license, which allows users to download, copy and build upon published articles, as long as the author and publisher are properly credited, which ensures maximum dissemination and a wider impact of our publications.

The book as a whole is distributed by MDPI under the terms and conditions of the Creative Commons license CC BY-NC-ND. 


\section{Contents}

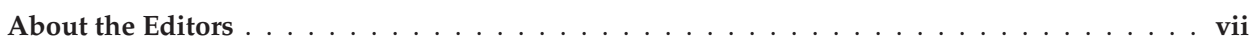

\section{Pierpaolo Marano}

Management of Distribution Risks and Digital Transformation of Insurance Distribution-A

Regulatory Gap in the IDD

Reprinted from: Risks 2021, 9, 143, doi:10.3390/risks9080143 . . . . . . . . . . . . . . . . . . 1

\section{Marta Ostrowska}

Regulation of InsurTech: Is the Principle of Proportionality an Answer?

Reprinted from: Risks 2021, 9, 185, doi:10.3390/risks9100185 . . . . . . . . . . . . . . . . . . 13

\section{Ramona Rupeika-Apoga and Stefan Wendt}

FinTech in Latvia: Status Quo, Current Developments, and Challenges Ahead

Reprinted from: Risks 2021, 9, 181, doi:10.3390/risks9100181

Balijinder Kaur, Sood Kiran, Simon Grima and Ramona Rupeika-Apoga

Digital Banking in Northern India: The Risks on Customer Satisfaction

Reprinted from: Risks 2021, 9, 209, doi:10.3390/risks9110209

Agata Kliber, Barbara Będowska-Sójka, Aleksandra Rutkowska and Katarzyna Świerczyńska

Triggers and Obstacles to the Development of the FinTech Sector in Poland Reprinted from: Risks 2021, 9, 30, doi:10.3390/risks9020030 



\section{About the Editors}

Ramona Rupeika-Apoga is a Professor of Finance at the University of Latvia and the Head of the Department of Finance and Accounting. She is an Affiliate Professor at the University of Malta and Visiting Professor at the University of Lodz (Poland). Her accomplishments include leading various international and national research projects. The professor has more than 15 years of pedagogical experience at Latvian and European higher education institutions with specialized knowledge in Risk Management, International Finance, FinTech and Digital transformation of companies. A member of the Latvian Academy of Sciences, she specializes in Economics and Management Sciences, and has contributed to many internationally published journals related to Digital Finance, Access to Finance for SMEs, Financial Risk Assessment and Fintech Business Models. In addition, she serves as an editor for the European Research Studies Journal, International Journal of Economics \& Business Administration, Journal of Applied Economics and Business, Journal of Finance and Financial Law, and International Journal of Business and Economic Sciences Applied Research.

Pierpaolo Marano Pierpaolo Marano is a Law and Regulation Professor at the University of Latvia, the Catholic University of the Sacred Heart (Milan), and the University of Malta. He is also a scholar in residence at the University of Connecticut, School of law - Insurance Law Center, and an Honorary Fellow at the University of Hong Kong - Asian Institute of International Financial Law. A widely sought speaker on insurance law with over 130 academic papers published and one of the Italian Code of Private Insurance drafters, he serves as an academic member of the Insurance and Reinsurance Stakeholders Group at the European Insurance and Occupational Pensions Authority (EIOPA). In addition, he is the Director of the AIDA Europe Research Series on Insurance Law and Regulation published by Springer. Furthermore, he is co-editor of the book "InsurTech: A legal and Regulatory View", published in 2020 by Springer, while his article "Navigating InsurTech: The digitial intermediaries of insurance products and customer protection in the $\mathrm{EU}$ " is the most cited essay of the top-ranked Maastricht Journal of European and Comparative Law in the last three years. 



\section{Preface to "The Risk Landscape within FinTech and InsurTech Business Models"}

FinTech/InsurTech-based business models are gradually maturing and disrupting the offerings and management of financial services (banking, financial, and insurance) on the global stage. However, the understanding of the risk landscape of FinTech and InsurTech business models remains at an early stage due to the diverse nature of their activities and the rapid development of the field. Although FinTech and InsurTech offer the opportunity to accelerate economic growth and expand financial affordability/inclusion in all countries, they pose new risks to financial stability and integrity.

This Special Issue contains five articles that offer a discussion of state-of-the-art developments or introduce new theoretical or practical advances in the identification, measurement, and management of the risks arising from FinTech/InsurTech-based business models.

Though contributions to this Special Issue have now closed, research on the role of digital technologies in finance and insurance needs to continue. We are pleased to announce that a new Special Issue, "The risk landscape in the digital transformation of finance and insurance", will open in 2022 to explore the role of digital transformation in finance and insurance in a deeper and broader manner. The landscape of financial services is undergoing a major transformation in terms of the types of players involved, how money is used and provided, and the role that finance plays in relation to the natural environment, which is increasingly impacted by innovations in business models, technology, and environmental initiatives.

As a final note we would like to extend our most heartfelt thanks to the MDPI Editorial Team of Risks, especially Mr. Ivan Wang, the Assistant Editor of this Special Issue, acknowledged authors, and dedicated reviewers.

Ramona Rupeika-Apoga, Pierpaolo Marano

Editors 



\title{
Management of Distribution Risks and Digital Transformation of Insurance Distribution-A Regulatory Gap in the IDD
}

\author{
Pierpaolo Marano ${ }^{1,2}$
}

Citation: Marano, Pierpaolo. 2021. Management of Distribution Risks and Digital Transformation of Insurance Distribution-A Regulatory Gap in the IDD. Risks 9: 143. https://doi.org/10.3390/ risks 9080143

Academic Editor: Mogens Steffensen

Received: 28 June 2021

Accepted: 28 July 2021

Published: 2 August 2021

Publisher's Note: MDPI stays neutral with regard to jurisdictional claims in published maps and institutional affiliations.

Copyright: (C) 2021 by the author. Licensee MDPI, Basel, Switzerland. This article is an open access article distributed under the terms and conditions of the Creative Commons Attribution (CC BY) license (https:// creativecommons.org/licenses/by/ $4.0 /)$.
1 Faculty of Business, Management and Economics, The University of Latvia, LV-1586 Rīga, Latvia; pierpaolo.marano@lu.lv or pierpaolo.marano@unicatt.it

2 Department of Legal Studies, The Catholic University of the Sacred Heart, 20122 Milan, Italy

Abstract: The Insurance Distribution Directive (IDD) aims to regulate insurance distribution in the EU regardless of distribution channels and means. Although new technologies affect insurance distribution, the IDD does not explicitly regulate this digital transformation. Insurers and intermediaries must comply with detailed business conduct rules that aim to counteract distribution risks. However, the IDD exempts ancillary insurance intermediaries from its scope when they meet certain conditions. The article highlights the regulatory framework on insurance, requiring insurers and intermediaries to address distribution risks, and analyses how this exemption affects the management of distribution risks in online distribution from a legal perspective. The focus on online distribution depends on the scale such distribution can achieve. The consideration of the scale allows for challenging the political choice behind the exemption of ancillary insurance intermediaries, which consists of the principle of proportionality. A regulatory proposal to counteract these adverse effects is to remove the exemption from the IDD rules for ancillary intermediaries in online distribution. Such a proposal is compliant with the principle of technological neutrality and is in line with the new legislative proposals in the Digital Services Act and Digital Markets Act.

Keywords: insurance distribution; digital transformation; Insurance Distribution Directive; distribution risks; insurance distributors; product governance; principle of proportionality; principle of technological neutrality

\section{Introduction}

The EU regulatory framework on insurance requires insurers to identify and manage the risks inherent to the distribution process. Directive 2009/138 of the European Parliament and of the Council of 25 November 2009 on the taking-up and pursuit of the business of Insurance and Reinsurance (Solvency II) supposedly offers consideration of these risks as they can impact insurers from a prudential perspective. Moreover, the proper management of distribution risks prevents detrimental behaviours to customers. The latter directly suffer the detriment resulting from the distribution of poorly designed or inadequately distributed insurance products. Thus, customers would also benefit from the proper risk management of distribution risks in which both insurers and distributors fall into the same rules and supervision. This benefit aligns with the primary objective of the EU insurance regulation and supervision to protect policyholders (see Recital No. 16 and Article 27 of Solvency II). Directive (EU) 2016/97 of the European Parliament and of the Council of 20 January 2016 on insurance distribution (recast) (IDD) supplements Solvency II by introducing detailed business conduct rules addressed to insurers and distributors. In particular, the IDD aims to increase customer protection by strengthening their defence at the point of sale and anticipating the protection of designing insurance products with rules on product oversight and governance. Some of these rules assume a collaboration between insurers and distributors that must comply with the same standards and be supervised by the same authority. Thus, the proper management of distribution risks also depends on the proper functioning of such collaboration. 
The IDD regulates the insurance distribution but only incidentally considered the digital transformation of insurance distribution. The elaboration process of the IDD took place in parallel with this transformation, which is not the core of the IDD rules. In recent years, technological innovation and increasing connectivity supported a digital transformation of distribution channels including those distributing insurance products (Nicoletti 2021; Eling and Lehmann 2018; Stoeckli et al. 2018; Braun and Schreiber 2017; Comanac et al. 2016). Insurers have increased the use of new technologies to distribute directly to current and potential customers (Chrissantis 2016). Many insurance distributors support their business with new technologies (e.g., internet and mobile devices), creating hybrids.

Moreover, new insurance distribution channels arose, such as comparison websites, peer-to-peer insurance, and robo-advisors. In addition, intermediaries who carry out insurance distribution on an ancillary basis to their primary business have enriched the multi-channel nature of insurance distribution. These ancillary intermediaries supplement the offer of their products or services with insurance products, wherein the growing relevance of e-commerce and digital marketplaces integrating third-party vendors moved this cross-selling to online platforms. Therefore, the IDD extended the rules for other insurance distributors to these intermediaries. In principle, ancillary insurance intermediaries collaborate with insurers to manage distribution risks and they are both overseen by the supervisory authority. However, the IDD exempts ancillary insurance intermediaries from the rules applicable to insurance distributors where such intermediaries meet a premium/risk threshold.

The political choice to exempt these intermediaries assumes that the burden deriving from the rules would have been disproportionate to the protection objectives pursued with the introduction of such regulations. Therefore, this choice postulates that the exemption is tolerable; that is, it is compatible with the primary purpose of the EU insurance regulation purposed with protecting policyholders. However, the EU legislation made this assessment without specific consideration of the digital transformation that combines online sales with new technologies (e.g., AI, Big data, and IoT) and software that automate underwriting and claims, thus allowing ancillary intermediaries to reach a scale of their insurance distribution that they would hardly have achieved in face-to-face distribution.

Regulators are identifying and evaluating the challenges of digital transformation to the EU regulatory framework on insurance (EIOPA 2019, 2020a). Scholars have already highlighted some legal and regulatory issues concerning insurance distribution channels arising from this transformation (Anchen et al. 2015; Marano 2016, 2019; Ostrowska and Ziemiak 2020; Fras and Szaraniec 2020; Clemente and Marano 2020; Lima Rego and Carvalho 2020; Tereszkiewicz 2020; Ostrowska and Balcerowski 2021; Tereszkiewicz and Poludniak-Gierz 2021). Moreover, they have also evaluated how the IDD can affect the management of distribution risks (Bravo 2021). However, the literature overlooked the role played by ancillary insurance intermediaries in the management of distribution risks. If the IDD exempts these intermediaries from its rules, managing distribution risks could be more difficult for insurers and detrimental to customers. These intermediaries carry out insurance distribution on an ancillary basis to their primary business. The more the primary business is online, the more the scale of the activity can increase, including the cross-selling of insurance products. Therefore, the present essay analyses the regulatory choice to exempt ancillary insurance intermediaries from the IDD rules. The hypothesis to be investigated concerns whether the exemption is still consistent in the online distribution carried out by ancillary insurance intermediaries, considering the need to manage distribution risks for the insurers and avoid detriments to policyholders. The conclusion is that the consideration of the scale of online distribution allows for challenging the exemption of ancillary insurance intermediaries and calls policymakers to reconsider such an exemption in the upcoming revision of the IDD. 


\section{Materials and Methods}

The first subsection is devoted to listing the distribution risks and introducing the ancillary insurance intermediaries. Their knowledge provides the preliminary background to better understand how the exemption from the IDD rules can affect the management of these risks. Based on a legal approach to the relevant EU regulatory framework on insurance, the analysis outlines the relevance of these risks for insurers and customer protection. Moreover, it describes the definition of ancillary insurance intermediaries and the threshold introduced under the IDD to exempt these intermediaries from its rules.

The second subsection outlines how the IDD addresses distribution risk. The essay uses the analytical method to identify the IDD rules that create business conduct risks to be managed by insurers and distributors. The analysis aims to highlight the relevance of the collaboration between insurers and distributors in managing these risks. The relevance is not limited to these entities. It is also beneficial to the supervisory authority and, above all, to customers. Such knowledge enables one to understand how the exemption from these IDD rules can affect the management of distribution risks and ultimately to appreciate this study's significance.

\subsection{Setting the Scene: Distribution Risks and Ancillary Insurance Intermediaries}

The significance of the risks for insurance undertakings transcends assessing the risk underwritten under each insurance contract. The EU regulatory framework on insurance provides that insurers must be fully aware of the risks they face, including those not related to the underwritten risks.

Solvency II provides that the Solvency Capital Requirement (SCR) must be calibrated to ensure that all quantifiable risks to which an insurance (or reinsurance) undertaking is exposed to are considered. Solvency II describes that the SCR must consider underwriting risks, market risks, credit risks, and operational risks comprising legal risks (see Article 101(4) of Solvency II). Thus, the risks assessment is broader than those inherent in the single insurance coverage (Van Hulle 2019, p. 187). In addition, Solvency II acknowledges that insurers may adequately address some risks only through governance requirements rather than through the quantitative requirements reflected in the SCR. An effective system of governance is essential for the adequate management of the insurance undertaking and the regulatory system (see Recital No. 29 of Solvency II). Therefore, the risk management system of the (re)insurance undertaking must also consider risks that are not (or not entirely) included in the calculation of the SCR (see the risks listed under Article 44(2) of Solvency II). These risks include the actual or potential exposure to reputational and strategic risks and the interrelationship between these risks and other material risks (EIOPA 2015, Guideline 23). Quantitative (SCR) and qualitative (risk management system) requirements allow for achieving the main objective of insurance regulation and supervision in the EU, namely the protection of policyholders and beneficiaries (see Recital No. 16 and Article 27 of Solvency II). The risk assessment is relevant to insurers and their supervisors to verify the state of solvency, establish technical provisions, establish the assets and own eligible funds (see Article 30(2) of Solvency II), and prevent detriments to customers from the design of poor products or mis-selling practices. Indeed, the risk management system of the insurer must manage, monitor, and report the key issues affecting the undertaking's reputation, considering the expectations of stakeholders and the sensitivity of the market (EIOPA 2015, Guideline 23).

The adoption of Solvency II changed the risk profile of the insurance undertaking vis-à-vis the policyholder. Therefore, Solvency II called the European Commission to propose the revision of Directive 2002/92/EC on insurance mediation (IMD), considering the consequences of Solvency II for policyholders (see Recital No. 139 of Solvency II). The Directive (EU) 2016/97 on insurance distribution (IDD) results from this request. The IDD supplements Solvency II by setting forth business conduct rules by placing the relationship between insurers and their customers in higher relevance to identify and manage the related risks. In particular, the IDD aims to increase customer protection by strengthening 
their protection at the point of sale and anticipating such defence at designing insurance products with rules on product oversight and governance. The primary importance of customer protection for the EU insurance regulation and supervision requires careful consideration of the risks arising from the design and distribution of insurance products to the customers.

These risks are qualified as distribution risks and classified as follows: (i) risks to the quality and volume of the insured portfolio caused by actions of the distribution channel; (ii) risks to the insurer's income-generating capacity, long-term financial sustainability, and brand value caused by actions of the distribution channel; and (iii) risks to own distribution channels which ultimately can affect the profitability and sustainability of companies (Gutterman 2016, p. 3; Bravo 2021, p. 356). Regulators have highlighted how these risks can arise from e-commerce (IAIS 2003). In addition, the literature analysed distribution risks from a prudential perspective (Hsin-Chun 2016, pp. 43-50) as they can pose a material risk to an insurer's sustainability, brand value, and income-generating potential (Gutterman 2016, p. 14). The literature also discussed the risk of e-commerce and business conduct regulation (Hsin-Chun 2016, pp. 51-53; Rokas 2016, pp. 17-18; Chrissantis 2016; Abramovsky and Kochenburger 2016) and the implications of introducing the IDD in managing distribution risks in the insurance undertakings by assuming that distribution risks are ultimately the insurer's responsibility, irrespective of the distribution channel used (Bravo 2021, p. 356).

However, the literature did not adequately consider an element relevant to managing these risks in the EU. Insurers are involved in managing the risks associated with the distribution process if their distributors are legally required to comply with the IDD rules and are overseen by the supervisory authority. Although the IDD sets forth business conduct rules to insurers and other distributors, the IDD exempts the ancillary insurance intermediaries from its scope where they meet a premium/risk threshold.

The ancillary intermediaries are any natural and legal person who, for remuneration, takes up or pursues insurance distribution activity on an ancillary basis. It means that they are ancillary where their principal professional activity is activity other than insurance distribution. They only distribute certain insurance products complementary to a good or service; the insurance products concerned do not cover life assurance or liability risks unless that cover complements the good or service that the intermediary provides as its principal professional activity (see Article 2(1)(4) of IDD). These intermediaries fall into the IDD scope but they are exempt from the IDD rules wherein they meet all the following conditions (see Article 1(3) of IDD):

(a) the insurance is complementary to the good or service supplied by a provider, where such insurance covers: (i) the risk of breakdown, loss of, or damage to the good or the non-use of the service supplied by that provider; or (ii) damage to or loss of baggage and other risks linked to travel booked with that provider;

(b) the amount of the premium paid for the insurance product does not exceed EUR 600, calculated on a pro-rata annual basis; and

(c) by way of derogation from point (b) where the insurance is complementary to a service referred to in point (a) and the duration of that service is equal to or less than three months, and the amount of the premium paid per person does not exceed EUR 200 .

As a result, when exempt ancillary insurance intermediaries carry out the distribution of insurance products, (i) insurers are not facilitated in managing distribution risks and (ii) customers increase their exposure to these risks, or at least to those risks assuming a collaboration between the insurer and distributor for their management.

The next section outlines how the IDD addresses distribution risks and the relevance of the collaboration between insurers and distributors in managing these risks. 


\subsection{Distribution Risks and the IDD}

In the insurance market, the customers' purchase process depends heavily on intermediaries. A poor risk selection process and inappropriate distribution channel activities are thus expected to have consequences on customer satisfaction, policyholder behaviour, and abnormal lapse rates (Bravo 2021, p. 357)

The IDD addresses distribution risks depending on the distribution channel and the mismanagement of such channel. Risks related to the distribution channel are mis-selling, inappropriate underwriting practices, and choice of inadequate staff. The mismanagement of the distribution channel exposes the channel to reputational risks due to improper selling practices or selecting an inadequate distribution channel or intermediary.

The IDD sets forth the general principle that distributors must always act honestly, fairly, and professionally, in accordance with the best interest of their customers (see Article 17 of IDD), which applies in addition to more detailed conduct of business rules (Köhne and Brömmelmeyer 2018, pp. 728-29). These rules require distributors to sell insurance products with a demands-and-needs test based on the information obtained from the customer (see Article 20 of IDD). Distributors must also provide a product's suitability/appropriateness assessment for insurance-based investment products (see Article 30 of IDD). The rules also concern the conflicts of interest, remuneration and inducements, pre-contractual information, and cross-selling (see Articles 19, 20, 23, 24 28, and 29 of IDD). Moreover, customer protection is achieved through continuous professional training and development requirements to the distributors' employees (see Article 10 of IDD). The latter must maintain an adequate level of knowledge corresponding to the role they perform and the relevant market. In addition, the set of rules on product oversight and governance (POG) (see Article 25 of IDD) requires manufacturers to adopt a product approval process containing measures and procedures for designing, monitoring, reviewing and distributing insurance products, and corrective action for insurance products that are detrimental to customers (see Article 4 of Commission Delegated Regulation (EU) 2017/2359 of 21 September 2017, supplementing the IDD with regard to product oversight and governance requirements for insurance undertakings and insurance distributors).

The literature outlined how: (i) the demands-and-needs test, suitability and appropriateness requirements, and cross-selling provisions are expected to have the most significant impact on sales, distribution, underwriting, and customer management practices; (ii) the remuneration and incentives provisions are expected to impact product manufacturing, sales, and distribution activities significantly; and (iii) the product oversight and governance provisions are expected to impact insurers and intermediaries' product development and distribution activities (Bravo 2021, pp. 359-65).

Most of the duties arising from the rules are addressed to insurers who: (i) must draw up the pre-contractual information document concerning insurance-based investment products (KID) (see Article 5 of Regulation (EU) No. 1286/2014 of 26 November 2014 on key information documents for packaged retail and insurance-based investment products (PRIIPs), and the other insurance products (PID) (see Article 20(6) of IDD) and (ii) cannot make any arrangement by way of remuneration, sales targets, or otherwise that could provide an incentive to distributors or their employees to recommend a particular insurance product to a customer when the insurance distributor could offer a different insurance product that would better meet the customer's needs (see Article 17(3) of IDD).

However, some of the duties refer to distributors. How distributors fulfil these duties affects insurers' ability to supervise and manage the relevant risks. It is the case of the demands-and-needs test, the suitability/appropriateness assessment, and the advice eventually provided to the customer. Insurers can support intermediaries with templates and forms to conduct these activities but this may not happen-e.g., about brokers-and in any case, the duty falls directly to intermediaries. Moreover, insurance distributors cannot remunerate or assess the performance of their employees in a way that conflicts with their duty to act in accordance with the best interests of their customers and they must comply with continuing professional training, development requirements, and must 
be of a good repute. In the case of the cross-selling of insurance and other products or services, as part of a package or the same agreement, the insurance distributor specifies the demands and needs of the customer about insurance products that form part of the overall package or the same agreement. It follows that insurers must have adequate organizational safeguards to monitor the conduct of their distributors if they want to verify timely the proper distribution and compliance with the rules of conduct by the latter (see Article 10(3), of IDD). Thus, insurers must evolve the distribution agreements from agreements of a mainly commercial nature to agreements of an organizational nature to govern the information flows and allow for the controls required to manage distribution risks adequately. Distributors, in turn, have a duty to collaborate with insurance companies and possess an interest in doing so to appropriately manage the distribution risks that also concern themselves as supervised entities.

Indeed, the cooperation between insurers and distributors is paramount for ensuring the proper functioning of the set of rules on POG (Marano 2021, p. 64). These rules provide that the product design consists of identifying the target market and making the product testing, while product monitoring and review requires properly selection and informing and monitoring distribution channels. Furthermore, distributors must cooperate with manufacturers to monitor the distribution of insurance products to the identified target market and organize or apply a specific distribution strategy. Manufacturers and distributors must formalize the cooperation in the product distribution arrangements. In the case of co-manufacturing, the insurer and distributor sign a written agreement that specifies their collaboration to comply with the requirements for manufacturers referred to in the IDD, the procedures through which they shall agree on the identification of the target market and their respective roles in the product approval process (see Article art. 3(4) of Commission Delegated Regulation (EU) 2017/2359 of 21 September 2017, supplementing the IDD with regard to product oversight and governance requirements for insurance undertakings and insurance distributors).

In sum, the number and granularity of the business conduct rules introduced by the IDD increase the distribution risks for insurers and distributors. Therefore, collaboration between these entities is now essential for the proper management of these risks and it is facilitated as both entities must comply with insurance regulation. Moreover, supervisors can receive a clear picture of the distribution and products' governance functioning being as both the insurance and distributor are supervised.

The following section investigates the consequences to insurers and customers where ancillary insurance intermediaries do not fall into the IDD scope and therefore are not required to apply the relevant rules.

\section{Results}

Based on the previous analysis of the adverse effects arising from the exemption of ancillary insurance intermediaries from the IDD rules, this section challenges the exemption in online distribution. The analysis identifies the regulatory principle behind this exemption, which is the principle of proportionality, and demonstrates how online distribution contrasts with the reasons invoked to apply such principle to these intermediaries.

The IDD provides that customers benefit from the same level of protection despite the differences between distribution channels. To guarantee that the same level of protection applies and that the costumers can benefit from comparable standards, especially in disclosing information, a level playing field between distributors is essential (see Recital No. 6 of IDD).

However, the IDD does not apply to persons practising insurance distribution as an ancillary activity where a premium/risk size threshold is met. In this case, an insurance undertaking or insurance intermediary carrying out the distribution activity through an ancillary insurance intermediary that is exempted from the requirements set out in the IDD should ensure the fulfilment of some basic requirements: (i) the communication of its identity and of how the customer can complain; (ii) the demands and needs of the 
customer are considered; (iii) the pre-contractual information document is provided to the customer before the conclusion of the contract; and (iv) appropriate and proportionate arrangements are in place to comply with the provisions of acting in accordance with the best interest of customers and concerning the cross-selling (see Article 1(4) and Recital No. 15 of IDD). It follows that insurers must manage distribution risks from the insurance distribution activities conducted by ancillary intermediaries that are exempted from the IDD but the management could not be supported by the rules established for distributors falling into the IDD scope. Intermediaries that are exempted from the IDD rules are not subject to the supervision of insurance authorities and related administrative sanctions. The collaboration between insurer and distributor does not occur as they are both liable to the insurance supervisory authority. However, only the insurer is responsible to the authority.

EIOPA has been very clear about this responsibility. EIOPA's opinion is that manufacturers of insurance products are expected to apply the POG requirements regarding insurance products distributed by ancillary insurance intermediaries that are exempted from the IDD scope. Manufacturers must (i) provide all appropriate information on the insurance products and the identified target market to these intermediaries, and (ii) adopt adequate procedures to obtain all the information if the product is not in line with the interests, objectives, and characteristics of the identified target market or where other product-related circumstances arise that may adversely affect the customers (EIOPA 2018a).

Moreover, EIOPA's opinion in the case of distribution in the context of group insurance contracts is that the group members are considered customers regarding the application of POG requirements. Consequently, the target market must be defined, considering the features of the insurance product and the needs and objectives of the members, both in the case of compulsory and optional group insurance contracts (EIOPA 2018b). Thus, POG requirements also apply if the group insurance contract is signed and distributed by the exempted insurance ancillary intermediary. In addition, EIOPA stated that POG supervisory activities cover monitoring carried out by manufacturers to ensure that distributors act in line with the objectives of their over-arching POG policy and POG process for specific products. These activities also include whether manufacturers have adequate controls for some distribution channels (e.g., ancillary intermediaries or distance selling). Supervisors must pay particular attention to ancillary insurance intermediaries during the POG assessment to understand how manufacturers monitor these specific intermediaries while considering their ancillary nature and possible risks that could emerge (EIOPA 2020b, p. 15).

Furthermore, the political choice to exempt some intermediaries from the IDD redesigns the supervisory chain on distribution. The IDD sets forth the principle that the supervisory authority monitors both insurers and their distributors and assesses how they work together to comply with the IDD rules. Thus, the supervisor does not suffer any barrier in its relationship with distributors. However, if some distributors are exempted from the vigilance of the authority, the supervisory chain is lengthened. The authority supervises insurers who, in turn, oversee intermediaries that are exempted from complying with the IDD rules. As a result, the supervisor must rely on insurers' supervision of the exempted distributors and customers lose the protection provided by the direct supervision of intermediaries by the authority.

The principle of proportionality would justify such diminished customer protection. Proportionality pertains to drafting the European Union and the Member States' laws (Tridimas 1999, p. 66). Under this principle, a measure adopted by the EU institutions must not exceed the limits of what is appropriate and necessary to achieve the objectives pursued by the legislation in question (Tridimas 2006, p. 137).

The criteria used to exempt from the IDD rules are the premium paid and the risk covered by each insurance contract. These criteria do not consider the number of contracts that each ancillary insurance intermediary can distribute. Nature (risk) and size (premium) of the individual economic relationship (insurance contract) are deemed adequate to 
balance the need for protection and the burden for distributors. In contrast, considering the overall number (scale) of these economic relationships is deemed irrelevant.

It may be that nature and size are adequate more than scale as criteria for identifying the relevance threshold for applying the IDD rules where the distribution is carried out face-to-face. The economic significance of each insurance contract is not associated with the economic importance of the overall number of insurance contracts sold. The lack of consideration of the scale likely depends on considering the intrinsic limits of the faceto-face distribution (on the relevance of the scale for regulatory purposes, Baker and Dellaert 2018, p. 30). This distribution requires establishing relationships that are difficult to repeat in the same way and for large numbers due to the limitations of the time and place in which they take place. The principle of proportionality avoids disproportionate compliance burdens compared to the nature and size of the individual relationship. The scale reachable by all "physical" connections does not alter this assumption. In addition, the distribution activities carried out by the ancillary intermediaries can be challenging to supervise for the authority. The number of such intermediaries and their widespread distribution throughout the territory makes it very difficult for the supervisor to exercise adequate direct supervision on their distribution activities. Therefore, the exemption from the IDD can also be considered an efficiency threshold for the exercise of supervisory tasks. The supervisory burden would be disproportionate even for the authority if it should need to supervise below this threshold.

Considering size and nature as adequate criteria more than scale is coherent with the IDD's regulatory framework which did not put digital transformation at the core of its rules. However, the irrelevance of the scale raises concern to customer protection and distribution risk management when the threshold includes online distribution.

Such distribution makes it possible to reach an indefinite number of people and facilitate cross-border activities of insurers. Standardizing and automating the relationship between distributors and customers allows for repeating the same mistake indefinitely if corrective action is not activated. The collaboration between insurers and some distributors does not occur within uniform rules to which both entities are subject to supervision by the same authority. Compliance with the IDD rules depends on the agreement between insurers and these distributors; that is, the ability of insurers to agree with these distributors on how they must collaborate in managing these risks. This ability depends on the bargaining power of the parties involved. It does not derive from a legal obligation to which these intermediaries must comply. If the balance of power is favourable to the intermediary, the risk is that the latter prefers insurers that are less likely to manage distribution risks by imposing charges on intermediaries.

The exemption threshold may also constitute an incentive for regulatory arbitrage. The higher the compliance costs required of distributors by the IDD, the greater the incentive for intermediaries to evade these costs by distributing products that allow them to stay within the exemption threshold. Thus, intermediaries could push insurers to manufacture insurance products whose premium will enable them to remain within the exemption threshold. Considering the insurance premium calculation mainly depends on the risk underwritten by the insurer, the "need" to comply with the exemption threshold could lead insurers to adverse behaviour towards their customers. Insurers could manufacture products covering a lower risk to those corresponding to the interests and needs of the target market if they must charge a prefixed amount of premium.

Moreover, in the case of distributors carrying out business in a Member State (A) other than the Member State in which the insurer has its head office (B), the supervisory authorities of Member State A cannot activate the supervisory procedures envisaged for the breach of obligations, where distributors are registered as insurance intermediaries. Therefore, customer protection is challenging for the authority of Member State A with the risk of delays in detecting and prohibiting improper sales practices.

Regardless of the intermediary's opportunistic behaviour (and the insurer), the lack of insurance expertise of the exempt ancillary intermediaries is likely to postpone discovering 
the systematic error that depends on the automation of this relationship. Therefore, insurers should monitor this distribution as they still need to identify and manage the related risks under the POG rules.

Ultimately, the exemption from the IDD rules is likely to increase distribution risks for insurers and be detrimental to costumers to a greater extent for online activities than face-to-face activities that the EU legislator has mainly considered.

\section{Discussion-A Regulatory Proposal}

The principle of proportionality justifies the exemption of some ancillary intermediaries from the IDD. This principle can be usefully recalled considering a relationship between the distributor and customer in presence. The burden deriving from the IDD rules would be disproportionate to the nature and size of insurance contracts offered together with other products or services, while the scale can be deemed irrelevant. The last section outlined how this political choice can affect the management of distribution risks by insurers and be detrimental to customers by highlighting how the negative impact is likely to be higher in the online distribution.

A regulatory proposal to counteract these adverse effects is to remove the exemption from the IDD rules for ancillary intermediaries in online distribution. This proposal is consistent with the principle of technological neutrality, which is one of the guiding principles of the Commission's policies on digital innovation (Chatzara 2020, p. 14). This principle aims at repealing legal provisions (i) that are outdated, unnecessary, and/or excessive in the context of changing business models and/or the 'digital' environment, and (ii) where the underlying public policy objectives can be achieved similarly without representing a barrier to innovation.

The proposal to eliminate the exemption in online distribution introduces a different discipline for distributors due to the technological instrument. However, despite this, the proposal does not run counter to the principle of technological neutrality. Such a principle has undergone an evolution that allows it to affirm that the proposal is consistent.

First, technological innovation cannot justify more attenuated rules where the activity carried out is the same as the "traditional" one and the risks it exposes are the same. Given the technological neutrality of legislation, it is not relevant how digitised a company is or which technology it is using. To classify the undertaking, only the nature of the products or services offered and the risks taken by this entity are relevant (EIOPA 2019, p. 34).

Second, the technology-driven innovations that apply to the business cycle of insurance and insurance intermediation activities may lead to gaps other than those of "traditional" activities (OECD 2018, p. 13; EIOPA 2020b, p. 25): technology neutrality does not mean that the technology is neutral (Greenberg 2016).

\section{Conclusions}

Technology can affect the phenomena that have been regulated since the dawn of insurance. The digital technology environment can pose different challenges compared to those governed in the "traditional" environment in which insurance has developed. The ambition of many InsurTech start-ups is to automate the underwriting and intermediation of customers. It may lead to issues other than those that arose without such automation. The evolution of e-commerce and rising attractiveness of the customer's digital journey increases the digital marketplaces and attracts entrepreneurs to offer an insurance product as ancillary to a good or a service which is not insurance, as part of a package or the same agreement. These ancillary insurance intermediaries find such cross-selling as beneficial to their customers and profitable for themselves. However, the scale of their distribution activity increases compared to the one reachable with the cross-selling in presence.

The EU law is already addressing concerns related to the size of online platforms under the next Digital Services Act and Digital Markets Act. Both legislative proposals identify thresholds to apply the obligations to online platforms falling into their scope (see Article 25 of Digital Services Act and Article 3 of Digital Markets Act). Therefore, assessing the 
proportionality of compliance burdens for such intermediaries could be reconsidered due to the size their online businesses can reach. Indeed, this grander scale- the overall number of insurance contracts sold-must be met by greater attention to distribution risks for insurers and customers. In addition, the digital mode allows for the supervisor to exercise supervisory powers remotely, without on-site inspections. Therefore, the exemption as a threshold under which supervision cannot take place effectively is also overcome.

Funding: This research was funded by the Latvian Council of Science, Project DigiSMEs, project number LZP-2020/2-0061.

Institutional Review Board Statement: Not applicable.

Informed Consent Statement: Not applicable.

Conflicts of Interest: The authors declare no conflict of interest. The funders had no role in the design of the study; in the collection, analyses, or interpretation of data; in the writing of the manuscript, or in the decision to publish the results.

\section{References}

Abramovsky, Aviva, and Peter Kochenburger. 2016. Insurance Online: Regulatin and Consumer Protection in a Cyber World. In The "Dematerialized" Insurance. Distance Selling and Cyber Risks from an International Perspective. Edited by Pierpaolo Marano, Ioannis Rokas and Peter Kochenburger. Berlin: Springer, pp. 117-42.

Anchen, Jonathan, Frey Astrid, and Kirova Milka. 2015. Life Insurance in the Digital Age: Fundamental Transformation Ahead, Swiss Re Sigma: 6/2015. pp. 1-39. Available online: http://www.biztositasiszemle.hu/files/201512/sigma6_2015_en.pdf (accessed on 1 August 2021).

Baker, Tom, and Benedict G. C. Dellaert. 2018. Regulating Robo Advice across the Financial Services Industry. Iowa Law Review 103: 713-50. Available online: https://scholarship.law.upenn.edu/cgi/viewcontent.cgi?article=2742\&context=faculty_scholarship (accessed on 1 August 2021). [CrossRef]

Braun, Alexander, and Florian Schreiber. 2017. The Current InsurTech Landscape: Business Models and Disruptive Potential. Study Report. St. Gallen: Institute of Insurance Economics.

Bravo, Jorge M. 2021. IDD and Distribution Risk Management. In Insurance Distribution Directive: A Legal Analysis. Edited by Pierpaolo Marano and Kyriaki Noussia. Berlin: Springer, pp. 349-69.

Chatzara, Viktoria. 2020. FinTech, InsurTech and the Regulators. In InsurTech: A Legal and Regualtory View. Edited by Pierpaolo Marano and Kyriaki Noussia. Berlin: Springer, pp. 3-26.

Chrissantis, Christos S. 2016. Online Sales of Insurance Producus in the EU. In The "Dematerialized" Insurance. Distance Selling and Cyber Risks from an International Perspective. Edited by Pierpaolo Marano, Ioannis Rokas and Peter Kochenburger. Berlin: Springer, pp. 143-66.

Clemente, GianPaolo, and Pierpaolo Marano. 2020. The Broker Model for Peer-to-Peer Insurance: An Analysis of Its Value. Geneva Papers on Risk and Insurance: Issues and Practice. Basingstoke: Springer Nature, pp. 457-81.

Comanac, Andrada, Paola Musile Tanzi, and Fabio Ancarani. 2016. Insurance Companies and E-rketing Activities: An Empirical Analysis in the Italian Market. In The "Dematerialized" Insurance. Distance Selling and Cyber Risks from an International Perspective. Edited by Pierpaolo Marano, Ioannis Rokas and Peter Kochenburger. Berlin: Springer, pp. 85-108.

EIOPA. 2015. Guidelines on the System of Governance. Available online: https://www.eiopa.europa.eu/content/guidelines-systemgovernance_en (accessed on 1 August 2021).

EIOPA. 2018a. EIOPA Q\&A ID. 1615 of 10 July 2018. Available online: https://www.eiopa.europa.eu/content/1615_en?source=search (accessed on 1 August 2021).

EIOPA. 2018b. EIOPA Q\&A ID. 1617 of 10 July 2018. Available online: https://www.eiopa.europa.eu/content/1617_en?source=search (accessed on 1 August 2021).

EIOPA. 2019. Report on Best Practices on Licensing Requirements, Peer-to-Peer Insurance and the Principle of Proportionality in an Insurtech Context. Available online: https://register.eiopa.europa.eu/Publications/EIOPA \%20Best $\% 20$ practices $\% 20$ on $\% 20$ licencing\%20March\%202019.pdf (accessed on 1 August 2021).

EIOPA. 2020a. Discussion Paper on the (Re)insurance Value Chain and New Business Models. Available online: https://www.eiopa. europa.eu/content/discussion-paper-reinsurance-value-chain-and-new-business-models-arising-digitalisation_en (accessed on 1 August 2021).

EIOPA. 2020b. EIOPA's Approach to the Supervision of Product Oversight and Governance. Available online: https://www.eiopa. europa.eu/content/eiopa-approach-supervision-product-oversight-and-governance_en (accessed on 1 August 2021).

Eling, Martin, and Martin Lehmann. 2018. The Impact of Digitalization on the Insurance Value Chain and the Insurability of Risks. Geneva Papers on Risk and Insurance: Issues and Practice. Basingstoke: Springer Nature, vol. 43, pp. 359-96. 
Fras, Mariusz, and Monika Szaraniec. 2020. Digital Consultancy, Artificial Intelligence and Smart Contracts in Insurance Distribution. Selected Legal Problems. In Public and Private Law and the Challenges of New Technological and Digital Markets. II. Legal Aspects of FinTech. Edited by Elisabetta Bani, Beata Pachuca-Smulska and Edyta Rutkowska-Tomaszewska. Munich: Warsaw, C.H. Beck, pp. 259-71.

Greenberg, Brad A. 2016. Rethinking Technology Neutrality. Minnesota Law Review 100: 1495-562. Available online: https://ssrn.com/ abstract $=2748932$ (accessed on 1 August 2021).

Gutterman, Sam. 2016. Distribution Risks. In A Risk Book-Governance, Management and Regulation of Insurance Operations. Ottawa: International Actuarial Association. Available online: https://www.actuaries.org/iaa/IAA/Publications/iaa_riskbook/IAA/ Publications/risk_book.aspx (accessed on 1 August 2021).

Hsin-Chun, Wang. 2016. E-commerce and Distribution of Insurance Products: A Few Suggestions for an Apprpriate Regulatory Infrastructure. In The "Dematerialized" Insurance. Distance Selling and Cyber Risks from an International Perspective. Edited by Pierpaolo Marano, Ioannis Rokas and Peter Kochenburger. Berlin: Springer, pp. 39-58.

IAIS. 2003. Risk to Insurers Posed by Electronic Commerce. Issues Paper. Available online: https://www.iaisweb.org/page/ supervisory-material/issues-papers / / file/34284/risks-to-insurers-posed-by-electronic-commerce-july-2003 (accessed on 1 August 2021).

Köhne, Thomas, and Christoph Brömmelmeyer. 2018. The New Insurance Distribution Regulation in the EU-A Critical Assessment from a Legal and Economic Perspective. Geneva Paper on Risk Insurance: Issues and Practice. Basingstoke: Springer Nature, vol. 43, pp. 704-39.

Lima Rego, Margarida, and Joana Campos Carvalho. 2020. Insurance in Today's Sharing Economy: New Challenges Ahead or a Return to the Origins of Insurance. In InsurTech: A Legal and Regualtory View. Edited by Pierpaolo Marano and Kyriaki Noussia. Berlin: Springer, pp. 27-48.

Marano, Pierpaolo. 2016. The EU Regulation on Comparison Websites of Insurance Products. In The "Dematerialized" Insurance. Distance Selling and Cyber Risks from an International Perspective. Edited by Pierpaolo Marano, Ioannis Rokas and Peter Kochenburger. Berlin: Springer, pp. 59-84.

Marano, Pierpaolo. 2019. Navigating InsurTech: The digital intermediaries of insurance products and customer protection in the EU. Maastricht Journal of European and Comparative Law 26: 294-315. [CrossRef]

Marano, Pierpaolo. 2021. The Contribution of Product Oversight and Governance (POG) to the Single Market: A Set of Organizational Rules for Business Conduct. In Insurance Distribution Directive: A Legal Analysis. Edited by Pierpaolo Marano and Kyriaki Noussia. Berlin: Springer, pp. 55-74.

Nicoletti, Bernardo. 2021. Insurance 4.0. Benefits and Challenges of Digital Transformation. Berlin: Springer.

OECD. 2018. Financial Consumer Protection Approaches in the Digital Age. Available online: https://www.oecd.org/finance/G20OECD-Policy-Guidance-Financial-Consumer-Protection-Digital-Age-2018.pdf (accessed on 1 August 2021).

Ostrowska, Marta, and Maciej Balcerowski. 2021. The Idea of Robotic Insurance Mediation in the Light of the European Union Law. In InsurTech: A Legal and Regulatory View. Edited by Pierpaolo Marano and Kyriaki Noussia. Berlin: Springer, pp. 199-210.

Ostrowska, Marta, and Michal Ziemiak. 2020. The Concept of P2P Insurance: A Review of the Literature and EIOPA Report. Warsaw: Prawo Asekuracyjne, pp. 3-48.

Rokas, Ioannis. 2016. European and International Distribution of Insurance Products. In The "Dematerialized" Insurance. Distance Selling and Cyber Risks from an International Perspective. Edited by Pierpaolo Marano, Ioannis Rokas and Peter Kochenburger. Berlin: Springer, pp. 3-38.

Stoeckli, Emanuel, Christian Dremel, and Falk Uebernickel. 2018. Exploring characteristics and transformational capabilities of InsurTech innovations to understand insurance value creation in a digital world. Electronic Market 28: 287-305. [CrossRef]

Tereszkiewicz, Piotr. 2020. Digitalisation of Insurance Contract Law: Preliminary Thoughts with Special Regard to Insurer's Duty to Advise. In InsurTech: A Legal and Regualtory View. Edited by Pierpaolo Marano and Kyriaki Noussia. Berlin: Springer, pp. 127-46.

Tereszkiewicz, Piotr, and Katarzyna Poludniak-Gierz. 2021. Liability for Incorrect Client Personalization in the Distribution of Consumer Insurance. Risks 9: 83. [CrossRef]

Tridimas, Takis. 1999. Proportionality in Community Law: Searching for the Appropriate Standard of Scrutiny. In The Principle of Proportionality in the Laws of Europe. Edited by Evelyn Ellis. Oxford: Hart Publishing

Tridimas, Takis. 2006. The General Principles of EU Law2. Oxford: Oxford University Press.

Van Hulle, Karel. 2019. Solvency Requirements for EU Insurers. Cambridge: Intersentia. 



\section{Regulation of InsurTech: Is the Principle of Proportionality an Answer?}

\section{Marta Ostrowska}

Citation: Ostrowska, Marta. 2021 Regulation of InsurTech: Is the Principle of Proportionality an Answer? Risks 9: 185.

https://doi.org/10.3390/ risks 9100185

\section{Academic Editors:}

Ramona Rupeika-Apoga,

Pierpaolo Marano and Salvador

Cruz Rambaud

Received: 6 September 2021

Accepted: 14 October 2021

Published: 19 October 2021

Publisher's Note: MDPI stays neutral with regard to jurisdictional claims in published maps and institutional affiliations.

Copyright: (c) 2021 by the author Licensee MDPI, Basel, Switzerland. This article is an open access article distributed under the terms and conditions of the Creative Commons Attribution (CC BY) license (https:// creativecommons.org/licenses/by/ $4.0 /)$.
The PRICL Project Group, Faculty of Law, University of Zurich, Rämistrasse 74, CH-8001 Zürich, Switzerland; marta.ostrowska@rwi.uzh.ch

\begin{abstract}
In the view of the current discussion on how to regulate the emerging InsurTech companies, if at all, the author attempts to demonstrate that rather than automatically introducing new regulation, the principle of proportionality can, in most cases, help to adapt application of the existing rules and policy approaches to the InsurTech business models without incurring major regulatory changes. An example of peer-to-peer platforms is used to show how the specificity of each InsurTech company can be grasped by the three key criteria of proportionality: nature, scale and complexity.
\end{abstract}

Keywords: principle of proportionality; InsurTech; peer-to-peer; Insurance Distribution Directive; Solvency II Directive; insurance distributors

\section{Introduction}

In recent years, the insurance industry has undergone a process of digitalization, and insurance undertakings have modernized their processes and implemented innovative solutions to respond to the changing needs of the society. Nevertheless, the insurance sector is not considered the most innovative and the impression of an old-fashioned, conservative approach on the part of insurance undertakings still persists. The untapped potential to innovate was noticed by technology companies, which started to develop solutions that would improve insurance services. Starting from supporting the traditional insurers in developing their business, the so-called 'InsurTech' startups began technological revolution on the insurance market and are becoming real competitors to the traditional insurance services. Insurtech is the term being used to describe the new technologies with the potential to bring innovation to the insurance sector and impact the regulatory practices of insurance markets (OECD 2017, p. 3). The term also describes technology-led companies emerging in the insurance sector, which are taking advantage of new technologies to provide coverage to a more digitally savvy customer base. This paper focuses on the latter.

Obviously, the increase of InsurTech has triggered regulatory concerns. There was no doubt that alongside the benefits, the new technology also brings new potential risks and, for this reason, the use of new technology in insurance should be controlled. Ideally, the InsurTech companies would be subject to the existing regulation and no major changes, or a separate regime would be necessary. However, a natural question that follows is whether the existing insurance regulation is adequate enough to accommodate the use of new technology and new entrants. The discussion in this field focuses mainly on how to make the regulation 'technologically neutral' and to reduce the entry barriers (see e.g., Tereszkiewicz 2020; Marano 2019).

\section{Materials and Methods}

With a view to the above, this paper attempts to address the question of whether the principle of proportionality can be considered a helpful tool in adapting the existing regulation to the specificity of InsurTech companies, and if, so, whether it is sufficient. The principle of proportionality is already present in insurance regulation and serves to 
adjust the regulation to the specificity of different market participants. Hence, the question seems valid.

We start by showing the examples of InsurTech companies (Section 4.1). To this end, the paper consults the existing literature on InsurTech and websites of selected InsurTech companies. This part serves to demonstrate how the new technology changes traditional business models and what is the added value. Following such a description, Section 4.2 attempts to identify the regulatory issues that the InsurTech companies' activity entails. Because insurance regulation aims to accommodate different interests (policyholders protection, enhancing competition) and, therefore, the outcome should be a compromise between these interests, the problem is tackled from two perspectives: InsurTech companies and national supervisory authorities. The InsurTechs' perspective is presented based on the results of the surveys conducted among the market players and shows how the current regulatory environment inhibits development of their business. The perspective of the supervisory authorities is represented by the International Association of International Insurance Supervisors. It is focused on the risks that the InsurTechs' activity may pose to customers and policyholders. Presentation of the regulatory issues from both perspectives demonstrates the areas where insurance regulation should be improved and/or should address.

Having understood the problem, the second part of the paper moves to address the research question. To see if the identified regulatory issues can be tackled by the principle of proportionality without imposing any radical regulatory changes, we will look first at the function of proportionality (Section 4.3). To this end, two main EU insurance directives, Directive 2009/138 of the European Parliament and of the Council of 25 November 2009 on the taking-up and pursuit of the business of Insurance and Reinsurance (Solvency II) and Directive (EU) 2016/97 of the European Parliament and of the Council of 20 January 2016 on insurance distribution (recast) (IDD), are analyzed to determine how they implement proportionality. The choice of the Directives is justified by the fact that these are the legal acts that cover the regulatory issues identified in the first part. Subsequently, the theoretical analysis of proportionality is tested with the regulatory issues identified in Section 4.2. The last Section concludes.

\section{Results}

As will be apparent in the coming section, the above-described analysis allows claiming that the principle of proportionality is an adequate and sufficiently flexible (Marano 2017, p. 14) measure to embrace the activity of the InsurTech companies (Marano 2017, p. 14; Marano and Siri 2021). A correct application of proportionality based on an understanding of how the InsurTech companies operate and what is required to make their innovations work as planned can serve as a remedy for most of the identified regulatory issues and thereby prevent from incurring more radical regulatory changes. Nevertheless, the analysis shows that where the regulation becomes more prescriptive or rule-based there is little that proportionality can help with. This is because proportionality comes into play only where a requirement can be applied with different intensities. If a requirement is not designed to be applied proportionately to the undertaking's risk profile, products sold, nature of distributor, or type of the activities pursued, it must be applied to all undertakings equally. Now, if such a requirement creates an obstacle for InsurTechs to operate, proportionality cannot help in overcoming the obstacle. The requirement should be either repealed or changed in a legislative process in a way that would accommodate InsurTechs' business models.

\section{Discussion}

\subsection{InsurTech Companies in Insurance Distribution-Selected Examples}

Among the myriad of different InsurTech start-ups there are companies which pursue activities falling into the scope of insurance activity (Lemonade, HavenLife, Ottonova) and insurance intermediation (Friendsurance, Teambrella, Laka). 
Perhaps the best-known 'digital insurer' - an InsurTech company holding an insurance license is Lemonade. Lemonade improves the traditional insurance business model by offering homeowners' and renters' insurance powered by artificial intelligence and behavioral economics. Lemonade is different from traditional insurance in that the customer experience is improved (the claims handling process is fully digitalized and requires no paperwork, the insurance is offered via IA app), the insurance premium is more precisely calibrated to the client's risk exposure (calculation of the insurance premium is based on many detailed factors, including risk prevention measures put in place) and it is registered as a public benefit corporation (a portion of the Lemonade's underwriting profits is donated to charity projects chosen by the customers) (Moodie 2017). The improved customer experience is also a main feature of Ottonova and HavenLife providing life and health insurance respectively. Besides these differences, the core of these InsurTechs' insurance activity is the same as the traditional one (OECD 2017, p. 159; Braun and Schreiber 2017, p. 159).

Many more InsurTech companies turn to the insurance intermediation proposing new distribution alternatives for traditional models. The most distinct one is known as peer-to-peer where the focus is put on the risk mitigation through the peer pressure (Marano 2019, p. 12). Typically, the customers of peer-to-peer InsurTechs are provided with the platform where they register and create group of peers (users). Peers within one group share the same needs or are interested in using the same insurance product. The bond between the peers can be even stronger if they are connected personally or through mutual business. Upon joining the group, each peer pays a premium which is then split in two parts. One part is paid to the cash back pool and the other is transferred to a partner insurance company. The loss is primarily paid from the money collected in the cash back pool, however, when the loss exceeds the agreed capped limit, it is paid by the partner insurance company. The traditional insurer will also step in if the cashback pool is exhausted. At the end of the year, if the overall amount of the paid claims is low, the peers may decide if they want to receive a cashback payment or keep the remaining money in the cashback pool to renew the coverage (Ziemiak and Ostrowska 2020, p. 35). This peer-to-peer arrangement may be organized by an insurance company, an insurance intermediary, e.g., Friendsurance (usually broker) or 'self-governing' platform acting as a purely technical service provider, e.g., Teambrella (in this case the platform cannot perform any insurance or insurance distribution activities) (EIOPA 2019, p. 26).

Another example of an innovative distribution model is Laka, provider of insurance coverage for cyclists where the consumer makes payments at the end of the month, based on the exact cost of claims settled during that period (Laka Ltd. registered in London, UK, authorized and regulated by the Financial Conduct Authority). The premium will never be more than the personal cap of the customer. It seems that the model resembles peer-to-peer arrangement, at least in part. Laka offers the customers an option to join a collective (peers group). If the policyholder is part of the collective and the collective has no claims in a month, the members of the collective are not charged a premium that month (Laka Ltd. n.d., p. 8).

The innovations of the above models are created around the reduction of the premium, alternative risk mitigation techniques, increase of trust (through transparency about the company's earnings, clarity of the policy wording) and change of the customers' perception of insurance and insurance industry (insurance as a social good rather than a necessary evil).

\subsection{Identification of the Regulatory Issues}

Innovations are generally a positive development and there is a common consensus that they should be supported. An important factor influencing development of innovations is regulation which may be either open to innovations, thereby accommodating new business structures or obsolete and too stiff. Clearly, the latter would be seen as a serious obstacle for the InsurTech startups discouraging them to enter the insurance industry, regardless of the services they would provide. Consequently, such a regulation would 
inhibit the overall development of insurance as well as the competition in the insurance market. All of that is to the detriment of the customers.

Considering the potential negative consequences of an obsolete regulation, it is in everybody interests (customers, insurance undertaking and intermediators, and other InsurTech startups) to make insurance regulation InsurTech friendly without compromising on the main objectives of the regulation (customers/policyholders protection, financial stability, undistorted competition). To do so, it should be first identified whether, and if so why, the currently binding insurance regulation is unaccommodating to the InsurTech companies.

\subsubsection{The InsurTech Companies' Perspective}

The Geneva Association's survey carried out among insurers shows that the InsurTech companies' concerns regarding the regulation concentrate mostly around three issues: default paper requirements (insurance document delivery), medical exam requirements or absence of the provisions of telehealth, insurance distribution regulation (The Geneva Association 2021, p. 12). In another survey on InsurTech carried out by EIOPA, Insurance Europe indicated the following legal barriers to InsurTech in the existing European insurance legislation: default paper requirements (especially in IDD Directive and PRIIPs Regulation), unnecessary, burdensome reporting requirements, overly strict requirements in case of outsourcing of key functions, requirement to carry out appropriate product testing, licensing requirements (Insurance Europe 2018, pp. 1, 3, 4).

The compulsory use of paper appears as a legal barrier in both surveys. As demonstrated in the previous section, the innovations employed by the InsurTechs rely heavily on the paperless contact with the customers. The whole process of choosing insurance coverage, entering into an insurance contract and subsequent execution of the contract is digitalized. It fastens insurance acquisition and claims handling but, most importantly, it improves the customer's experience which is key for the InsurTech business. Whenever the regulation sets out a requirement of a compulsory use of paper (e.g., Article 23 of the IDD Directive), the requirement kills the innovation.

Another challenging requirement regards product testing. IDD Directive requires insurance undertakings to carry out appropriate product testing before bringing that product to the market or significantly adapting it, or in case the target market has significantly changed (Article 25(1) of IDD Directive and Article 6 of the Commission Delegated Regulation (EU) $2017 / 2358$ of 21 September 2017). When assessing the methods of product testing, the NSAs look at the structures that are in place within an organization in respect of product testing (i.e., what product testing looks like on paper) and whether the product testing processes and procedures are fully embedded within an organization (i.e., how product testing is implemented in practice) (EIOPA 2020, p. 12). The Insurance Europe notices that considering most InsurTech related products are tested in real-time and quick reaction to market needs is key for innovation to work, compliance with the product testing requirements may become troublesome as it lengthens the time to bring innovate products to the market (Insurance Europe 2018, p. 4).

For those InsurTech companies which wish to become an insurer or an insurance agent/broker already the licensing requirements themselves may become challenging. There are potentially prohibitive capital and fit and proper requirements (Insurance Europe mentions cases in the Netherlands where InsurTech companies applying for licenses ran into difficulties regarding certain licensing requirements (e.g., management should have a certain experience in the industry and/or consist of a number of persons when scaling up) (Insurance Europe 2018, p. 2) which could turn out to be a barrier to enter (OECD 2017, p. 29). Finally, even though an InsurTech company obtains the insurance license, the requirements on the insurance activity may turn out to be overly burdensome and eventually make the business unprofitable. For instance, an overwhelming number of reporting requirements which are criticized for being overly complex or for the fact that they duplicate, or overlap are a real burden to most of the traditional insurance undertakings 
(European Commission 2018, pp. 7, 10). If the supervisory reporting is considered costly and complicated by those market participants who run insurance business for years, have resources and well-developed business, obviously, compliance with the supervisory reporting will be even more difficult for the new InsurTech entrants. Further to this, there are also requirements on outsourcing of functions and insurance activities which are considered overly strict. Typically, InsurTechs entering the insurance business are small-sized and do not have enough appropriately qualified human resources. They will most likely outsource most of the key functions or insurance activities, at least at the beginning of their activity. Therefore, in theory, to allow InsurTechs to start the activity and to anchor their presence to the market, the regulation should facilitate the outsourcing process. Meanwhile, though, it is complained that Solvency II inhibits the process by requiring, for instance, to adopt a written policy for the outsourced functions and insurance activities, designating an employee responsible for supervising the outsourcing process or by stipulating that the ultimate responsibility for the outsourced functions remains with the management board of the InsurTech company (Insurance Europe 2018, p. 4).

\subsubsection{The NSA's Perspective}

Some of the respondents in the Geneva Association's survey indicated conservatism of the national supervisory authorities (NSAs) as a barrier to innovate (The Geneva Association 2021, p. 10). This conservatism may result from the fact that the NSAs do not understand or have sufficient knowledge on how the InsurTechs actually work. Naturally, it builds a mistrust on the NSAs' side and implies stricter approach towards the supervision of InsurTechs.

The NSAs main goal is to ensure that customers enjoy the same level of protection, regardless of the distribution channel. The IAIS understands that the new technologies and innovations provide a unique opportunity to provide customers with products that are tailored to their needs in a best possible way, however, the IAIS' concern is whether the processes behind the use of new technology are fair. The IAIS has thoroughly analyzed the most popular innovations used in the market and voiced its concerns regarding the potential risks they may pose to the customers. The following represent a few examples. First, introduction of innovative solutions usually increases the number of parties involved in the execution of insurance relationship and makes the interactions more complex (Braad Olesen 2017). Second, the use of digital marketing campaigns and the increased collection and use of data (e.g., via social media platforms) may lead to customers being manipulated to buy an insurance product, without them being aware (IAIS 2018, pp. 15-16). Third, it is doubtful if the automated advice can solve every limitation of traditional faceto-face advice and therefore replace the human advice. IAIS believes that the automated advice may pose the risk of misunderstanding or a reduced detection of contradicting answers by customers if the automation is total. Furthermore, one of the most challenging aspects is if the automated advisors can detect when the customer is in doubt (IAIS 2018, p. 19). Fourth, there are price comparison websites that are not subject to specific disclosure requirements. In such a case, transparency is reduced, and it may affect adversely the customers' ability to make informed decisions (IAIS 2018, p. 20). Finally, reduction of transparency is also observed where algorithms and automated decision-making are employed. Here, it is feared that it can lead to unfair discrimination, or the policyholders may complain that forecasts made by an algorithm might not be explainable (IAIS 2020, pp. 11-12). For this reason, the German NSA has already stated that black-box models would not be accepted (BaFin 2018, p. 13).

As already mentioned, there is no doubt that innovation is necessary for the development of the markets and products and that its implementation should be strongly supported also by the NSAs (IAIS 2018, p. 34). Nevertheless, the above concerns cannot be ignored. The NSAs are thus facing the challenge of finding the right balance between acting as a promoter of the innovative solutions and businesses and protecting the customer. 
To do so, it is crucial for the NSAs to understand how exactly these innovations work and how the InsurTechs are behaving with impact on outcomes for consumers.

Other than innovations as such, the NSAs may also not be familiar with the specificity of entities providing the innovations that wish to enter the insurance markets. Unlike the traditional insurers and insurance intermediaries, the InsurTech companies may not have experience or knowledge of financial services regulation, may have different entity structures and approaches to consumer related risks. The IAIS notices that it may require a proactive strategy for outreach and engagement with these new entrants to inform and "educate" them on relevant supervisory matters and the proper compliance attitude (IAIS 2018, p. 30). One way to know the InsurTech business better is establishing a 'regulatory sandbox' approach designed to assist new market entries. More precisely, it helps InsurTech companies to gain access to fast, frank feedback on the regulatory implications of their solutions, and identifies areas where the regulatory framework needs to adapt to enable further innovation in the interests of consumers.

Further to this, the NSAs should continuously monitor new developments and cooperate with InsurTechs as to how the potential risks resulting from their activity may be mitigated.

\subsection{Principle of Proportionality. (How) Does It Come into Play?}

Solvency II and IDD Directives are two principal EU insurance regulations covering (re-)insurance activity and insurance distribution respectively. The undertakings subject to these regulations range from traditional big (re-)insurance undertakings providing coverage to thousands of policyholders to small, specific captive insurance undertakings with only one policyholder. The selection of the insurance distributors is also fairly diversified as it includes the insurance undertakings, brokers, tied and independent agents, coverholders, and ancillary insurance intermediary. When the same regulation governs such a diversified market, to provide a business-friendly environment that is to the mutual benefit of both customers and regulated undertakings, it must be designed in a way that accommodates all different market participants. In other words, the regulation must avoid creating unnecessary burden that can discourage undertakings to take up business or to develop by, for example, employing innovations (Harbo 2015, p. 37). In this vein, the principle of proportionality was introduced to Solvency II (Van Hulle 2019, p. 171). Later on, proportionality was also adopted in IDD (see recitals 72, 17, 23 of IDD). Because the directives cover different areas of insurance law, the principle of proportionality embedded therein slightly differs, however, its function remains the same. Namely, in both directives, proportionality serves to adjust the regulation to the specificity of an individual undertaking by allowing to increase or decrease the intensity of the regulation and supervision (see more in Ostrowska 2020, p. 39; Löfvendahl and Yong 2018, p. 4).

\subsubsection{Proportionality in Solvency II-Insurance Activity}

Since Solvency II imposes requirements regarding the insurance activity and the requirements are risk-based (Purves 2011, p. 641), the intensification of the regulation and supervision is adjusted to the risk profile of a regulated undertaking. The risk profile is defined by three criteria: nature, scale and complexity of the risks inherent in the business of an undertaking. Thus, in practice, application of proportionality comes down to calibrate a requirement to those three criteria.

Although nature, scale and complexity of a risk are not legally defined, the supervisory authorities made an effort to explain their meaning by issuing guidelines and other nonbinding instructions (see for instance CEIOPS 2008; EIOPA 2015a; IAIS 2008). Based on these guidelines, nature of the risk refers to the insurance risk of an undertaking. The insurer should consider whether it underwrites long- or short-tail business, whether it is a low frequency and high severity business or consists of high frequency and low severity risks and who are the policyholders (CEIOPS 2008, p. 6). Complexity of the risks refers to all the risks borne by the undertaking, including e.g., operational risk or market risk. The nature 
and complexity of the risks should thus provide a picture of the undertaking resulting from the analysis of the origination of the risks, the correlation between the types of risks and the mitigations and diversifications (Grima 2020, p. 226). The full picture of a risk profile must be completed with the scale of the risks which depends on the scale of the undertaking's balance sheet and materiality of the risks (CEIOPS 2008, p. 6).

Now, if an InsurTech company seeks to obtain an insurance license, it means that the business it wishes to pursue falls within the scope of the definition of the insurance activity and as such it presents the risks associated with the insurance activity. In other words, it results that the core of the activity of InsurTechs does not differ from the activity of the traditional insurance undertakings. Consequently, it is justified to subject the InsurTech company to the risk-based Solvency II Directive as the regulation introduced therein is appropriate and necessary to achieve the objectives of insurance regulation (see recital 133 of Solvency II Directive). At the same time, taking into account the specificity of InsurTechs as well as the role of proportionality, the principle should be considered instrumental in applying the regulation to the InsurTech companies.

There is no doubt that proportionality is an adequate tool to address the concerns regarding a too strict system of governance requirements or the excessive supervisory reporting and bring the InsurTech companies a regulatory relief, at least technically (see Commission of the European Communities 2007, pp. 24-26). The following paragraphs will now demonstrate how proportionality may be of help for the InsurTechs on their way to adapt to Solvency II Directive as it stands today.

We start with the system of governance where Solvency II Directive does not prescribe any specific system of governance. This is because there is no one system that would work well for all undertakings. The variety of (re-)insurers subject to the EU insurance regulatory framework makes it impossible to create common rules on the organization of the system of governance, not to mention that neither would it be the best solution from the high-quality legislation perspective (i.e., criticized 'one-size-fits-all' approach). It is only possible to outline the results that are expected of the system of governance that is recognized as proportional, which EIOPA did by issuing Guidelines on system of governance (EIOPA 2015a). For this reason, the regulation on system of governance is mostly principle-based which allows insurance undertakings to freely decide on their own system of governance as long as it is proportionate to the nature, scale and complexity of the operations of the insurers (Article 41(2) of Solvency II Directive). The principle of proportionality has been introduced here as a general principle ruling the whole regulation of the system of governance which means that all provisions on system of governance should be interpreted according to the nature, scale and complexity of the operations of the insurance undertakings. If an InsurTech is small or medium-sized, or if its business is relatively simple and straightforward, a less sophisticated governance system should be sufficient (Van Hulle 2019, p. 400). What is meant by a less sophisticated governance system must be of course specified individually. I will, however, present issues which may be common for many InsurTechs, taking as an example an InsurTech startup with an innovative technology-led business model wishing to enter the EU insurance market. First, Solvency II Directive introduces a requirement that an undertaking must organize at least four key governance functions: risk management, internal control, internal audit and actuarial (Articles 44, 46, 47, 48 of Solvency II) where each function is operationally independent (Article 268(1) of Commission Delegated Regulation (EU) 2015/35 of 10 October 2014 (Delegated Regulation)). Establishment of four independent functions was proved to be burdensome for small and less complex undertakings, such as (re-)insurance captives, which for their size tend to outsource most of the functions (AON 2011, p. 3). This may be the case of most of the small-sized companies or companies that are entering the market, including InsurTech startups. The principle of proportionality helps to ease this burden by allowing the insurance undertakings to outsource the key functions (Article 49 of Solvency II Directive) or to combine them (recital 32 of Solvency II Directive). If the functions are combined, it should be ensured that the conflicts of interests are avoided, and 
the judgement is independent. One key function that, in principle, cannot be combined with other functions is the internal audit function (Article 271(1) of Delegated Regulation). Article 271(2) of Delegated Regulation provides however for a very narrow exclusion to this prohibition, according to which a person carrying out the internal audit function may also carry out other key functions if (i) this is appropriate with respect to the nature, scale and complexity of the risks inherent in the undertaking's business and (ii) no conflict of interest arises for the person carrying out the internal audit function and (iii) the costs of maintaining person for the internal audit function that do not carry out other key functions would impose costs on the undertaking that would be disproportionate with respect to the total administrative expenses. EIOPA further specifies what is meant by this exclusion and states that the performance of the internal audit function by the same person or persons which perform the compliance, risk management or actuarial function is only possible where the undertaking has a risk profile that does not entail large or complex risks, i.e., where the undertaking only writes standard lines of business on a limited scale and where the undertaking is not invested in complex investment products (EIOPA 2015b, p. 83). If this description corresponds with an InsurTech startup's risk profile, it would be justified for that InsurTech to apply the exclusion. In such a case, the InsurTech would need to be able to demonstrate to the supervisory authority, on request, that the conflicts of interest are properly dealt with and no concerns remain that the objectivity and independence of the internal audit function is compromised (EIOPA 2015b, p. 83). If combination of functions is not an option, it is also possible to outsource them. In principle, there is no qualitative limitation to outsourcing, i.e., as to which functions or activities can be outsourced. Yet, if the outsourced function or activity is critical or considered important operational function, the outsourcing of such function cannot put at risk the InsurTech's quality of governance, increase its operational risk, hinder the supervisory process or undermine the service to the policyholder (Article 49(2) of Solvency II Directive). The part of key activities or functions that must be retained in the InsurTech compared with tasks outsourced should be assessed having regard to the nature, scale and complexity of its business. Obviously, the InsurTech cannot outsource all its functions and activities. It must retain sufficient expertise and resources to monitor and manage its risks. The part of key activities and functions that the insurer retains must be such that the insurer will be in a position to resume direct control over an outsourced activity either by insourcing or through an alternative outsourcing arrangement (Van Hulle 2019, p. 460). This must be assessed having regard to the nature, scale and complexity of the InsurTech.

The proportionality of the system of governance is also relevant where the InsurTechs use AI within their organization. In the recent EIOPA's report, it is underlined that the governance measures that the insurance undertakings must implement (e.g., transparency and explainability policies, human oversight, data management) should be proportionate to the AI use case and its impact on both consumers and those insurance undertakings (EIOPA 2021, pp. 8, 17). To help InsurTech assess the impact and justify the choice of the governance measures, the report suggests following the AI use case impact assessment which determines the impact by the potential harm caused by the use of AI to an individual and to the insurance undertaking (EIOPA 2021, p. 18). If, according to the impact assessment, a concrete AI use case has low impact, there is no need for the InsurTech to implement sophisticated measures but instead, they can be limited to the minimum required.

Besides the system of governance, proportionality is also instrumental for the supervisory reporting duties. The regular reporting obligations include the Solvency and Financial Condition Report, the regular supervisory report, Own Risk and Solvency Assessment and annual and quarterly quantitative report templates (Article 304(1) of the Delegated Regulation). Submission of these reports is obligatory and the frequency of reporting varies from quarterly to at least every three years. Both big-sized and small-sized insurance undertakings complain that the supervisory reporting in its current form is unnecessarily costly for its intended purposes and often overlaps with other disclosure requirements (European Commission 2018, pp. 7, 10). If the issue is raised by experienced big-sized 
insurers, most likely it will also be a challenge for a small-sized InsurTech startup. The principle of proportionality may help to minimize the burden of the reporting in at least two ways. First, instead of submitting annual and quarterly report templates, the InsurTech could limit the reporting duties to the annual quantitative templates only if proves the following: (i) the submission of quarterly information is overly burdensome in relation to the nature, scale and complexity of the risks inherent in its business and (ii) the quarterly information is reported at least annually (Article 35(6) of Solvency II Directive). Second, NSA may limit regular supervisory reporting or exempt the InsurTech from reporting on an item-by-item basis, where (i) the submission of that information would be overly burdensome in relation to the nature, scale and complexity of the risks inherent in its business, (ii) the submission of that information is not necessary for the effective supervision of the InsurTech, (iii) the exemption does not undermine the stability of the financial systems concerned in the EU and (iv) the InsurTech is able to provide the information on an ad-hoc basis (Article 35(7) of Solvency II Directive). Although in both cases, the limitation of the reporting duties depends on the prior approval of the NSA, it is worth noticing that the small-sized InsurTechs should be prioritized when determining the eligibility of the undertakings for those exemptions (Article 35(6) of Solvency II Directive).

As seen in the above examples, the principle of proportionality does offer a general possibility to adjust the Solvency II framework to the InsurTech specificity (particularly size of the business and the use of IA). Each time the InsurTech would wish to apply proportionality, it will be key to specify its risk profile and, most importantly, if (and how) the innovative business models and the technology used by that InsurTech affect the risk profile. Do certain business models increase or decrease the risk of insolvency? Does the technology used by InsurTech companies expose the policyholders to higher risks or provides greater safety? For instance, the risk mitigation techniques applied within the peer-to-peer arrangements or application of the technology that allows for controlling the risk may decrease the overall complexity of the risks inherent to the business. In turn, if the InsurTech adopts new technologies or innovates processes or products where they represent the supervisory concerns mentioned earlier, it would perhaps increase the complexity and therefore the InsurTech should make sure that the appropriate internal control or security measures are in place.

Although, technically, proportionality enables to adjust the regulation to the specificity of the InsurTech companies, it should be underlined that the history of the principle in the insurance industry shows that the mere fact the principle exists is not enough. Namely, the practical application of proportionality revealed to be too troublesome both for the NSAs and the insurance companies. It is complained that the proportionality is not applied to its fullest extent or is not applied at all (Batten and Di Capua 2020; Insurance Europe 2018; Insurance Europe and AMICE 2019) which leads to the situation where in fact 'one-size-fitsall' approach persists. It should be stressed, however, that the criticism does not question proportionality as such. The principle is commonly recognized as indispensable to apply the EU regulatory framework (see e.g., Insurance Europe 2018, p. 3; ECIROA 2008, p. 5). Rather, the criticism focuses on the procedural aspects of the application of proportionality.

The insufficient and inconsistent application of the principle is a general problem, however, it may be particularly damaging to innovative business models. Based on experiences in the German and French markets, the InsurTech companies faced the difficulties relating to licensing exactly for this reason (Insurance Europe 2018, p. 1). The principle of proportionality is now being revised within the Solvency II review and different ways to improve its application and supervision are being analyzed. The accounts are also taken of the InsurTechs needs and interests (the proportionality toolbox suggested by the Dutch Association of Insurers facilitates activity of small and medium-sized insurers as well as InsurTechs (see Dutch Association of Insurers and Insurance Ireland 2019, p. 3). 


\subsubsection{Proportionality in IDD Insurance Distribution}

Since most of the InsurTech companies are active in the insurance intermediation area, the conduciveness of the regulation on the insurance distribution is particularly important in terms of the InsurTech regulation. Meanwhile, the Geneva Association survey shows that the insurance distribution regulation is considered a barrier by $44 \%$ of respondents, including Germany (The Geneva Association 2021, p. 12) (IDD Directive is also claimed to be burdensome by Insurance Europe (see Insurance Europe 2021, p.10)).

IDD Directive follows the suit of Solvency II and implements the principle of proportionality to accommodate different insurance distributors and thereby create a level playing field (Marano, p. 6). Here, however, proportionality refers not only to the risk profile of an undertaking (recital 23 of IDD Directive) but primarily to the activities performed, the nature of the insurance products sold and the nature of the distributor (Article 25(2) of IDD). The intensity of the regulation is adjusted to the activities performed, nature of the products offered and type of the distributor. The intensity of supervision is additionally adjusted to the nature, scale and complexity of the risks inherent in the business of a particular distributor. There are no general guidelines on how to calibrate specific requirements to the activities performed, nature of the products offered or type of the distributor. Occasionally, EIOPA explains what impactful elements are considered when assessing proportionality of individual requirements. For example, with respect to the product oversight and governance, the NSAs should consider whether the distribution activity is the principal professional activity or an ancillary activity, whether the distributor is acting as a tied agent or an independent broker (type of the distributor) (EIOPA 2020, p. 7), manufacturers' business model, activities pursued (designing and manufacturing of insurance products and/or distribution of insurance products) and kinds of product offered (their complexity), distribution and outsourcing arrangements, characteristics of the different target markets (EIOPA 2020, p. 8).

Similarly to Solvency II Directive, there seems to be nothing against application of proportionality to the InsurTech companies. Quite the opposite, in fact. The element to which the regulation should be adjusted are so broad and generic that they can embrace the specifics of InsurTech. Again, however, what may be problematic is the practical application of proportionality. Besides, the uncertainty about how to calibrate a requirement to e.g., complexity of the product sold, application of proportionality is virtually impossible. This is because some of the requirements set out by IDD Directive are rule-based and leave no room for the proportional adjustment. The problem regards e.g., Article 23 of IDD Directive which imposes obligation to provide the relevant information to the customer on paper. The industry argues that the InsurTechs should be exempted from this obligation. However, nonapplication of the obligation cannot be justified by the application of proportionality. This is because according to the idea behind the principle of proportionality, proportionality can never lead to the non-application of a requirement (Van Hulle 2019, p. 172). It is explained that because all the measures (requirements) are appropriate and necessary, if application of proportionality allowed for nonapplication of a requirement, it would question its necessity. On a separate note, it is interesting to notice here that the principle of proportionality in the bank regulation slightly differs in this respect. Namely, proportionality applied in the bank regulation allows to apply certain regulations only to those institutions which are relevant to the issue being addressed by those regulations (e.g., a regulation intended to be addressed to systemically significant banking institutions which at the same time should not be applied to other institutions which are not deemed to be systemically significant). As a result, proportionality allows to waive certain rules, rather than apply them in a simplified or less prescriptive way, whenever an institution is only marginally exposed to the risks that those rules are designed to control (EBA Banking Stakeholder Group 2015, p. 29). Perhaps the same concept transposed to the insurance regulation could address the problem of the default paper requirements. 


\section{Conclusions}

This paper attempted to examine whether the application of existing rules and policy approaches might be adapted to meet the development of InsurTech companies without incurring major regulatory changes. Based on the above discussion, two provisional conclusions arise.

First, the principle of proportionality does appear adequate and sufficiently flexible to embrace the activity of the InsurTech companies, at least for now and at least where the regulation is not too much prescriptive or rule-based. The conclusion is shared by the Insurance Europe which stresses that proper and consistent application of the principle of proportionality can ensure both traditional insurance distributors and new InsurTech companies to provide innovative products when the activity and risk are the same (Insurance Europe 2018, p. 3). For the purpose of the application of a requirement in a proportional manner, the valuation of the risk profile should take into account the influence of the innovation and new technology used by InsurTech companies. The NSAs should use the concept of the regulatory sandbox not only to test whether the innovation is safe for the customers but also as an opportunity to understand how the innovations work and then to use what they learned to enhance the application of the principle of proportionality towards the InsurTechs.

The first conclusion may change however if the innovative business models developed to the point where the financial buffers imposed by Solvency II would no longer be needed. Clearly, this is an extremely abstract vision of the future, yet, judging on the pace of technological development so far, its potential should be never underestimate.

Second, a mere application of proportionality will not make the regulation 'technologically neutral'. This is because in the current regulation application of the principle cannot lead to a nonapplication of a requirement and therefore the application of proportionality cannot justify nonapplication of the requirement that limits technological development, e.g., a compulsory use of paper documentation. In these cases, the principle of proportionality will not suffice, and more radical changes should be introduced instead.

Funding: This research received no external funding.

Institutional Review Board Statement: Not applicable.

Informed Consent Statement: Not applicable.

Conflicts of Interest: The author declares no conflict of interest.

\section{References}

AON. 2011. Ensuring the Proportional Treatment of Captives under SOLVENCY II, 13.07.11. London: AON.

BaFin. 2018. Big Data Meets Artificial Intelligence. Available online: https://www.bafin.de/SharedDocs/Downloads/EN/dl_bdai_ studie_en.html;jsessionid=17D8386C1A00AD740CF23AB405425824.1_cid298 (accessed on 4 October 2021).

Batten, Ron, and Luigi Di Capua. 2020. Speech by Ron Batten and Luigi Di Capua at the Conference on Review of the Solvency II organized by the European Commission on 29 January 2020, Video of the Conference. Available online: https://webcast.ec. europa.eu/conference-on-review-of-the-solvency-ii (accessed on 16 October 2021).

Braad Olesen, Peter. 2017. InsurTech-Insurance a New Way, Presentation at the IAIS Global Seminar 2017, Slide 2. Available online: https://www.iaisweb.org/page/events/global-seminar/london-2017/global-seminar-videos (accessed on 4 October 2021).

Braun, Alexander, and Florian Schreiber. 2017. The Current InsurTech Landscape: Business Models and Disruptive Potential. St. Gallen: Institute of Insurance Economics, University of St. Gallen.

CEIOPS. 2008. Advice to the European Commission on the Principle of Proportionality in the Solvency II Framework Directive Proposal. CEIOPS-DOC-24/08. May.

Commission of the European Communities. 2007. Commission Staff Working Document-Accompanying Document to the Proposal for a Directive of the European Parliament and of the Council Concerning Life Assurance on the Taking-Up and Pursuit of the Business of Insurance and Reinsurance-Solvency II-Impact Assessment Report, Brussels. Available online: https: / / ec.europa.eu/ smart-regulation/impact/ia_carried_out/cia_2007_en.htm (accessed on 4 October 2021).

Dutch Association of Insurers and Insurance Ireland. 2019. A Proportionality Toolbox for Solvency II. Discussion Paper. Available online: https:/ / www.insuranceireland.eu/news-and-publications /news-press-release/dutch-and-irish-insurance-associationscall-for-a-proportionality-toolbox-for-solvency-ii (accessed on 4 October 2021). 
EBA Banking Stakeholder Group. 2015. Proportionality in Bank Regulation. A Report by the EBA Banking Stakeholder Group. Available online: https://www.eba.europa.eu/documents/10180/807776/European+Banking+Authority+Banking+Stakeholder+ Group-+Position+paper+on+proportionality.pdf (accessed on 4 October 2021).

ECIROA. 2008. Position Paper on the Treatment of Captives in Solvency II. Available online: http://www.eciroa.org/wp/wp-content/ uploads/2008/09/position-paper-captives-solvency-ii.pdf (accessed on 4 October 2021).

EIOPA. 2015a. Guidelines of System of Governance. EIOPA-BoS-14/253. Frankfurt am Main: EIOPA.

EIOPA. 2015b. Final Report on Public Consultation No. 14/017 on Guidelines on System of Governance. EIOPA-BoS-14/253. Frankfurt am Main: EIOPA, p. 83.

EIOPA. 2019. Report on Best Practices on Licensing Requirements, Peer-to-Peer Insurance and the Principle of Proportionality in an InsurTech Context. Luxembourg: EIOPA.

EIOPA. 2020. EIOPA's Approach to the Supervision of Product Oversight and Governance. Luxembourg: EIOPA.

EIOPA. 2021. Artificial Intelligence Governance Principles: Towards Ethical and Trustworthy Artificial Intelligence in the European Insurance Sector. A Report from EIOPA's Consultative Expert Group on Digital Ethics in Insurance. Frankfurt am Main: EIOPA.

European Commission. 2018. Summary Report of the Public Consultation on the Fitness Check on Supervisory Reporting Having Taken Place from 1 December 2017 to 14 March 2018. Brussels: European Commission.

Grima, Simon. 2020. Proportionality in the application of insurance solvency requirements: The case of small EU jurisdictions. Paper presented at the XXI Conference Modern Aspects of the Legal and Regulatory Insurance Concept, Sabac, Serbia, September 25-27.

Harbo, Tor-Inge. 2015. The Function of Proportionality Analysis in European Law. Nijhoff Studies in EU Law. Boston: Leiden, vol. 8.

IAIS. 2008. Guidance Paper on the Regulation and Supervision of Captive Insurers. Guidance Paper No. 3.6. Basel: IAIS.

IAIS. 2018. Issues Paper on Increasing Digitalization in Insurance and Its Potential Impact on Consumer Outcomes. Basel: IAIS.

IAIS. 2020. Issues Paper on the Use of Big Data Analytics in Insurance. Basel: IAIS.

Insurance Europe. 2018. Insurance Europe Response to EIOPA Stakeholder Survey on InsurTech. Available online: https://www. insuranceeurope.eu/publications/1810/response-to-eiopa-stakeholder-survey-on-insurtech/ (accessed on 4 October 2021).

Insurance Europe. 2021. Response to the EIOPA Survey on the Application of the Insurance Distribution Directive. Brussels: Insurance Europe.

Insurance Europe and AMICE. 2019. Proposal for Making Proportionality Work in Solvency II; Brussels: Insurance Europe, September 30. Available online: https://www.insuranceeurope.eu/publications/1756/insurance-europe-and-amice-proposals-for-makingproportionality-work-in-solvency-ii/ (accessed on 18 October 2021).

Laka Ltd. n.d. Bicycle Insurance Policy. Policy Wording. Registered in London, UK. Available online: https://uploads-ssl.webflow. com/5ede4851209ff080a70e63e6/6009ae336ea217c84961be7b_Laka_policy\%20wording\%202.0\%2021\%3A01\%3A21.pdf (accessed on 18 October 2021).

Löfvendahl, Gunilla, and Jeffery Yong. 2018. Proportionality in the Application of Insurance Solvency Requirements. FSI Insights on Policy Implementation No. 14. Basel: Bank for International Settlements, December.

Marano, Pierpaolo. 2017. Sources and Tools of the Insurance Regulation in the European Union. In Insurance Regulation in the European Union. Solvency II and Beyond. Edited by Pierpaolo Marano and Michele Siri. New York: Palgrave Macmillan.

Marano, Pierpaolo. 2019. Navigating InsurTech: The digital intermediaries of insurance products and customer protection in the EU. Maastricht Journal of European and Comparative Law 26: 294-315. [CrossRef]

Marano, Pierpaolo, and Michele Siri. 2021. Regulating InsurTech in the European Union. Journal of Financial Transformation 54.

Moodie, Alison. 2017. How Artificial Intelligence Could Help the Insurance Industry Trustworthy. Available online: https://www. theguardian.com/sustainable-business/2017/jan/28/insurance-company-lemonde-claims (accessed on 4 October 2021).

OECD. 2017. Technology and Innovation in the Insurance Sector. Paris: OECD.

Ostrowska, Marta. 2020. The Principle of Proportionality in the EU Insurance Regulation. Paper presented at XXI Conference Modern Aspects of the Legal and Regulatory Insurance Concept, Sabac, Serbia, September 25-27.

Purves, Robert. 2011. Europe: The architecture and content of EU insurance regulation. In Research Handbook on International Insurance Law and Regulation. Edited by Julian Burling and Kevin Lazarus. London: Edward Elgar Publishing, pp. 621-55.

Tereszkiewicz, Piotr. 2020. Digitalization of Insurance Contract Law: Preliminary Thoughts with Special Regard to Insurer's Duty to Advise. In InsurTech: A Legal and Regulatory View. Edited by Marano Pierpaolo and Noussia Kyriaki. Berlin: Springer, pp. 127-46.

The Geneva Association. 2021. Regulatory Considerations for Digital Insurance Business Models. Issue Brief. Geneva: The Geneva Association.

Van Hulle, Karel. 2019. Solvency Requirements for EU Insurers. Solvency II Is Good for You. Brussels: Intersentia.

Ziemiak, Michał, and Marta Ostrowska. 2020. The Concept of P2P Insurance: A Review of the Literature and EIOPA Report. Prawo Asekuracyjne 1: 31-48. 


\title{
FinTech in Latvia: Status Quo, Current Developments, and Challenges Ahead
}

\author{
Ramona Rupeika-Apoga ${ }^{1, *}$ and Stefan Wendt ${ }^{2}$ \\ Faculty of Business, Management and Economics, University of Latvia, LV-1586 Rīga, Latvia \\ Bifröst University, 311 Bifröst, Iceland; stefanwendt@bifrost.is \\ Correspondence: rr@lu.lv
}

Citation: Rupeika-Apoga, Ramona, and Stefan Wendt. 2021. FinTech in Latvia: Status Quo, Current Developments, and Challenges Ahead. Risks 9: 181. https:// doi.org/10.3390/risks9100181

Academic Editor: Mogens Steffensen

Received: 30 July 2021

Accepted: 9 October 2021

Published: 14 October 2021

Publisher's Note: MDPI stays neutral with regard to jurisdictional claims in published maps and institutional affiliations.

Copyright: (c) 2021 by the authors. Licensee MDPI, Basel, Switzerland. This article is an open access article distributed under the terms and conditions of the Creative Commons Attribution (CC BY) license (https:// creativecommons.org/licenses/by/ $4.0 /)$.

\begin{abstract}
FinTech has been in the focus of discussion for quite some time. However, the market share of FinTech companies is still relatively small compared to that of more traditional financial services. The purpose of this paper is to analyse the status quo, current developments, and challenges ahead for the Latvian FinTech sector. We combine three analyses: a political and legal, economic, social, and technological environment (PEST) analysis; a survey among FinTech companies; and an analysis of the size and financial performance of FinTech companies during the last 10 years. We find that the current status of regulation is one of the main obstacles to FinTech development, because it does not sufficiently consider FinTech-specific aspects. Problems in attracting a skilled workforce and an environment that is not very supportive of new developments in finance are further challenges and might explain at least part of the growth and financial performance difficulties. A revision, modernization, and harmonization of regulation is essential to create a level playing field for all market participants: FinTech companies, traditional financial service providers, and those originally traditional players that are integrating FinTech solutions in their business model. Further efforts are also required to foster Latvia's attractiveness for a skilled workforce. We hope that this study helps increase the visibility of Latvian FinTech and contributes to the development of the new Latvian FinTech strategy.
\end{abstract}

Keywords: FinTech; financial markets; PEST analysis; survey analysis

\section{Introduction}

FinTech has been in the focus of the discussion in the financial industry, in politics and regulation and in academic research for quite some time. However, even though FinTech has often been labelled a disruption to the financial industry (Gomber et al. 2018; Laidroo et al. 2021a), the market share of FinTech companies is still relatively small in most areas compared to more traditional financial services (IMF 2019). Definitions of FinTech cover both the application of new technologies to financial services and corresponding new business models, processes, and products. According to OECD (2018), "FinTech involves not only the application of new digital technologies to financial services but also the development of business models and products which rely on these technologies and more generally on digital platforms and processes". Similarly, the Financial Stability Financial Stability Board (2019) defines FinTech as "technology-enabled innovation in financial services that could result in new business models, applications, processes or products with an associated material effect on the provision of financial services".

For our study of FinTech companies in Latvia, we use the definition provided by the Bank of Latvia in line with the definitions by the OECD and the Financial Stability Board: a FinTech company is "a company which develops and uses new and innovative technologies in the area of financial services. This leads to the development of new financial products and services or a significant improvement of the existing ones" (Bank of Latvia 2020). This definition also reflects the EU Parliament's definition, according to which FinTech should 
be understood "as finance enabled by or provided via new technologies, covering the whole range of financial services, products and infrastructure" (The European Parliament 2017). FinTech companies in Latvia provide services that are complementary to traditional financial services, but also services that represent (potential) substitutes for services covered by traditional financial service providers. Therefore, the development of FinTech increases competition in markets for financial services. It is worth mentioning, though, that FinTech development is not limited to pure FinTech companies. Traditional financial service providers have also made increasing efforts to integrate FinTech solutions into their business models, which means that it is not fully possible to consider FinTech completely separately from more traditional financial service providers.

The success of FinTech development depends on, e.g., access to finance and human resources and the attitude of regulators, in particular with regard to openness to innovation and flexibility (Rupeika-Apoga and Thalassinos 2020). Additionally, the risks for potential and actual clients (Horn et al. 2020) and trust in financial services play important roles (Oehler and Wendt 2018). In Latvia, FinTech development meets well developed financial market infrastructure as well as a highly skilled workforce with relatively high entrepreneurial ability. Additionally, Latvia is internationally highly ranked in the context of the information and communications technology (ICT) development, showing strong positions in Internet subscriptions, electricity access, and supply quality, and the percentage of Internet users among the adult population (World Economic Forum 2019, 2020). Depending on their specific activities, FinTech companies are regulated and monitored by the Latvian Financial and Capital Market Commission (FCMC 2021a), the Consumer Protection Center (CRPC), or the State Revenue Service. FinTech-specific legislation is not existent in Latvia, though. Additionally, Latvia has a much more detailed and rigorous approach to customer due diligence than other countries (Saksonova and Koleda 2017), which affects FinTech companies as customers of Latvian banks, and in cases where FinTech companies want to obtain an FCMC license to provide their service.

Despite the publication of some market factsheets, e.g., by the commercial bank Swedbank (Swedbank 2020) and Fintech News Baltic blogs (FinTech Baltic 2020), a comprehensive understanding of the main drivers of the development of FinTech companies in Latvia has not yet been achieved. The purpose of this study is to add to this understanding, to shed light on the status quo, current developments, and challenges ahead for the Latvian FinTech sector, and to develop suggestions on how to foster FinTech development in Latvia.

To achieve the purpose of this study, we combine three analyses: first, we perform an analysis of the political and legal, economic, social, and technological environment (PEST analysis) that FinTech companies are facing in Latvia. Second, we analyse these companies' responses to a survey with particular emphasis on their own assessment of current and potential future developments. Third, we analyse the size and financial performance of FinTech companies in Latvia during the last 10 years.

Our contribution to the academic literature and the public and political debate is four-fold. First, with its focus on the environment Latvian FinTech companies are facing, their own assessment of various drivers and obstacles of FinTech development, and their actual size and financial performance, we substantially contribute to a comprehensive understanding of the complex topic of FinTech development in Latvia. Improving such an understanding will also help raise awareness for FinTech in Latvia.

Second, based on the results of our analyses, we discuss suggestions on how to support FinTech development in Latvia. These suggestions might be of particular interest for FinTech companies, for traditional financial service providers, and for policy makers and regulators.

Third, the current research assists in the development of the new Latvian FinTech strategy by providing findings based on the results of the FinTech Survey. This paper helps policymakers to understand the main obstacles and challenges in the development of the FinTech market. The new policy is expected to be finalised by 31 October 2021. 
Fourth, the findings of this study also provide implications beyond Latvia. Latvia is a small country with a small market, which might not necessarily appear of particular importance on a global scale or when it comes to international comparison in the context of FinTech. However, when it comes to FinTech, the small size of a country is not necessarily a disadvantage. As part of the Global Fintech Index City Rankings report 2020, Findexable (2019) ranks Latvia's immediate neighbours Lithuania and Estonia fourth and tenth, respectively, in its global FinTech country rankings. According to the Fintech News Network, Latvia, Zimbabwe, and Israel have witnessed the highest surge in FinTech interest worldwide in 2021 (FinTech Baltic 2021). Hence, our findings for Latvia can also be relevant to other small countries, such as Lithuania, Estonia, Malta, Belarus, Gibraltar, and others.

We find that the current status of regulation is one of the main obstacles to FinTech development. This is reflected in both the PEST analysis and the responses to the survey. The regulation currently does not sufficiently consider FinTech-specific aspects. A revision, modernization, and harmonization of regulation in particular across different categories of financial services, across different types of companies/institutions providing these services, irrespective of a higher or lower degree of involvement of new technologies, and internationally would truly provide a level playing field for all market participants: FinTech companies, traditional financial service providers, and those originally traditional players that are integrating FinTech solutions in their business model. Comprehensive regulation would also correspond to our finding that FinTech companies see themselves less in a disruptive role, but they emphasise partnership with traditional banks and that traditional financial service providers will integrate new technology. The size and financial performance of FinTech companies in Latvia during the last ten years indicates some difficulties when it comes to growth and when it comes to establishing and maintaining business models that are financially sustainable. Problems in attracting a skilled workforce and an environment that is not very supportive of new developments in finance are further challenges and might explain at least part of the growth and financial performance difficulties. Hence, further efforts are required to foster Latvia's attractiveness for a skilled workforce.

The structure of this paper is as follows. The next section, Section 2, focuses on the data and methodology. Section 3 uses a PEST analysis framework to investigate the environment that the Latvian FinTech companies are facing. Section 4 presents and discusses these companies' responses to a survey with particular emphasis on their own assessment of current and potential future developments. Subsequently, Section 5 provides an overview of the financial performance of a number of FinTech companies in Latvia during the last 10 years. Section 6 discusses the findings and concludes.

\section{Data and Methodology}

The PEST analysis uses desk research methodology, also including the analysis of corresponding regulation. To identify potential survey participants and to be able to analyse size and financial performance, we needed to identify FinTech companies that are registered in Latvia, because there is no official list of such companies. Neither the Latvian central bank, nor the FCMC, nor the Ministries of Finance and Economics provide a list of FinTech companies. The only available FinTech landscapes are provided by FinTech FinTech Baltic (2020) and Swedbank (2020). The Fintech Latvia Startup Map 2020 consists of 50 FinTech startups (FinTech Baltic 2020). According to the Latvian FinTech Report 2020 prepared by Swedbank in cooperation with Startin, however, the number of FinTech companies in 2019 was 75, and in 2020, it reached 91 (Swedbank 2020).

Difficulties in classifying FinTech companies relate to the emergence of new business models, which make it difficult to gather a comprehensive list. While we use the definition of FinTech provided by the Bank of Latvia, this definition also captures traditional financial service providers using new and innovative technologies. To help identify FinTech compa- 
nies, a company's business model and operations must reflect the definition and fall into at least one of the following seven areas:

- Analytics - data mining, data (business) analytics, big data analysis, machine learning, artificial intelligence used for automated advice, chatbots, customer relations management, and data handling.

- Banking infrastructure-user interface, processing enhancement, technology infrastructure, various trading platforms, and software companies with a focus on the financial sector.

- Deposit and Lending - crowd investing, crowdlending, invoice trading, and other lending forms such as payday loans.

- Distributed Ledger Technology-cryptocurrency and everything encompassing blockchain technology, even from companies that are payment or crowdfunding companies at the same time.

- Insurance-insurance-related products and services and InsurTech.

- Payments-mobile payments, online payments, money transfers, and anything related to payments.

- Investment management-online investment processes based on algorithms and models, robo-advisors, and social trading.

This classification is similar to the one used in the IFZ FinTech Study 2018 (Ankenbrand et al. 2019) and the FinTech Report Estonia 2019 (Tirmaste et al. 2019).

To find companies to be included in our analysis, we identified companies listed as FinTech companies in the Crunchbase, a platform for finding business information about private and public companies (Crunchbase 2020) and checked whether these companies fell under our definition. Then, we added FinTech companies found from other data sources: Key Capital for Latvia (Key Capital 2020), Alternative Financial Services Association of Latvia (The Alternative Financial Services Association of Latvia 2021), and Investment and Development Agency of Latvia (Investment and Development Agency of Latvia 2020). Additionally, the list of FinTech companies was cross-checked against the Register of Enterprises of the Republic of Latvia to ensure that only FinTech companies incorporated in Latvia are considered. This differs from the FinTech lists provided by FinTech Baltic and SwedBank, as they also include companies registered in other countries but operating in Latvia. In 2019, we identified 66 companies that meet our criteria. However, during the preparation of the paper, some companies were dissolved due to mergers or acquisitions, changed countries of registration, or were in the liquidation process. As a result, 56 companies were selected for inclusion in the dataset. As the definition of FinTech is controversial, and as the FinTech sector is rapidly evolving, we understand that our dataset can never be complete.

The survey questions were mainly based on the IFZ FinTech Study 2019 questionnaire (Ankenbrand et al. 2019) and the FinTech Report Estonia 2019 (Tirmaste et al. 2019) and were modified to assess the development of Latvian FinTech companies. The survey starts with general questions about the company, such as business model (B2B vs. B2C) and fields of activity, and questions on fields of activity, revenue model, and on some details of the operations. Then, the survey asks participants to rate a number of problem areas, such as competition, access to finance, and regulation, on how pressing they are on a scale from 1 (not pressing) to 10 (extremely pressing). ${ }^{1}$ The final section of the survey includes questions on the current and expected future relationship between FinTech and traditional banking and between FinTech and the Latvian state, on the main triggers of FinTech development and the role of regulation. Most of the questions in this section of the survey were open-ended questions; for a few questions, some predefined response items were included but were always accompanied by an open-ended response option. The results section will provide more details on the response items.

The survey was conducted as an online survey in the summer of 2019. Links to the online questionnaire (on Google docs) were sent via email to the 56 companies identified as FinTech companies. Corresponding email addresses were determined based on data 
presented in local business registries or companies' webpages or found through personal contacts. If possible, the email was targeted directly to the company's owners, board members, or executives (e.g., CEO, CFO). In the remaining cases, it was sent to the company's general email address. The first email was followed by two to three reminders. In some cases, follow-up phone calls and instant messaging through social media were also used to increase the response rate. Local institutions helped also by spreading the word about the survey, and news sites were used for the same purpose. We received a total of 21 responses, which corresponds to a response rate of 37.5 percent, but it also means that 62.5 percent did not respond. Even though the number of responses does not allow detailed statistical analysis, the response rate can be considered satisfactory for this type of survey (Hoque 2004; Olson and Slater 2002; Rikhardsson et al. 2020).

In addition, and to examine the latest trends in the development of FinTech companies in Latvia, we collected size and financial performance measures for the FinTech companies that responded to the survey from Bureau van Dijk's Orbis database (Bureau van Dijk 2021) for the period from 2010 to 2019. As size measures, we include the number of employees, turnover, and total assets; as financial performance measures, we include return on equity (RoE) and profit margin. Given the low number of companies, we abstain from detailed statistical analysis but provide corresponding descriptive statistics instead. Even though using data for these companies instead of all FinTech companies in Latvia might bias our results to some degree, using the smaller sample of companies that responded to the survey allows us to discuss the size and financial performance development and the responses to the survey jointly.

Another challenge is the increasing number of FinTech companies over time. This means that we do not have data for all companies across the entire period from 2010 to 2019. Additionally, in very few cases, data points are missing. This means that results from comparing between years need to be interpreted with caution, in particular because new market entries are typically smaller than already established companies.

\section{The Latvian FinTech Environment}

To provide a thorough overview of the Latvian FinTech environment, we analyse the political and legal, economic, social, and technological environment (PEST analysis) (Sammut-Bonnici and Galea 2015). This analysis of the environment FinTech companies are facing in Latvia is essential to be able to understand the status and development of FinTech in Latvia.

The analysis of the political and legal environment is of importance due to increased competition between cities and, in particular, countries to become FinTech centres or hubs. Taking into account the experience of other countries, regulation can be an effective tool in stimulating innovation and economic development. Differences in the legal environment can lead to regulatory arbitrage between different jurisdictions (Rupeika-Apoga and Thalassinos 2020). Combining this thought with differences in political support or goodwill can even lead to regulatory/politically induced arbitrage within the same jurisdiction between cities or regions with different political situations (Ito et al. 2020). Eventually, this can trigger a race to the bottom between jurisdictions in deregulating the legal environment and/or an escalation in political and potential financial support to attract or keep FinTech companies. This becomes even more interesting when considering that relatively similar business models might be categorized quite differently depending on whether corresponding products and services are offered by traditional financial intermediaries or by FinTech companies and even depending on different types of FinTech companies (Tirmaste et al. 2019).

The economic environment refers to external economic factors that affect the economy, e.g., purchasing habits of consumers / customers and businesses, and therefore affect aspects such as actual and potential market size and development, entrepreneurial activity, and performance of FinTech companies. Customer purchasing power, taxes, unemployment, and many other economic factors can promote or hinder the development of FinTech 
companies (Filimonova et al. 2020). The PEST analysis helps us assess how favourable the economic environment is in Latvia compared to neighbouring countries and Europe.

FinTech companies, as with any other company, operate in a society, while each society constructs its own social environment. The main factors affecting the social environment, and hence, FinTech companies also include, e.g., the educational system and literacy level, attitudes towards innovative products, lifestyle, occupational distribution and consumer preferences, labour force expectations, consumption habits, and social inequality (Kluza et al. 2021). FinTech companies must be aware of the social preferences of society in relation to its needs and desires, and they must adapt to the social environment in which they operate in order to be competitive.

The technological environment includes forces associated with scientific improvement and innovation that provide new ways of producing goods and services, as well as new methods and techniques for conducting business (Saksonova 2014). FinTech is inherently connected with technological development. In order to study the current situation and development of the Latvian FinTech sector, it is necessary to analyse aspects such as the pace of technological progress and institutional mechanisms for the development and application of new technologies, to name a few.

\subsection{Political and Legal Environment}

\subsubsection{EU Regulatory Framework}

As Latvia has been a member of the European Union (EU) since 2004, EU regulation provides the main regulatory framework. In 2018, the European Commission adopted the FinTech action plan for the development of a more competitive and innovative financial sector in Europe with the main purpose of increasing supervisory convergence toward technological innovation and to allow the EU financial sector to benefit from new technologies (The European Commission 2018). Not only is the purpose to build a capital markets union but also a digital single market for consumer financial services in order to allow innovative products and solutions to spread quickly across the EU. One of the purposes is to prevent regulatory arbitrage between the legal statuses, legislation, and supervision in the member states. EU regulation focuses on the application of the same rules to the same services and the same risks regardless of the type of legal entity concerned or its location in the Union, technology neutrality and a risk-based approach, taking into account the proportionality of legislative and supervisory actions to risks and materiality of risks (The European Parliament 2017).

Latvia has implemented European regulation on a number of aspects that also relate to FinTech. Implemented directives include the Payment Services Directive (PSD2) (The European Parliament and of the Council 2015), the Directive on the prevention of the use of the financial system for the purposes of a Money Laundering and Terrorist Financing (AMLD5) (The European Parliament and of the Council 2018), the Markets in Financial Instruments Directive (MiFID-2) (The European Parliament and of the Council 2014), NearField Communication (NFC) (European Union 2009), and the Investment Firms Directive ((EU) 2019/2034) (IFD)) and the Investment Firms Regulation ((EU) 2019/2033)) (IFR) (The European Parliament and of the Council 2019b); the new Prospectus Regulation (Commission Delegated Regulation (EU) 2019/980) regarding the format, content, scrutiny, and approval of prospectuses has been published in the Official Journal (The European Commission 2019). However, Latvia's more detailed and rigorous approach to customer due diligence than other countries and higher compliance cost create challenges for FinTech companies as customers of Latvian banks and when obtaining an FCMC license.

In addition, in November 2021, a new regulation on European providers of crowdfunding services for businesses will enter into force. This regulation is part of the Commission's FinTech action plan with the aim of introducing a unified system across all EU member states to facilitate the provision of cross-border co-financing services (The European Parliament and of the Council 2020). 


\subsubsection{Latvian Regulatory Framework}

As there is no specific legislative framework for FinTech companies in Latvia, they have to obtain licenses that match their business models if they require licensing, such as deposit-taking, investment management, capital raising, issue of financial instruments, provision of payment or electronic money services, insurance, or provision of consumer credit services. The FCMC or the CRPC regulate and supervise FinTech companies, depending on their financial services. The main supervisor is FCMC, while CRPC is responsible for, e.g., consumer protection, market surveillance, and the safety of products and services.

The main market participants are credit institutions, credit unions, investment management companies, investment brokerage firms, alternative investment fund managers, insurance companies, payment institutions, private pension funds ${ }^{2}$, and electronic money institutions. All institutions are subject to national laws and regulations, including the licensing process. There is a broad variety of rules and regulations, which means that financial institutions are regulated very differently depending on the segment of the financial sector they are active in. Hence, the following overview cannot provide a complete picture of corresponding regulations but is intended to provide a brief idea of the regulatory framework. ${ }^{3}$

Credit institutions and credit unions (financial cooperatives) need to submit to the FCMC (The Financial and Capital Market Commission 2002) the corresponding application and documents to receive an operating licence (permit). The minimum initial capital for a credit institution is five million euros, while for credit unions, the minimum initial capital is 2500 euros, and the decision to issue a licence is adopted by the European Central Bank based on a draft proposal by FCMC. Regulation that applies to credit institutions includes, e.g., the Deposit Guarantee Law (The Parliament of the Republic of Latvia 2015a) and the Law on the Recovery and Resolution of Credit Institutions and Investment Firms (The Parliament of the Republic of Latvia 2017). Credit Unions are regulated by the Credit Union Law (The Parliament of the Republic of Latvia 2001a) and the Regulations on the State Fee for the Issue of a Special Permit (Licence) for Individual Types of Entrepreneurial Activity (Cabinet of Ministers 2011). FinTech companies that are only interested in offering consumer lending services are regulated by the Consumer Protection Act (The Parliament of the Republic of Latvia 1999) and monitored by the CRPC. These companies do not need a licence as a credit institution but should obtain a license from the CRPC, and their initial capital must be at least EUR 425,000.

Investment-related services are provided by investment management companies, investment brokerage firms (investment firms), and by alternative investment fund managers. Corresponding regulation includes, for investment management companies, e.g., the Law on the Investment Management Companies (The Parliament of the Republic of Latvia 1997), the Commercial Law (The Parliament of the Republic of Latvia 2000), and the Investor Protection Law (The Parliament of the Republic of Latvia 2001b). For investment firms, which provide investment and ancillary (non-core) services, such as brokerage, investment advice, portfolio management, and custody services, regulation includes, e.g., the Law on the Financial Instruments Market (The Parliament of the Republic of Latvia 2003) and the regulatory enactments of the FCMC, and potentially, regulation by the Latvian Central Depository. For alternative investment fund managers, the Law on Alternative Investment Funds and their Managers (The Parliament of the Republic of Latvia 2013), the FCMC normative acts, EU Regulations, the Commercial Law, and other regulatory enactments apply. An alternative investment fund manager can commence its activities after its registration with the FCMC (registered manager) or after the receipt of the corresponding license (licensed manager). Additionally, investment management companies and investment firms must apply for a licence from the FCMC. The minimum initial capital shall be EUR 125,000 for investment management companies. On 26 June 2021, most investment firms became subject to a new prudential framework, composed of Regulation (EU) 2019/2033 (The European Parliament and of the Council 2019c) and Directive (EU) 2019/2034 (The European Parliament and of the Council 2019a). A permanent minimum capital require- 
ment set in the regulation is EUR 75,000, EUR 150,000, or EUR 750,000, depending on the activities of the investment firm.

Insurance companies are regulated under the Law on Insurance and Reinsurance (The Parliament of the Republic of Latvia 2015b), the Compulsory Civil Liability Insurance of Owners of Motor Vehicles Law (The Parliament of the Republic of Latvia 2004), the Insurance Contract Law (The Parliament of the Republic of Latvia 2018), the Insurance and Reinsurance Distribution Law (The Parliament of the Republic of Latvia 2019), and the Law on Insurance and Reinsurance. If they intend to offer particular insurance classes (motor vehicle third-party liability insurance, aircraft or ship ownership liability insurance, general liability insurance, credit insurance, suretyship insurance, or life assurance), a minimum initial capital of EUR 3.7 million applies, in other cases, a minimum initial capital of EUR 2.5 million applies.

Institutions that offer payment services as specified in Article 1 (1) of the Law on Payment Services and Electronic Money (The Parliament of the Republic of Latvia 2010) need a licence from the FCMC. If a natural or legal person wishes to offer payment services but is not required to obtain a licence as a payment institution, it needs to be registered at the FCMC. The initial capital of a licensed payment institution must be at least EUR 20,000 if it provides only money remittance services, EUR 50,000 if it provides only the payment initiation services, and EUR 125,000 if it provides any of the payment services referred to in the above-mentioned Article 1 (1), Subparagraphs a, b, c, d, or e. No initial capital is required if it only provides an account information service. However, a payment institution that provides an account information service and/or a payment initiation service needs to have its professional civil liability insurance. Additionally, financial allowances for persons intending to provide only an innovative payment service, which requires the authorisation of a payment institution or electronic money institution, are described in the Law on Payment Services and Electronic Money.

Institutions that wish to issue electronic money need a licence from FCMC or-if they do not need a licence-need to be registered at the FCMC. These institutions are entitled to provide payment services in accordance with the Law on Payment Services and Electronic Money. The initial capital of a licensed electronic money institution shall be at least EUR 350,000 , also in the case that it additionally offers payment services (The Parliament of the Republic of Latvia 2010).

Even though some other services provided by FinTech companies might currently not need a licence from FCMC or CRPC, the regulatory framework for such innovative activities is evolving. Investment platforms, for example, need to obtain a licence from FCMC during the transition period. The State Revenue Service monitors cryptocurrencyrelated activities. Similar to regulators in other countries, the FCMC has launched a regulatory innovative sandbox and hub $\mathrm{b}^{4}$ to allow testing of innovative financial services, such as a new or substantially improved electronic payment or electronic money services. The intention behind such a testing opportunity is to reveal whether or not the innovative financial service leads to one or more of the following improvements (FCMC 2021b):

- increased competition, i.e., is the innovative financial service more advantageous, less costly and easier to use than traditional services;

- potential response from traditional market participants, either by improving their service or by adopting the innovative business model;

- access for consumers and non-professional customers to market segments that have traditionally not been available to them.

\subsection{Economic Environment}

One of the preconditions for vibrant FinTech development is a well-developed economic environment. Since the general economic environment in a country, such as economic growth, economic policy, tax rates, ease of conducting business, and costs, affects FinTech businesses, FinTech companies - due to their high degree of international mobilityare typically located where the economic environment best meets their business needs. 
Low tax rates and local monetary policy (currency stability, interest rates) are typically considered as the most important factors.

According to a Global Financial Centres Index (GFCI) survey, the most important elements of a competitive environment for FinTech providers include the availability of skilled professionals and access to finance combined with big data analytics and cybersecurity as most important applications (Yeandle and Mainelli 2015). With regard to the level of development of the financial market infrastructure, there is a need for an efficient trading system and a variety of tradable financial instruments, such as stocks, bonds, and derivatives. Well-developed financial markets allow financing via traditional channels, such as stock exchanges or banks, or via alternative channels, such as crowdfunding, venture capital, or business angels. The efficiency of the payment system, its speed, and its security, also play important roles (Rupeika-Apoga and Nedovis 2016).

The World Bank World Bank Group's (2020) Doing Business Report ranks Latvia 19th among the 190 countries covered by the report (World Bank Group 2020). While that report draws a relatively positive picture for the overall business environment, the Global Financial Centres Index (GFCI) ranks the Latvian capital Riga in March 2020 only 70th out of 108 cities. While this rank is nearly the same as in 2016, when Riga ranked 71st, the city had climbed to rank 45 in the meantime and outperformed centres such as Stockholm (46th), Liechtenstein (48th), and Copenhagen (52nd) (Long Finance and Financial Centre Futures 2020; Solovjova et al. 2018). However, Riga could not maintain this position, mainly due to the major scandals related to the anti-money laundry (AML) processes, involving several Latvian banks.

On the Global Entrepreneurship Index, which measures the quality and dynamics of entrepreneurship ecosystems, Latvia ranked 45th out of 137 countries in 2019, which is lower than Latvia's neighbours Estonia (22nd) and Lithuania (37th). In the different subcategories, Latvia's rank ranged from 38th for entrepreneurial ability to 51st for entrepreneurial aspiration (Ács et al. 2019)

In the Findexable (2019) Global FinTech Index City Rankings 2020, Latvia ranks 49th out of 65 countries, with Riga ranking 34th among 50 leading European cities and 96th among 238 cities worldwide. Again, Latvia is outperformed by Lithuania (4th rank) and Estonia (10th rank) (Findexable 2019).

\subsection{Social Environment}

One of the main sources of FinTech competitiveness and development is a skilled and educated workforce (Rupeika-Apoga and Saksonova 2018). This relates to the local professional workforce, representing the majority of the workforce, and to a smaller number of international professionals, who follow and develop their business moving from country to country, as well as to the relationship between these two groups. FinTech development requires a highly skilled international workforce with deep and extensive knowledge and experience in financial and technology services. A large number of highly qualified potential local employees as result of, e.g., strong education policies combined with flexible labour legislation would allow companies to recruit and expand according to business needs. Attracting international professionals requires open and flexible immigration policies.

The IMD World Talent Ranking (Institute for Management Development 2019), which evaluates the extent to which economies develop, attract, and retain highly skilled professionals, ranks Latvia 12th in investment and development, 48th in appeal and 41st in readiness, resulting in an overall rank of 34 th out of 63 countries. Latvia ranks particularly well when it comes to female labour force (2nd), government expenditure on education per student (7th), and pupil-teacher ratio in secondary education (9th). However, brain drain (50th), remuneration in services professions (51st), and effective personal income tax rate (47th) represent main obstacles.

In 2019, the Global Competitiveness Report (World Economic Forum 2019) ranked Latvia 22nd regarding skills, but only 100th out of 141 countries regarding ease of finding a 
skilled workforce. Overall, Latvia ranks 28th regarding the labour market, with favourable conditions in wage flexibility (10th) and workers' rights (26th), but low scores in ease of hiring foreign labour (113th) and labour tax rate (114th). Further, the Europe 2020 Competitiveness Report (World Economic Forum 2020) ranks Latvia 5th in labour market and employment but only 22nd in education and training and 25th in social inclusion.

\subsection{Technological Environment}

The World Economic World Economic Forum (2019) ranks Latvia 15th out of 141 countries when it comes to information and communication technology (ICT) adoption, with a particularly strong position in mobile-broadband and fibre internet subscriptions (12th), even though Latvia only ranks 32nd regarding Internet users within the adult population. Moreover, electricity access is excellent (2nd), while electricity supply quality (34th) and digital skills among the active population (39th) still need improvement (World Economic Forum 2019).

However, out of 27 European countries, Latvia ranks only 20th in digital agenda and 24th in Innovative Europe index, significantly lagging behind its neighbours Estonia (5th in digital agenda and 12th in Innovative Europe), and Lithuania (11th in digital agenda and 21st in Innovative Europe) according to the Europe 2020 Competitiveness Report (World Economic Forum 2020).

\section{Survey Results}

This section presents the main findings of the survey. We start with a general portrait of the responding FinTech companies and then link the survey to the PEST factors (political and legal, economic, social and technological environment).

\subsection{General Portrait of the Responding FinTech Companies}

In total, 21 out of 56 FinTech companies responded to the survey. The distribution of the companies by their activity type is presented in Figure 1.

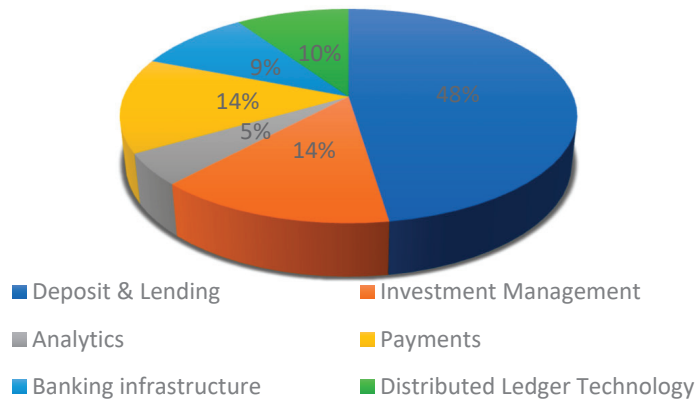

Figure 1. Breakdown of the responding FinTech companies by their field of activity.

Ten of the respondents stated their core field of activity as deposit and lending, three stated payments, and three stated investment management or investment brokerage. Two stated distributed ledger technology, one analytics, payments, transaction processing, and public finance management, and two stated analytics and banking infrastructure. This means that, even though deposit and lending represents the largest group, the group of respondents is quite diverse and includes representatives of most of the essential areas of FinTech activity. The attractiveness of deposits and lending as a FinTech business model can be explained by the fact that Latvians typically borrow during periods when there is an unforeseen need for additional financial resources, and most of these borrowers are young people (Rupeika-Apoga and Saksonova 2018). This group of customers might not 
be particularly appealing for traditional banks, which largely leave this part of the market to FinTech companies.

Most of the respondents follow the B2C business model providing their services to individual clients $(81 \%)$, focusing on both the Latvian market and international clients. About one-fourth of the FinTech companies work with both individual clients and other businesses. Even though the FinTech companies see the greatest business potential in the Baltic and Scandinavian markets, the geographical distribution of their activities includes the EU countries, the Americas, as well as the countries of the Commonwealth of Independent States, Australia and New Zealand. So far, only a few companies are active in Asia.

The connection between FinTech companies' main activity and their revenue sources (Laidroo et al. 2021a) is also obvious in our sample (see Figure 2). Since the main activity of the surveyed companies is deposits and lending, their main income comes from commission payments and interest income. Other revenue sources, such as license fees, centralized hosting of business applications, trading income, data, advertising income, or other play a minor role or no role at all.

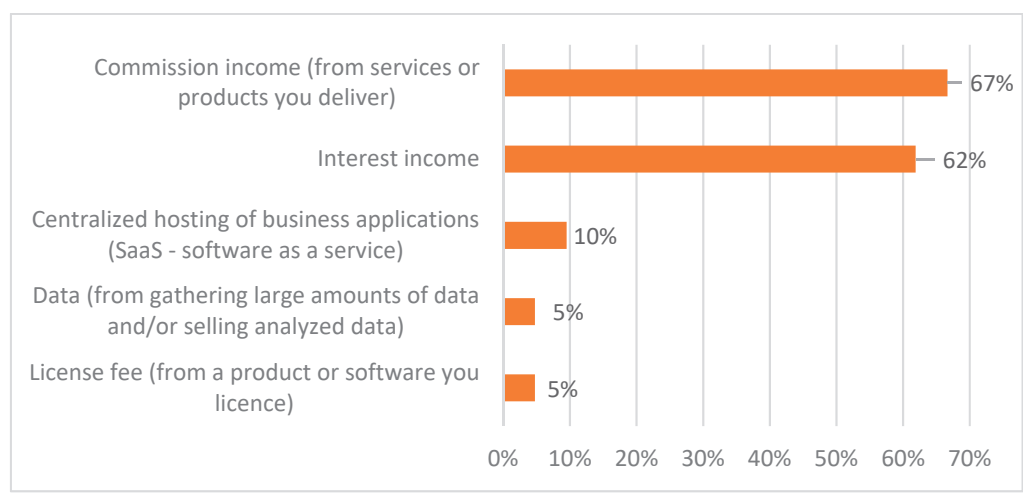

Figure 2. Revenue model (multiple responses allowed).

To finance their activities, FinTech companies primarily depend on their founders (16 out of the 21 respondents), followed by crowdfunding (six), venture capital (five), issuing securities (four), and business angels (three). Only two respondents indicate funding via retained earnings, and two indicate banks as source of funding (see Figure 3).

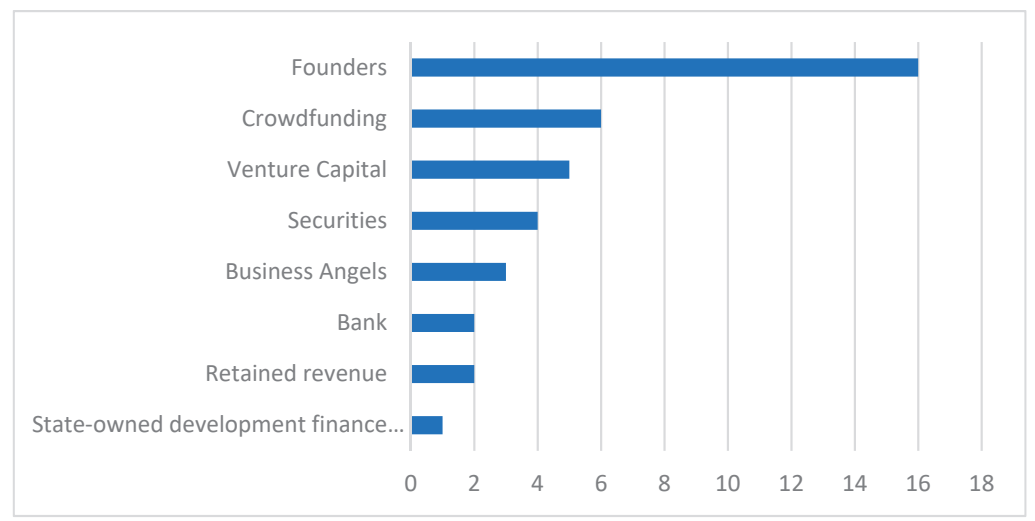

Figure 3. Sources of funding, number of FinTech (multiple responses allowed). 


\subsection{Assessment of Development Prospects for FinTech Companies}

In this section, we investigate the FinTech companies' responses with regard to the impact of the political and legal, economic, social, and technological environment on their competitiveness and potential future development. This means that the results in this section complement the PEST analysis presented in Section 3.

With regard to the economic environment, in particular the competitive environment, FinTech companies were asked to name their main competitors. Mostly, they mentioned other FinTech companies providing services in the same field, as well as traditional service providers such as banks and non-financial sector companies such as IT companies.

They were also asked to evaluate their situation relative to their competitors based on profit margin, fixed costs to assets, ability to scale, innovativeness, ease of compliance, and customer costs on a Likert scale from 1 to 7 ; the anchors of the seven-point scale differ between the items and are further explained below. The responses with regard to ease of compliance provide indication of their assessment of the legal and regulatory framework, profit margin, fixed costs to assets, and customer costs, representing economic factors. Ability to scale describes the ability to respond to an increasing or expanding workload or volume, reflecting the social and economic factors. The question how innovative the respondents are reflects social and technical factors. Figure 4 presents the corresponding findings.

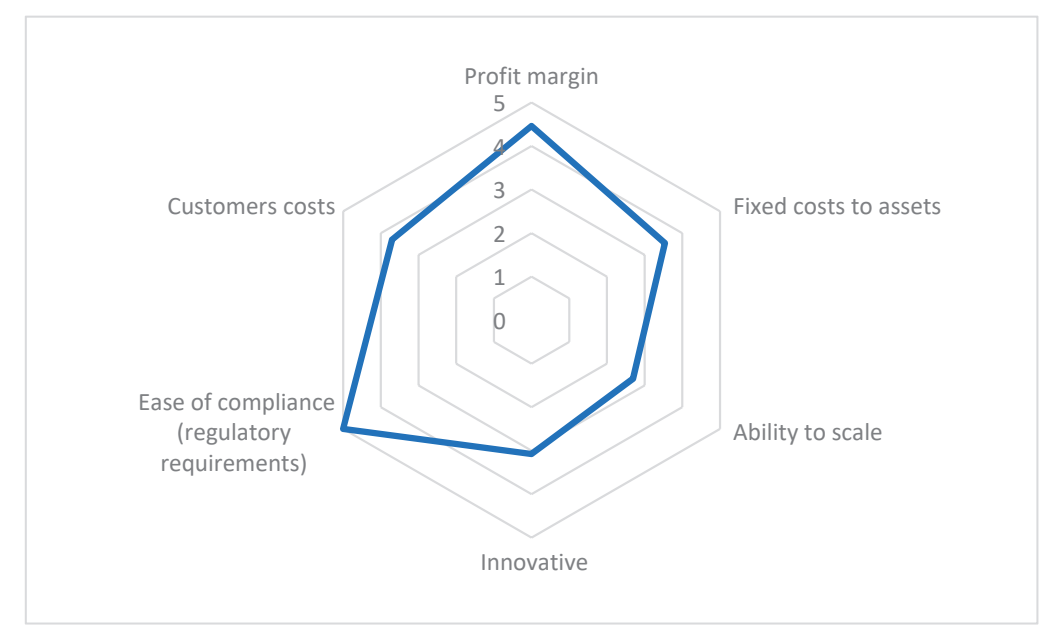

Figure 4. Responses to the request to evaluate the FinTech company against competitors; 1 = low, 7 = high (means).

Ease of compliance with regulatory requirements is assessed on the scale from " 1 , not subject to high compliance regimes" to "7, subject to very high compliance regimes". The responses have an average value of 5 . Even though we did not specifically label the middle of the scale, this means the value of 4 represents being in a similar situation as the competitors; we interpret these responses as indication that the FinTech companies feel themselves as being under a stricter compliance regime than the competitors. Profit margin (on a scale from " 1 , very low" to "7, very high") has an average response of 4.5 , which is slightly above the middle of the scale. The companies might therefore see their business as slightly more profitable than their competitors. Fixed costs to assets and Customer costs, each on a scale from " 1 , very low costs" to "7, very high costs", receive average responses of 3.5 and 3.7, respectively. This means that they assess their costs as similar or slightly below their competitors' costs. Ability to scale (on a scale from "1, very scalable" to " 7 , not scalable") has an average response value of 2.7, which indicates that the respondents consider their activities as being more scalable than the activities of their competitors. 
On a scale from " 1 , very innovative" to "7, not innovative", the respondents assess their innovativeness with an average value of 3.1, which would reflect higher innovativeness than the competitors.

Even though FinTech is often considered disruptive of traditional financial services (Gomber et al. 2018), the survey responses to the questions of how FinTech companies will change traditional banks, as presented in Table 1, leave a different impression. Nineteen of the 21 respondents expect that FinTech companies will be partners of traditional banks, and sixteen respondents expect that traditional banks will adopt new technologies, modernize, and digitalize. Still, nine respondents also expect that customer ownership will be with FinTech companies, while traditional banks will become commoditized service providers. Only three respondents assume that traditional banks will not survive, and one respondent expects that traditional banks will become irrelevant.

Table 1. Responses to the question how the FinTech companies will change traditional banks (multiple responses allowed).

\begin{tabular}{ll}
\hline \multicolumn{1}{c}{ Response Items } & Number of Responses \\
\hline Pre-defined items & 16 \\
\hline $\begin{array}{l}\text { Traditional banks will adopt new technologies, modernize } \\
\text { and digitalize. }\end{array}$ & 3 \\
\hline $\begin{array}{l}\text { Traditional banks will not survive and will be replaced by } \\
\text { new technology-driven banks. }\end{array}$ & 19 \\
\hline FinTech companies will be partners of traditional banks. & 9 \\
\hline $\begin{array}{l}\text { Traditional banks will become commoditized service } \\
\text { providers, leaving customer ownership to FinTech } \\
\text { companies. }\end{array}$ & 1 \\
\hline $\begin{array}{l}\text { Traditional banks will become irrelevant as customers } \\
\text { interact directly with individual financial services providers } \\
\text { (FinTech). }\end{array}$ & 1 \\
\hline Other responses & 1 \\
\hline Traditional banks will not save retail and SME business. & \\
\hline $\begin{array}{l}\text { Situation will vary from market to market, thus so many } \\
\text { scenarios are selected. }\end{array}$
\end{tabular}

Exploring further the potential cooperation between FinTech companies and traditional banks, we specifically asked the open-ended question of how the respondent's FinTech company has cooperated with traditional banks. The answers reflect the variety of FinTech business models among our respondents. The cooperation ranges from the use of banking services, such as bank account services, daily payments or transfers, and funding opportunities, to client/customer identification and exchange, providing analytics and other services to banks, $\mathrm{API}^{5}$ access to banking infrastructure, credit card acquisition and payment innovations, and promotion of the financial industries.

We also asked in an open-ended question what the main triggers behind FinTech development are. Six respondents mentioned IT/technology development/digitalisation, changes in technological opportunities or innovation as main triggers. This underlines the importance of the technology factor, as explained in the PEST analysis. Additionally, strong customer focus is reflected in several responses that see customer mind-set and expectations, customer needs, and customer centric products as main triggers, reflecting the impact of social factors on the development of the FinTech industry. However, six respondents also see the regulatory framework as the main trigger.

One respondent elaborates:

Fintech embraces inclusiveness of financial services within different areas and allows to create targeted solutions for customers to try out without changing their bank. Incum- 
bents have failed in both innovation and communication, thus creating space for new players. As well-payment services directives are a significant trigger for increase of competition.

Further, respondents mentioned the economic and business environment, bank charges and outdated banks, qualified human resources and talents, access to capital, and start-up incubators as main triggers for FinTech development.

When asked about how pressing specific predefined problems are on a scale from 1 (not pressing) to 10 (extremely pressing), the respondents answered as shown in Table 2 and Figure 5. When considering the median values, regulation is the most pressing problem (median: 8), followed by availability of skilled staff or experienced managers (median: 7). Competition, finding customers, and access to finance rank third, with a median of 6 for each of these three categories. Cost of production or labour and expansion to international markets are relatively speaking less pressing (median: 5 ). When considering the distribution of the responses, however, it also becomes obvious that agreement among respondents about how pressing the given problems are is low, in particular with regard to access to finance and competition. A relatively low level of variation is apparent for, e.g., cost of production or labour.

Table 2. Responses to the question how pressing specific problems are; $1=$ not pressing, $10=$ extremely pressing.

\begin{tabular}{|c|c|c|c|c|c|c|c|c|c|c|c|c|}
\hline Level of How Pressing & 1 & 2 & 3 & 4 & 5 & 6 & 7 & 8 & 9 & 10 & $\mathbf{N}$ & Median \\
\hline \multicolumn{13}{|l|}{ Number of responses to predefined items } \\
\hline Competition & 2 & 0 & 1 & 2 & 2 & 6 & 5 & 1 & 1 & 1 & 21 & 6 \\
\hline Finding customers & 0 & 1 & 3 & 1 & 2 & 4 & 5 & 3 & 2 & 0 & 21 & 6 \\
\hline Access to finance & 2 & 2 & 3 & 1 & 1 & 2 & 5 & 2 & 1 & 2 & 21 & 6 \\
\hline Cost of production or labour & 0 & 0 & 6 & 2 & 4 & 4 & 2 & 2 & 1 & 0 & 21 & 5 \\
\hline $\begin{array}{c}\text { Availability of skilled staff or experienced } \\
\text { managers }\end{array}$ & 0 & 0 & 5 & 1 & 2 & 2 & 4 & 6 & 1 & 0 & 21 & 7 \\
\hline Regulation & 0 & 1 & 3 & 0 & 2 & 1 & 0 & 6 & 5 & 3 & 21 & 8 \\
\hline Expansion to international markets & 0 & 1 & 3 & 4 & 3 & 2 & 3 & 3 & 0 & 1 & 20 & 5 \\
\hline Other & 1 & 0 & 0 & 0 & 0 & 0 & 0 & 0 & 0 & 0 & 1 & 1 \\
\hline
\end{tabular}

The responses to the question how the Latvian state could contribute to the FinTech sector development as presented in Table 3 confirm the request for special regulation for FinTech companies (sixteen responses). Additionally, eleven respondents saw regulatory sandboxes as meaningful contributions, and seven respondents considered tax relief important. Although the predefined response items only focus on a limited range of potential government support, none of the respondents suggested further government support options.

Table 3. Responses to the question how the Latvian state could contribute to the FinTech sector development (multiple responses allowed).

\begin{tabular}{cc}
\hline Response Items & Number of Responses \\
\hline Predefined items & 16 \\
\hline Special regulations. & 11 \\
\hline Regulatory sandboxes. & 7 \\
\hline Tax relief. & 1 \\
\hline Other responses & \\
\hline Mostly none. &
\end{tabular}




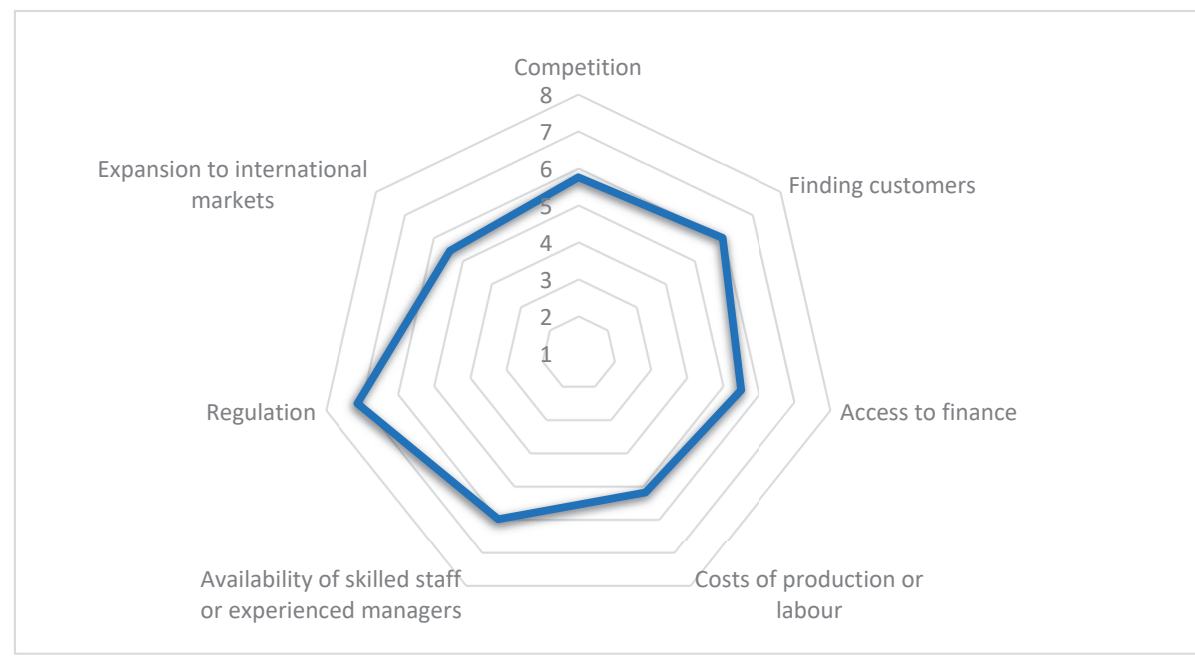

Figure 5. Responses to the question how pressing specific problems are; $1=$ not pressing, $10=$ extremely pressing (means).

The request for special regulation for FinTech companies is also reflected in the responses to the open-ended question if participants feel that existing financial service regulations are restricting their activities and-if yes-in what way. Only three of the sixteen responses indicate that financial service regulations are not restricting their activities. Twelve respondents answer that financial service regulations are restricting their activities. They elaborate on this by mentioning, e.g.,

There is no $100 \%$ relevant regulation for our specific business.

or

They try to box all new innovations in existing framework which mostly does not work.

Several respondents also mention the loan price limit from 1 July 2019 on, which is, in their opinion, not in alignment with the cost of capital of non-bank lenders.

However, FinTech companies who responded to our survey are in regular communication with state organizations (see Table 4). Communication with the State Revenue Service and the FCMC are mentioned most frequently, with twelve and eleven responses, respectively. Even though not included in the predefined response items, nine respondents mention, in the open-ended part of the question, the Consumer Rights Protection Center as an organization with which they regularly communicate. Only single respondents mention other organizations, such as the Bank of Latvia or the Ministry of Economics.

Overall, regulation and availability of skilled staff and experienced managers are the most pressing issues for Latvian FinTechs companies. Due to the supervisory status granted by the Committee of Experts on the Evaluation of Anti-Money Laundering Measures and the Financing of Terrorism (MONEYVAL) in 2018, supervision of the financial sector has become much more detailed and rigorous compared to other EU countries. To provide services, the FinTech company needs to have an account with a commercial bank. However, FinTech companies as risky start-ups with low turnover but with the potential to become future competitors do not represent an attractive group of clients for commercial banks. Moreover, there appear to be problems of communication between FinTech companies and the regulator. The expectations of the regulator need clarification, as there are currently many uncertainties that lead to additional legal costs and extended product development cycle. This conclusion is in line with our assessment of the legal environment in Section 3.1. FinTech companies must obtain licenses from various regulatory bodies, and the rules are not always sufficiently clear, in particular for innovative products and services. Even 
though regulators offer some support and advice, FinTech companies see the current regulatory structure as a substantial obstacle.

Table 4. Responses to the question of which state organizations they communicate with on a regular basis.

\begin{tabular}{cc}
\hline Response Items & Number of Responses \\
\hline Predefined items & 12 \\
\hline State Revenue Service & 11 \\
\hline Financial and Capital Market Commission & 1 \\
\hline Bank of Latvia & 9 \\
\hline Other responses & 1 \\
\hline PTAC/Consumer Rights Protection Center & 1 \\
\hline Ministry of Economics & 1 \\
\hline Development) & 1 \\
\hline LIAA (Investment and Development Agency) & 1 \\
\hline Municipalities & 1 \\
\hline $\begin{array}{c}\text { None } \\
\text { conservative and they are not ready to help young } \\
\text { entrepreneurs" }\end{array}$ & \\
\hline
\end{tabular}

Companies also find that there is a shortage of local, highly skilled employees, which can be alleviated by reorienting training towards an IT specialty. Such effort, however, will take time. Another solution would be to hire foreign specialists. Given the relatively low salary level in Latvia compared to the EU, potential specialists would need to come from outside the EU. However, due to the rather strict immigration policy, it will be difficult to attract specialists from outside the EU. The FinTech companies' situation regarding attractiveness for skilled personnel is also reflected in our conclusions on the social environment as part of the PEST analysis. Latvia suffers from high brain drain, low wages in the service sector, and high effective personal income tax rate.

\section{Size and Financial Performance of FinTech Companies}

In this section, we analyse the 21 FinTech companies that responded to the survey to determine the latest trends in financial performance and size. Table 5 displays statistics for three size measures: number of employees (Panel A), turnover (Panel B), and total assets (Panel C). On average, the number of employees increases continuously between 2010 and 2017 and remains stable afterwards. Even though the average might be influenced by one relatively large company as reflected by the maximum number of employees in the sample, the median number of employees largely confirms the steady increase until 2017 and stable figures in 2018 and 2019. Moreover, from 2017 on, the number of companies in the sample is quite stable. 
Table 5. Size of FinTech companies.

\begin{tabular}{|c|c|c|c|c|c|c|c|c|c|c|}
\hline & 2010 & 2011 & 2012 & 2013 & 2014 & 2015 & 2016 & 2017 & 2018 & 2019 \\
\hline \multicolumn{11}{|c|}{ Panel A: Number of employees } \\
\hline Mean & 6 & 14 & 18 & 32 & 33 & 39 & 43 & 46 & 47 & 46 \\
\hline St. Dev. & 6 & 17 & 25 & 57 & 67 & 70 & 80 & 74 & 70 & 64 \\
\hline Median & 5 & 8 & 9 & 14 & 11 & 14 & 20 & 24 & 24 & 26 \\
\hline Min & 1 & 0 & 1 & 1 & 1 & 3 & 3 & 1 & 3 & 2 \\
\hline Max & 18 & 56 & 86 & 200 & 243 & 260 & 322 & 311 & 295 & 266 \\
\hline $\mathrm{N}$ & 6 & 8 & 9 & 10 & 11 & 12 & 14 & 15 & 15 & 16 \\
\hline \multicolumn{11}{|c|}{ Panel B: Turnover in thousand USD } \\
\hline Mean & 528 & 3953 & 7710 & 12,571 & 9773 & 9623 & 8306 & 8852 & 10,589 & 9213 \\
\hline St. Dev. & 266 & 6978 & 15,712 & 28,498 & 22,360 & 22,037 & 11,798 & 11,417 & 13,233 & 10,733 \\
\hline Median & 703 & 787 & 926 & 2698 & 1822 & 3078 & 1910 & 2586 & 5121 & 4069 \\
\hline Min & 105 & 103 & 82 & 89 & 247 & 3 & 1 & 8 & 32 & 101 \\
\hline Max & 761 & 20,920 & 48,959 & 92,909 & 76,504 & 85,168 & 39,230 & 36,770 & 42,509 & 30,354 \\
\hline $\mathrm{N}$ & 5 & 7 & 8 & 9 & 10 & 13 & 16 & 17 & 17 & 18 \\
\hline \multicolumn{11}{|c|}{ Panel C: Total assets in thousand USD } \\
\hline Mean & 776 & 4622 & 16,548 & 30,970 & 27,527 & 21,734 & 21,029 & 24,150 & 21,153 & 19,252 \\
\hline St. Dev. & 605 & 8122 & 40,316 & 76,071 & 78,379 & 51,725 & 42,655 & 46,834 & 36,511 & 30,893 \\
\hline Median & 585 & 1736 & 2141 & 2980 & 1675 & 3201 & 3450 & 4093 & 2549 & 3677 \\
\hline Min & 181 & 270 & 374 & 861 & 55 & 162 & 43 & 141 & 368 & 595 \\
\hline Max & 2050 & 25,912 & 130,451 & 245,895 & 297,402 & 204,791 & 176,417 & 195,143 & 149,172 & 124,631 \\
\hline $\mathrm{N}$ & 6 & 8 & 9 & 9 & 13 & 14 & 16 & 17 & 18 & 19 \\
\hline
\end{tabular}

Interestingly, however, the development of turnover and total assets is not completely in line with the increase in the number of employees. Turnover and total assets increase quite strongly between 2010 and 2013. Subsequently, turnover fluctuates around the 2013 level both in terms of mean and median values and only increases substantially again in 2018. Total assets fluctuate around the 2013 level until the end of the observation period in terms of median values, whereas mean values drop quite significantly between 2013 and 2015 and largely remain at the 2015 level until 2019. The latter effect seems to be driven by the largest company in the dataset as indicated by the development of the maximum value. The decline in turnover and total asset value can be attributed to several reasons. First, due to increased competition, borrowing interest rates have dropped significantly. While in 2010, the rates of some lending companies reached $400 \%$ per annum, maximum rates were about $50 \%$ per annum in 2014. Second, due to changes in the legislation to protect clients, several restrictions are imposed on lending companies, including the maximum interest rate, the penalty rate, and the maximum repayment amount. Third, in 2015 and 2016, two large new players in crowdfunding joined the market, hence increasing competition for lending companies. Fourth, the Latvian market is small; therefore, several large players significantly influence the overall statistics of the development of the FinTech industry.

Table 6 presents financial performance figures in terms of return on equity (RoE, Panel A) and profit margin (Panel B). Most striking is the huge variation in financial performance over time, as indicated by the development of mean and median values, and between companies, as indicated by standard deviation and minimum and maximum values. The relatively few FinTech companies that are included at the beginning of the observation period show quite high financial performance in 2010 and 2011. Financial performance drops, though, in 2012 and fluctuates around this level with quite substantial 
swings in until 2016 or 2017, depending on the measure. Only towards the end of the observation period, financial performance seems to improve, at least for some of the measures.

Table 6. Financial performance of FinTech companies.

\begin{tabular}{ccccccccccc}
\hline & $\mathbf{2 0 1 0}$ & $\mathbf{2 0 1 1}$ & $\mathbf{2 0 1 2}$ & $\mathbf{2 0 1 3}$ & $\mathbf{2 0 1 4}$ & $\mathbf{2 0 1 5}$ & $\mathbf{2 0 1 6}$ & $\mathbf{2 0 1 7}$ & $\mathbf{2 0 1 8}$ & $\mathbf{2 0 1 9}$ \\
\hline \multicolumn{7}{c}{ Panel A: Return on Equity in percent } \\
\hline Mean & 77.8 & 51.9 & 2.1 & 20.0 & 2.8 & -11.2 & 20.2 & 2.2 & 9.9 & 26.6 \\
\hline St. Dev. & 65.6 & 24.6 & 83.7 & 38.5 & 36.7 & 64.4 & 77.5 & 107.5 & 180.8 & 38.3 \\
\hline Median & 77.8 & 58.7 & 15.6 & 14.3 & 13.5 & -4.9 & 3.7 & 38.7 & 26.6 & 25.5 \\
\hline Min & 12.2 & 12.6 & -177.7 & -36.6 & -60.3 & -128.7 & -123.4 & -330.7 & -555.1 & -72.4 \\
\hline Max & 143.4 & 81.7 & 107.8 & 74.8 & 48.6 & 100.0 & 199.0 & 93.8 & 410.5 & 99.4 \\
\hline N & 2 & 5 & 8 & 8 & 11 & 11 & 11 & 12 & 15 & 14 \\
\hline & & & & Panel B: Profit margin in percent & & & \\
\hline Mean & 2.7 & 36.1 & 15.4 & 2.1 & 3.8 & 11.3 & 9.4 & 4.4 & 19.9 & 8.5 \\
\hline St. Dev. & 43.9 & 16.4 & 22.7 & 27.9 & 29.0 & 20.8 & 42.3 & 25.3 & 25.6 & 40.9 \\
\hline Median & 22.6 & 42.0 & 12.4 & 2.1 & 9.3 & 5.5 & 2.1 & 0.8 & 15.2 & 13.2 \\
\hline Min & -71.7 & 3.3 & -28.4 & -41.6 & -59.5 & -15.3 & -79.4 & -40.6 & -25.4 & -71.4 \\
\hline Max & 37.2 & 56.2 & 53.1 & 45.9 & 38.5 & 44.4 & 93.1 & 50.2 & 91.5 & 95.4 \\
\hline N & 4 & 7 & 7 & 9 & 8 & 10 & 12 & 13 & 14 & 16 \\
\hline
\end{tabular}

As indicated above, we need to interpret these results with caution. However, the huge variation over time and across companies indicates that, overall, the FinTech sector does not appear to have found a basis for stable business development and financial performance. Furthermore, the huge negative financial performance by some of the companies, as partially reflected by the minimum values, might indicate that some of the business models might not (yet) be financially sustainable. Reasons for this situation could be the strong dominance and competition between deposits and lending companies. The development of other activities, such as payment services, investment management, and insurance, has, though, the potential to open up new business opportunities.

\section{Discussion and Conclusions}

The purpose of this paper was to analyse the status quo, current developments, and challenges ahead for the Latvian FinTech sector. Our analysis has been divided into three parts: a PEST analysis to investigate the environment that Latvian FinTech companies are facing, an analysis of survey responses with particular emphasis on FinTech companies' own assessment of current and potential future developments, and an analysis of the financial performance of FinTech companies in Latvia during the last 10 years.

The results of the analysis of the political and legal, economic, social, and technological environment (PEST analysis) draws a mixed picture. The legal environment is largely predetermined by EU regulation, which also means that it is scattered across different types of financial services. Depending on the provided financial services, FinTech companies are regulated and monitored by the FCMC, the CRPC, or the State Revenue Service, since there is no legislation that comprehensively focuses on FinTech in Latvia. Instead, regulation that was established with focus on what nowadays are considered traditional financial services also applies to FinTech companies or no regulation exists yet for some of the new services. The overall economic environment can be considered positive, but Latvia still falls behind, e.g., its neighbours Estonia and Lithuania in quality and dynamics of the entrepreneurship ecosystems. Additionally, in the specific finance-related economic environment, Latvia should improve its situation. The social environment is favourable in particular with 
regard to level of skills and educational aspects as well as, e.g., labour market and female labour force. However, brain drain, remuneration in service professions, the labour tax rate, difficulties in hiring foreign labour, and, in general, difficulties in finding a skilled workforce raise substantial concerns. Even though Latvia does not reach top ranks when it comes to digital agenda and digital skills, its technological environment regarding, e.g., ICT adoption and electricity access is well developed.

The survey responses support the conclusions from the PEST analysis. For Latvian FinTech companies, regulation is the most pressing problem. This, however, is not a purely Latvian issue. Studies in neighbouring countries confirm that regulation represents a serious obstacle for FinTech development. In Poland, FinTech companies consider regulation ambiguous, imprecise, and requiring too much bureaucracy. They "[claim] that the rules are backward, neither follow the rapidly changing reality nor take the existence of the FinTechs into account" (Kliber et al. 2021). The same applies to Estonia, where the most critical problems are related to finding customers and to regulation (Laidroo et al. 2021b). Another result of the survey analysis is that the availability of a skilled staff or experienced managers is perceived as quite a pressing problem, which is, again, in line with the PEST analysis results. Further aspects, such as competition, finding customers, and access to finance, are perceived as pressing but to a lower degree than regulation and availability of skilled staff.

A result that is quite interesting in the context of the general idea of FinTech as disruption to the (traditional) finance industry, which is typically purported in the literature and in the public debate, is the survey respondents' view of integration of and collaboration between traditional banks and FinTech companies. FinTech is less perceived as disruptive but more as a driving force for innovation and modernization in the entire finance sector.

The size and financial performance of FinTech companies in Latvia during the last ten years indicates some difficulties when it comes to growth, and when it comes to establishing and maintaining business models that are financially sustainable. This is, of course, in line with the general situation in areas with high levels and speed of innovation. Not all business ideas become successful; some business will disappear, while new business models take over. However, when jointly looking at the results of the PEST analysis and the size and financial performance, the weaknesses that some of the aspects of the environment reveal seem to be significant obstacles for FinTech development.

In the context of our findings regarding regulation, it is no surprise that FinTech companies request specific FinTech regulation. The response to this request, however, requires some further considerations. On one hand, the absence of a legal framework that specifically focuses on FinTech might provide some additional comparative advantages to the FinTech market players compared to traditional financial service providers, at least in initial stages of development. On the other hand, and, in particular, in subsequent stages, this absence slows down the development of the market and the creation of a level playing field, both nationally and in the context of positioning Latvia as a FinTech hub internationally. More meaningful, however, both in the context of avoiding regulatory arbitrage of single market considerations and of increasing integration of FinTech solutions in more traditional financial service providers, is a revision, modernization, and harmonization of regulation, in particular across different categories of financial services, across different types of companies/institutions providing these services, irrespective of a higher or lower degree of involvement of new technologies, and internationally. Such a regulation would truly provide a level playing field and would foster competition.

In 2018, the Committee of Experts on the Evaluation of Anti-Money Laundering Measures and the Financing of Terrorism (MONEYVAL) granted Latvia supervisory status (Council of Europe 2019). As a result, supervision of the financial sector has been significantly strengthened, and Latvia has a much more detailed and rigorous approach to due diligence of clients than other countries, which creates a competitive disadvantage. Similarly, regulatory uncertainty is causing problems to FinTech companies looking to obtain an FCMC license to provide their service. Particular uncertainty exists regarding 
activities related to cryptocurrencies and other crypto assets. Additional regulation is often seen as an obstacle to the development of the sector. However, the thoughts on regulation presented above would not necessarily result in more regulation. Instead, a revision, modernization and harmonization might lead to less, or at least less complex, regulation. It requires though that the regulation needs to cover all financial services and should not leave blank spots for some of them. Currently, the FinTech industry needs to rely on the traditional banking industry, as, for example, all FinTech companies require a traditional bank account, as a result, making them dependent on banking policy.

It is worth mentioning, though, that Latvia's rigorous approach to strengthen its AML/CFT framework has proven fruitful and, according to the Financial Action Task Force Status (FATF), Latvia is not on the FATF List of Countries that have been identified as having strategic AML deficiencies (Financial Action Task Force 2021). This allows Latvia to think ahead and develop FinTech strategy, with an aim to identify and reduce any barriers to the growth of FinTech start-up companies. As the Latvian FinTech strategy is under development by a workgroup made up of the Ministry of Finance, the Financial and Capital Market Commission of Latvia, Fintech industry representatives, banks, the Investment and Development Agency of Latvia (LIAA), and various professional industry associations, our study provides contributions to the discussion and strategy development. Beyond regulation, the strategy development should particularly focus on further increasing the skill base and improving access to skilled employees, both nationally and internationally.

Our study is not without limitations. First, even though the response rate to our survey can be considered satisfactory, the survey respondents still only cover part of FinTech in Latvia. For future research and for the debate in the context of Latvian FinTech strategy development, it would be beneficial to include more FinTech companies. Second, we primarily focus on supply-side related drivers of FinTech development. To achieve a comprehensive understanding of drivers of FinTech development, the demand side also needs to be considered, regarding, e.g., consumers' and other customers' demand for FinTech solutions, their technology acceptance, financial and IT literacy, and individual characteristics of (potential and actual) users of FinTech services (Oehler et al. 2021).

Author Contributions: Conceptualization, R.R.-A. and S.W.; methodology, R.R.-A. and S.W.; formal analysis, R.R.-A. and S.W.; investigation, R.R.-A. and S.W.; data curation, R.R.-A.; writing-original draft preparation, R.R.-A. and S.W.; writing-review and editing, R.R.-A. and S.W.; visualization, R.R.-A. and S.W. All authors have read and agreed to the published version of the manuscript.

Funding: This research was funded by LATVIAN COUNCIL OF SCIENCE, grant number LZP2020/2-0061, project DigiSMEs.

Institutional Review Board Statement: Not applicable.

Informed Consent Statement: Not applicable.

Data Availability Statement: Data are available from authors upon reasonable request.

Acknowledgments: The survey used in this study is part of a larger European study of FinTech in Eastern Europe and we especially want to thank Laivi Laidroo (TalTech School of Business and Governance Department of Economics and Finance) for her help in developing the questionnaire. We are also grateful to Inna Romanova (University of Latvia) for her support in the survey implementation. We would like to thank all the companies who took part in the survey. We also would like to thank the head of the Alternative Financial Services Association of Latvia Gints Āboltinš for promoting the survey. We are grateful to all of those who have spared their time to read the preliminary version of the paper and give us valuable comments. While the first version of the paper was written, Stefan Wendt was at Reykjavik University, Iceland.

Conflicts of Interest: The authors declare no conflict of interest. 


\section{Notes}

1 The survey additionally included some questions on the financial situation of the companies and how they evaluate themselves vis à vis competitors. These questions were not considered for the further analysis though, because we decided to collect financial information on survey participants separately for a longer observation period.

2 Private pension funds are not further considered in the following descriptions due to relatively low relevance in the context of FinTech.

3 Beyond the regulatory situation described in this section, all financial service providers are subject to the Law on the Prevention of Money Laundering and Terrorism and Proliferation Financing (The Parliament of the Republic of Latvia 2008). The main institutions dedicated to combating money-laundering are the Financial Intelligence Unit of Latvia, FCMC, the State Revenue Service and CRPC.

4 Combined with potential free FCMC expert advice in PSD2, crowdfunding and/or virtual assets.

5 Application programming interface.

\section{References}

Ács, Zoltán J., Szerb László, Esteban Lafuente, and Markus Gábor. 2019. GEI_2019_Final-1. In Global Entrepreneurship Index. Washington, DC: Global Entrepreneurship and Development Institute, pp. 1-71. [CrossRef]

Ankenbrand, Thomas, Andreas Dietrich, and Denis Bieri. 2019. IFZ FinTech Study 2019 An Overview of Swiss FinTech. IFZ FinTech Study. Luzern: Institute of Financial Services Zug IFZ, p. 144.

Bank of Latvia. 2020. FINTECH Glossary. Available online: https:/ /www.bank.lv/en/publications-r/other-publications/fintechglossary (accessed on 15 June 2021).

Bureau van Dijk. 2021. Private Company Information-Orbis. Available online: https://www.bvdinfo.com/en-gb/ (accessed on 17 June 2021).

Cabinet of Ministers. 2011. Regulations Regarding the Special Permit (Licence) for the Provision of Consumer Credit Services. Riga: Cabinet of Ministers.

Council of Europe. 2019. Anti-Money Laundering and Counter-Terrorist Financing Measures Latvia 1 St Enhanced Follow-Up Report (MONEYVAL). Strasbourg: Council of Europe.

Crunchbase. 2020. Discover Innovative Companies and the People behind Them. Available online: https://www.crunchbase.com/ (accessed on 24 June 2021).

European Union. 2009. Internet of Things: An Action Plan for Europe. In Communication from the Commission to the European Parliament, the Council, the European Economic and Social Committee and the Committee of the Regions. Maastricht: European Union.

FCMC. 2021a. FinTech Monitoring. Available online: https://www.fktk.lv/en/licensing/innovation-and-fintech/fintech-monitoring/ (accessed on 27 May 2021).

FCMC. 2021b. Regulatory Sandbox. Available online: https://www.fktk.lv/en/licensing/innovation-and-fintech/innovationsandbox/ (accessed on 27 May 2021).

Filimonova, Irina Viktorovna, Irina Viktorovna Provornaya, Anna V. Komarova, Ekaterina A. Zemnukhova, and Mikhail V. Mishenin. 2020. Influence of Economic Factors on the Environment in Countries with Different Levels of Development. Energy Reports 6: 27-31. [CrossRef]

Financial Action Task Force. 2021. Countries-Latvia. Available online: https://www.fatf-gafi.org/countries/\#Latvia (accessed on 22 June 2021).

Financial Stability Board. 2019. FinTech and Market Structure in Financial Services: Market Developments and Potential Financial Stability Implications-Financial Stability Board. Basel: Financial Stability Board.

Findexable. 2019. The Global Fintech Index 2020. London: Findexable.

FinTech Baltic. 2020. First Ever Latvia Fintech Startup Map Draft Released-Fintech in Baltic. January 27. Available online: https: / fintechbaltic.com/1575/ fintechlatvia/latvia-fintech-startup-map-2020/ (accessed on 23 June 2021).

FinTech Baltic. 2021. Latvia Named Top Country with Largest Growth Fintech Interest Since 2020-Fintech in Baltic. Available online: https: / fintechbaltic.com/4707/fintechlatvia/latvia-named-top-country-with-largest-growth-fintech-interest-since2020/ (accessed on 23 June 2021).

Gomber, Peter, Robert J. Kauffman, Chris Parker, and Bruce W. Weber. 2018. On the Fintech Revolution: Interpreting the Forces of Innovation, Disruption, and Transformation in Financial Services. Journal of Management Information Systems 35: 220-65. [CrossRef]

Hoque, Zahirul. 2004. A Contingency Model of the Association between Strategy, Environmental Uncertainty and Performance Measurement: Impact on Organizational Performance. International Business Review 13: 485-502. [CrossRef]

Horn, Matthias, Andreas Oehler, and Stefan Wendt. 2020. FinTech for Consumers and Retail Investors: Opportunities and Risks of Digital Payment and Investment Services. In Palgrave Studies in Sustainable Business in Association with Future Earth. Cham: Palgrave Macmillan, pp. 309-27. [CrossRef]

IMF. 2019. Fintech: The Experience So Far. IMF Policy Paper 77. Washington, DC: IMF.

Institute for Management Development. 2019. IMD World Talent Ranking 2019. Washington, DC: Institute for Management Development. 
Investment and Development Agency of Latvia. 2020. Areas of Activity. Available online: https://www.liaa.gov.lv/en/about-us/ areas-activity (accessed on 19 June 2021).

Ito, Takatoshi, Kenta Yamada, Misako Takayasu, and Hideki Takayasu. 2020. Execution Risk and Arbitrage Opportunities in the Foreign Exchange Markets. Working Paper 26706. Cambridge: National Bureau of Economic Research. [CrossRef]

Key Capital. 2020. FinTech Companies in LatvialKey Capital/Europe. Available online: https://www.keycapital.eu/ fintechcompaniesinlatvia (accessed on 15 May 2021).

Kliber, Agata, Barbara Będowska-Sójka, Aleksandra Rutkowska, and Katarzyna Świerczyńska. 2021. Triggers and Obstacles to the Development of the FinTech Sector in Poland. Risks 9: 30. [CrossRef]

Kluza, Krzysztof, Magdalena Ziolo, and Anna Spoz. 2021. Innovation and Environmental, Social, and Governance Factors Influencing Sustainable Business Models-Meta-Analysis. Journal of Cleaner Production 303: 127015. [CrossRef]

Laidroo, Laivi, Anneliis Tamre, Mari-Liis Kukk, Elina Tasa, and Mari Avarmaa. 2021a. FinTech Report Estonia 2021. Tallinn: Finance Estonia.EU. [CrossRef]

Laidroo, Laivi, Ekaterina Koroleva, Agata Kliber, Ramona Rupeika-Apoga, and Zana Grigaliuniene. 2021b. Business Models of FinTechs-Difference in Similarity? Electronic Commerce Research and Applications 46: 101034. [CrossRef]

Long Finance and Financial Centre Futures. 2020. The Global Financial Centres Index 28. London: Long Finance and Financial Centre Futures.

OECD. 2018. Financial Markets, Insurance and Private Pensions: Digitalisation and Finance. Paris: OECD.

Oehler, Andreas, and Stefan Wendt. 2018. Trust and Financial Services: The Impact of Increasing Digitalisation and the Financial Crisis. In The Return of Trust? Institutions and the Public after the Icelandic Financial Crisis. Bingley: Emerald Publishing Limited, pp. 195-211. [CrossRef]

Oehler, Andreas, Matthias Horn, and Stefan Wendt. 2021. Investor Characteristics and Their Impact on the Decision to Use a Robo-Advisor. Journal of Financial Services Research. forthcoming.

Olson, Eric M., and Stanley F. Slater. 2002. The Balanced Scorecard, Competitive Strategy, and Performance. Business Horizons 45: 11-16. [CrossRef]

Rikhardsson, Pall, Stefan Wendt, Auður Arna Arnardóttir, and Throstur Olaf Sigurjónsson. 2020. Is More Really Better? Performance Measure Variety and Environmental Uncertainty. International Journal of Productivity and Performance Management 70: 1446-69. [CrossRef]

Rupeika-Apoga, Ramona, and Eleftherios Thalassinos. 2020. Ideas for a Regulatory Definition of FinTech. International Journal of Economics and Business Administration 8: 136-54. [CrossRef]

Rupeika-Apoga, Ramona, and Roberts Nedovis. 2016. The Foreign Exchange Exposure of Domestic Companies in Eurozone: Case of the Baltic States. European Research Studies Journal 19: 165-78. [CrossRef]

Rupeika-Apoga, Ramona, and Svetlana Saksonova. 2018. SMEs' Alternative Financing: The Case of Latvia. European Research Studies Journal 21: 43-52. [CrossRef]

Saksonova, Svetlana, and Oksana Koleda. 2017. Evaluating the Interrelationship between Actions of Latvian Commercial Banks and Latvian Economic Growth. Procedia Engineering 178: 123-30. [CrossRef]

Saksonova, Svetlana. 2014. Foreign Direct Investment Attraction in the Baltic States. Journal: Business: Theory and Practice 15: 114-20. [CrossRef]

Sammut-Bonnici, Tanya, and David Galea. 2015. PEST Analysis. In Wiley Encyclopedia of Management. Hoboken: John Wiley \& Sons, Ltd. [CrossRef]

Solovjova, Irina, Ramona Rupeika-Apoga, and Inna Romānova. 2018. Competitiveness Enhancement of International Financial Centres. European Research Studies Journal 21: 5-17. [CrossRef]

Swedbank. 2020. Latvian Fintech Report 2020. Gothenburg: Swedbank.

The Alternative Financial Services Association of Latvia. 2021. Members. Available online: https://www.lafpa.lv/en/about-us/ members/ (accessed on 12 July 2021).

The European Commission. 2018. FinTech Action Plan: For a more Competitive and Innovative European Financial Sector EN. Brussels: The European Commission.

The European Commission. 2019. Commission Delegated Regulation (EU) 2019/980. Official Journal of the European Union L 166/26. Available online: https:/ / eur-lex.europa.eu/legal-content/EN/TXT/?uri=CELEX\%3A32019R0980 (accessed on 12 July 2021).

The European Parliament and of the Council. 2014. Directive 2014/65/EU of the European Parliament and of the Council. Official Journal of the European Union L 173/349. Available online: http://data.europa.eu/eli/dir/2014/65/oj (accessed on 12 July 2021).

The European Parliament and of the Council. 2015. Directive (EU) 2015/2366 of the European Parliament and of the Council of 25 November 2015 on Payment Services in the Internal Market, Amending Directives 2002/65/EC, 2009/110/EC and 2013/36/EU and Regulation (EU) No 1093/2010, and Repealing Directive 200. Official Journal of the European Union L 337/35. Available online: http:/ / data.europa.eu/eli/dir/2015/2366/oj (accessed on 12 July 2021).

The European Parliament and of the Council. 2018. Directive (EU) 2018/843 of the European Parliament and of the Council. Official Journal of the European Union L 156/43. Available online: http:/ /data.europa.eu/eli/dir/2018/843/oj (accessed on 12 July 2021). 
The European Parliament and of the Council. 2019a. DIRECTIVE (EU) 2019/2034 on the Prudential Supervision of Investment Firms and Amending Directives 2002/87/EC, 2009/65/EC, 2011/61/EU, 2013/36/EU, 2014/59/EU and 2014/65/EU. Official Journal of the European Union. Available online: https:/ / eur-lex.europa.eu/legal-content/EN/TXT/?uri=CELEX:32019L2034 (accessed on 19 July 2021).

The European Parliament and of the Council. 2019b. EUR-Lex-32019L2034-EN-EUR-Lex. Official Journal of the European Union L 314/64. Available online: http:/ / data.europa.eu/eli/dir/2019/2034/oj (accessed on 12 July 2021).

The European Parliament and of the Council. 2019c. REGULATION (EU) 2019/2033 on the Prudential Requirements of Investment Firms and Amending Regulations (EU) No 1093/2010, (EU) No 575/2013, (EU) No 600/2014 and (EU) No 806/2014. Official Journal of the European Union L 314/1. Available online: http:/ / data.europa.eu/eli/reg/2019/2033/oj (accessed on 15 July 2021).

The European Parliament and of the Council. 2020. REGULATION (EU) 2020/1503 of The European Parliament and of The Council of 7 October 2020 on European Crowdfunding Service Providers for Business. Official Journal of the European Union L $347 / 1$. Available online: http:/ / data.europa.eu/eli/reg/2020/1503/oj (accessed on 19 July 2021).

The European Parliament. 2017. Report on FinTech: The Influence of Technology on the Future of the Financial Sector (2016/2243(INI)). A8-0176/2017. Brussels: The European Parliament. [CrossRef]

The Financial and Capital Market Commission. 2002. Regulations on the Issue of Credit Institution and Credit Union Operating Licences. Riga: The Financial and Capital Market Commission.

The Parliament of the Republic of Latvia. 1997. Law on the Investment Management Companies. Riga: The Parliament of the Republic of Latvia.

The Parliament of the Republic of Latvia. 1999. Consumer Rights Protection Law. Riga: The Parliament of the Republic of Latvia.

The Parliament of the Republic of Latvia. 2000. Commercial Law. Riga: The Parliament of the Republic of Latvia.

The Parliament of the Republic of Latvia. 2001a. Credit Union Law. Riga: The Parliament of the Republic of Latvia.

The Parliament of the Republic of Latvia. 2001b. Investor Protection Law. Riga: The Parliament of the Republic of Latvia.

The Parliament of the Republic of Latvia. 2003. Law on the Financial Instruments Market. Riga: The Parliament of the Republic of Latvia.

The Parliament of the Republic of Latvia. 2004. Compulsory Civil Liability Insurance of Owners of Motor Vehicles Law. Riga: The Parliament of the Republic of Latvia.

The Parliament of the Republic of Latvia. 2008. The Law on the Prevention of Money Laundering and Terrorism and Proliferation Financing. Riga: Latvijas Vestnesis.

The Parliament of the Republic of Latvia. 2010. The Law on Payment Services and Electronic Money. Riga: The Parliament of the Republic of Latvia.

The Parliament of the Republic of Latvia. 2013. Law on Alternative Investment Funds and Their Managers. Riga: The Parliament of the Republic of Latvia.

The Parliament of the Republic of Latvia. 2015a. Deposit Guarantee Law. Riga: The Parliament of the Republic of Latvia.

The Parliament of the Republic of Latvia. 2015b. Law on Insurance and Reinsurance. Riga: The Parliament of the Republic of Latvia.

The Parliament of the Republic of Latvia. 2017. Law on the Recovery and Resolution of Credit Institutions and Investment Firms. Riga: The Parliament of the Republic of Latvia.

The Parliament of the Republic of Latvia. 2018. The Insurance Contract Law. Riga: The Parliament of the Republic of Latvia.

The Parliament of the Republic of Latvia. 2019. The Insurance and Reinsurance Distribution Law. Riga: The Parliament of the Republic of Latvia.

Tirmaste, Kersti, Liina Voolma, Laivi Laidroo, Mari-Liis Kukk, and Mari Avarmaa. 2019. FinTech Report Estonia 2019. Tallinn: Finance Estonia.EU. [CrossRef]

World Bank Group. 2020. Doing Business 2020: Comparing Business Regulation in 190 Economies. Washington, DC: World Bank Group. [CrossRef]

World Economic Forum. 2019. The Global Competitiveness Report 2019. Cologny: World Economic Forum. [CrossRef]

World Economic Forum. 2020. The Europe 2020 Competitiveness Report: Building a More Competitive Europe. Cologny: World Economic Forum.

Yeandle, Mark, and Michael Mainelli. 2015. The Global Financial Centres Index 17. The Global Finance Centres Index (GFCI)—Long Finance, 2015. Available online: https: / / ssrn.com/abstract=3671501 (accessed on 9 July 2021). 



\title{
Digital Banking in Northern India: The Risks on Customer Satisfaction
}

\author{
Balijinder Kaur ${ }^{1}$, Sood Kiran ${ }^{1}$, Simon Grima ${ }^{2}$ and Ramona Rupeika-Apoga ${ }^{3, *}$ \\ 1 Chitkara Business School, Chitkara University, Rajpura 140401, India; baljinder.kaur@chitkara.edu.in (B.K.); \\ kiran.sood@chitkara.edu.in (S.K.) \\ 2 Department of Insurance, Faculty of Economics Management and Accountancy, University of Malta, \\ MSD 2080 Msida, Malta; simon.grima@um.edu.mt \\ 3 Faculty of Business, Management and Economics, University of Latvia, LV-1586 Riga, Latvia \\ * Correspondence: rr@lu.lv
}

Citation: Kaur, Balijinder, Sood Kiran, Simon Grima, and Ramona Rupeika-Apoga. 2021. Digital Banking in Northern India: The Risks on Customer Satisfaction. Risks 9: 209. https://doi.org/10.3390/ risks 9110209

Academic Editor: Mogens Steffensen

Received: 10 October 2021

Accepted: 15 November 2021

Published: 17 November 2021

Publisher's Note: MDPI stays neutral with regard to jurisdictional claims in published maps and institutional affiliations.

Copyright: (c) 2021 by the authors. Licensee MDPI, Basel, Switzerland. This article is an open access article distributed under the terms and conditions of the Creative Commons Attribution (CC BY) license (https:// creativecommons.org/licenses/by/ $4.0 /)$.

\begin{abstract}
The widespread use of digital technologies and the current pandemic (COVID) have fueled the need and call for digital transformation in the banking sector. Although this has various benefits, it is a disruption to the norm to which a bank customer has to become accustomed. This variance means that customers would have to make some changes to their routine. This can constitute risks in terms of maintaining customer satisfaction at previous levels. These risks are associated with customer retention because a service or product needs to be aligned with customer expectations to avoid them switching to other service providers. Moreover, it can also have an effect on reputation. Offering digital account opening or remote deposits may not satisfy customers; competitive advantage depends on many aspects such as providing a hassle-free, personalized and cyber-secure experience, economic aspects and the needs of the society at large. Therefore, there is a need to understand the intensity of the risk factors that influence customer satisfaction for digitalized banking services and products. To do this, we carried out a structured survey, framed on the five dimensions of the SERVQUAL model, which was sent out to Northern Indian banking customers, to which we received 222 valid responses. We subjected the data received to Structural Equation Modelling using the SmartPLS version 3 application software. Results reveal that digital banking customers in Northern India are genuinely satisfied with the quality of services provided by digital banking. Moreover, 'reliability' has the strongest risk factor impact on customer satisfaction, followed by 'tangibility' and 'responsiveness'.
\end{abstract}

Keywords: digital banking; customer satisfaction; SERVQUAL model; risk management; service quality; digital transformation

\section{Introduction}

Digital technologies and the COVID pandemic have fueled the digital transformation, forcing changes in the structure of the banking industry's services and products. A successful transition from the old world to the new one requires a focus on multilevel governance (Leal Filho et al. 2020; Awan et al. 2020). The digital transformation has shifted the traditional process to a digital-systematized process, giving rise to a new face to the banking sector. However, using modern equipment and software is only one aspect of digital transformation in banking, as it also involves reviewing the management methods, communications, and organizational culture. Internet banking, innovative ancillary application software and databases have called for and enabled secure $24 / 7$ customer transaction services, enhancing the pace of competition in the sector. Many traditional banks around the world are now digital banks dominated by FinTech trends.

With this increased dissemination of technology, populations are forced to use digitalized banking for their routine transactions. Although this might be seen by some as having various benefits, it is a disruption to the norm to which a bank customer has to become 
accustomed. This variance means that customers need to make some changes to their routine, changes that constitute a risk to maintaining customer satisfaction at previous levels. Offering digital services or products may not satisfy customers. The competitive advantage depends on many aspects such as providing a hassle-free, personalized and cyber-secure experience, economic aspects and the needs of the society at large. Therefore, there is a need to understand the intensity of the risk factors that influence customer satisfaction for digitalized banking services and products.

The banking industry needs to strengthen and ensure the availability of quality web-based technological services to meet the competition and, at the same time, address customer needs (Zaidi and Rupeika-Apoga 2021). Consumers and businesses that were previously hesitant to switch to or rely on digital channels now enjoy the convenience and speed they provide, thereby increasing the likelihood that this change in habits will become permanent (Grima et al. 2020). To do this, it is necessary to rethink all internal processes, focusing on the customers' satisfaction, and think about how they look and work in a digital environment (Girlando et al. 2021; Pavia et al. 2021; Grima et al. 2021a).

In the simplest of terms, the digitalization of the banking business means that the traditional services offered by banks are now offered through digital means. Amongst these services are transferring funds from one bank account to another; viewing and managing your bank account details; requesting information on transactions carried out; checking your bank account balance; managing your loans; paying bills, etc. Digital banking is expected to provide a convenient, easy and secure way of carrying out banking services from the comfort of your home, any time, from your personal computer or laptop and using the bank's mobile app on your smartphone or tablet. This increases the speed of completing tasks (Japparova and Rupeika-Apoga 2017). While customers often confuse the difference between online banking, Internet, e-banking, mobile banking and digital banking, digital banking goes beyond other banking models and requires a comprehensive re-engineering of a bank's internal systems. Digital banking involves the digitization of every program and activity carried out by financial institutions and their customers. Digital banking is the future, potentially encompassing all digital programs and transactions that have ever been undertaken by a financial institution or the customers they serve. Various regulations and guidelines have and are being enacted to protect against cybersecurity and digital fraud (for example, the Digital Operations Resilience Act, which will come into force in 2022). However, what is the intensity by which the main risk factors affect customer satisfaction? Digitalization has opened up banks to the risk of not meeting client expectations and needs. Clients that are the core of every bank are now being asked to do something different, disrupting their way of life- that is, it involves a new risk since customers are asked to deviate from their norm. Therefore, there is a need to understand the intensity of the risk factors that influence customer satisfaction for digitalized banking services and products to facilitate informed management (Grima et al. 2021b).

We herein use the SERVQUAL model provided by Parasuraman et al. (1988) and Zeithaml et al. (1990) to determine the impact intensity of digital banking service quality on customer satisfaction in Northern India, by subjecting it to the five dimensions of service quality suggested in this model; specifically, (1) reliability, (2) assurance, (3) tangibility, (4) empathy and (5) responsiveness. In this study, we seek answers to questions about how the intensity of risk factors affects customer satisfaction with digital banking services and products, applying the five dimensions of service quality.

Research Question (RQ): Which of these five dimensions provide the highest level of risk concerning customer satisfaction?

Risks associated with customer satisfaction arise from the difference between perceived expectations of service and perceived performance of a service, known as quality of service (Raza et al. 2015; Toor et al. 2016). This can be defined as the assessment of services provided by the organization to the customers. Service quality is also considered as the judgment of an organization as excellent or superior, based on their performance. It helps in building the perception about the organization's service in the minds of consumers and 
assists in retaining a corporate image, catching the attention of new customers and maintaining the profitability position of an organization. Usually, consumers tend to purchase goods and hire services from specific stores and specific experts because they are assured of receiving the best products and services. This creates a level of trust and loyalty among the consumers. The term service quality can also be defined as fulfilling the expectations and needs of the consumers as per their perception and it can be measured through ten major dimensions: Communication, Credibility, Security, Tangibles, Reliability, Responsiveness, Competence, Courtesy, Understanding, and Access (Parasuraman et al. 1988).

This study aims to fill the gap in the literature on understanding the intensity of the risk factors that influence customer satisfaction for digitalized banking services and products, in a way that facilitates informed management. While the five dimensions of SERVQUAL have become popular and widely used, this framework has also received many theoretical and practical criticisms. Several authors have recently tried to modify the classical model by adding new dimensions (Zouari and Abdelhedi 2021; Carrasco et al. 2012; Tumsekcali et al. 2021; Lizarelli et al. 2021). We use SERVQUAL to confirm that the classical five dimensions show a statistical relationship with customer satisfaction in the new digital age.

In addition, this study also takes into account the national dimension, as different cultures may relate differently to customer satisfaction (Pakurár et al. 2019; Zouari and Abdelhedi 2021). This study adds to the literature on customer satisfaction in the context of the banking sector in the digital age by taking a practical view of the situation of the banks in Northern India. Our findings have practical implications for risk managers, banking practitioners, policymakers and marketing personnel.

We found that customers in the northern region of India are genuinely satisfied with the quality of services provided by banks involved in the digital transformation. Overall, the results of the study show that 'Reliability' has a strong impact on customer satisfaction, followed by 'Tangibility' and 'Responsiveness'. Therefore, risk managers and policymakers should give increased attention to these SERVQUAL dimensions when designing or digitalizing new services and products. The study also suggests that all banks should provide accurate, reliable information; timely updates; maintenance of accounts; and error-free transactions while providing digital banking services. In addition, the bank needs to work on providing services that are easy, convenient and visually appealing with error-free transactions to enhance tangibility and responsiveness.

The structure of this paper is as follows. The next section, Section 2, provides a review of the literature and formulation of the hypotheses. In Section 3, we explain the methodology; in Section 4, we lay out the results and findings. Subsequently, in Section 5, we discuss the findings and conclude.

\section{Theoretical Background and Hypotheses}

Digital transformation is a process that recognizes that the digital landscape will always change and that consumer expectations will evolve with the landscape's ability to deliver consistently better results, leading to superior customer satisfaction. Digital technologies have changed consumer habits. Mobile devices, apps, machine learning, automation, and more allow customers to get what they want, virtually the moment they need it. Digital transformation is the integration of digital technology across all areas of the business, revolutionizing the way they work and deliver value to their customers. These new digital technologies have changed customer expectations, resulting in a new type of modern shopper. Today's consumers are constantly connected, have their applications, and know what they can do with technology (Rupeika-Apoga and Wendt 2021; Laidroo et al. 2021).

Digital transformation requires banks to rethink how they interact with their customers and how they are going to meet growing customer needs. As a result, a natural question arises: What models and methods can be used to measure changing customer satisfaction? 
In the banking sector, the SERVQUAL model is widely used to measure service quality, which compares the expectations of customers before receiving a service and their perception of actual service delivery (Carrasco et al. 2012; Zhou et al. 2021; Dinçer et al. 2019). SERVQUAL views service quality as an overall assessment of an organization by clients in relation to the quality of the services provided.

Tangibility deals with the physical aspects and represents the appearance of physical facilities, equipment, personnel and communication resources (Toor et al. 2016). Examples of this aspect in relation to banking include the appearance of bank statements, website design, updated equipment, and staff dealings. Tangibility helps in maintaining a contact between the employee and customer, which ultimately helps enhance the level of customer satisfaction (Lau et al. 2013).

Reliability represents the ability to perform the services as promised or maintain the same service quality over a period. Reliability helps in maintaining the reputation among consumers, by providing the promised services-for example, error-free transactions and timely updates of accounts. It helps in building trust and confidence among consumers (Lau et al. 2013).

Assurance deals with ensuring safety, freedom from risk and building trust among consumers (Rijwani et al. 2017). Banks should be able to provide a commitment to ensure the safety of customer monies, and a clear explanation must be given to the consumers regarding the insurance policies, margins and other services so that consumers are able to feel confident about the services provided (Lau et al. 2013).

Empathy means giving individual attention to the consumers (Rijwani et al. 2017). Banks need to cater for the different problems and needs of their customers. Knowledgeable employees must be employed to solve customer problems quickly. Dealing with customer problems is considered as one of the success factors of the service industry (Lau et al. 2013).

Responsiveness represents responsiveness to consumers, willingness to help them and providing quick services, which ultimately helps gain customer satisfaction (Toor et al. 2016).

People are using digital services as a new medium to cater for their daily requirements. The first time adoption of digital banking started in Finland with the use of the Automatic Teller Machine (Worku et al. 2016). The majority of today's banks provide digital banking facilities as per the needs and requirements of the customers to gain customer satisfaction and enhance their service quality.

Customer satisfaction means meeting the requirements of the customer as per their expectations. Generally, the customer has certain expectations while purchasing a product or hiring a service. If the service or a product meets the expectations of the consumers, ultimately, this leads to a happier and more satisfied customer. If the value of the services delivered is less than or not equal to the expectations of the customers, this leads to dissatisfaction among the consumers (Toor et al. 2016).

Customer satisfaction brings along loyalty among the consumers, which ultimately helps to gain market shares. If an organization wants its customer to be satisfied, it must understand the needs and expectations of its customers and perform accordingly. Dissatisfaction among customers regarding the product or service will result in a negative impact on the organization, damaging the image of the company and resulting in losing its best employees.

According to Fernández-Rovira et al. (2021), digitalization is seen as an effective tool for building customer loyalty by using data generated by the customers themselves to predict their behavior as consumers (Fernández-Rovira et al. 2021).

A study by Karjaluoto et al. (2002) in Finland identified the different factors that influence customer behavior and attitude formation towards online banking. This study was carried out through the provision of a questionnaire, which resulted in 1167 valid responses. They studied attitude formation using a structural equation model. Results of the study indicated that the most important factor behind the formation of attitude towards online banking is knowledge regarding Information Technology (IT). Knowledge regarding IT is a tangibility aspect. Raza et al. (2015) conducted research on internet 
banking and the level of customer satisfaction in Pakistan using the SERVQUAL model to understand the impact of service quality on customer satisfaction. They collected data from 400 respondents from Karachi city, Pakistan. The respondents were specifically chosen from internet banking users. Inferences have been drawn from the specific study that there exists a positive and direct relationship between reliability, responsiveness and tangibility, and customer satisfaction, whereas empathy had shown less of an effect on customer satisfaction. The researchers emphasized the management of internet banking to take effective measures to make websites more visually appealing and to increase the security and safety of digital information related to all bank accounts.

Chingang Nde and Lukong (2010), on the other hand, found that the SERVQUAL model is not the best measuring tool when it comes to measuring service quality in grocery stores. This is since the dimensions do not accurately measure the construct in that context. Meanwhile, Lizarelli et al. (2021) propose an integrative framework involving SERVQUAL, Analytical Kano (A-Kano), and QFD using fuzzy approaches (Fuzzy Inference System and 2-tuple fuzzy linguistic representation) to design and improve services.

Zouari and Abdelhedi (2021) propose adding two new dimensions to the existing SERVQUAL model of five dimensions: digitalization and compliance. Although their outcomes lend support to the extended SERVQUAL model, the results are derived based on a relatively average sample size in one country (Tunisia). Tumsekcali et al. (2021) extended the SERVQUAL model with two new criteria related to Industry 4.0 and the pandemic to understand and evaluate the service quality of public transport systems. Awasthi et al. (2011) presented a hybrid approach based on SERVQUAL and fuzzy TOPSIS for evaluating the service quality of urban transportation systems. This study focuses on determining the dominant and less important dimension/s of the SERVQUAL model that provide the highest level of risk with regard to customer satisfaction. We investigate the impact of five dimensions of service quality on customer satisfaction: reliability, assurance, tangibility, empathy and responsiveness.

Hypothesis 1 (H1). Tangibility has a significant impact on customer satisfaction in Digital Banking.

The above hypothesis has been framed based on the works of the following researchers:

Amin (2016) has examined the service quality of internet banking and the impact of service quality on customer loyalty and the level of customer satisfaction. The study involved a sample size of 520 respondents of Riyadh, Kingdom of Saudi Arabia. The study revealed that all the dimensions, i.e., personal needs, user-friendliness, site organization and efficiency of websites, have a positive relationship with service quality.

Chong et al. (2010) have empirically identified the factors that have an impact on the adoption of online banking in Vietnam. They collected sample data of 103 respondents and analyzed them using multiple regression analysis and correlation. The study revealed that factors such as trust, perceived usefulness and government support were significant.

Hypothesis 2 (H2). Reliability has a significant impact on customer satisfaction in Digital Banking.

The above hypothesis has been framed based on the works of the following researchers:

Ozretic-Dosen and Zizak (2015) critically examined the quality of banking services using the SERVQUAL model by collecting data from 200 students in Zagreb, Croatia. The study revealed that management needs to improve the banking services in the major dimensions, i.e., reliability, assurance and responsiveness.

Loonam and O'Loughlin (2008) conducted an exploratory study on the e-service quality of banking in Ireland. To fulfil the objective of the study, semi-structured interviews were carried out with digital banking customers selected by using a purposive sample technique. Results of the study revealed that the factors that are more important for digital banking services are trust, access, web usability and flexibility. 
Kuisma et al. (2007) performed research in Finland to identify the reasons behind consumers' resistance to internet banking. They carried out in-depth interviews with 30 respondents. Findings of the study indicated that the major reasons behind resistance to internet banking are resistance to innovation, feeling of insecurity and lack of information.

Hypothesis 3 (H3). Assurance has a significant impact on customer satisfaction in Digital Banking.

The above hypothesis has been framed based on the works of the following researchers:

Laforet and Li (2005) carried out a study on understanding market status, and targeted customers and consumer attitudes regarding online banking and mobile banking in China. Data were collected from 300 respondents through questionnaires. The results of the study showed that, in China, the most targeted customers are males rather than females. Perception of risk, knowledge about IT, lack of awareness and understanding among customers were considered as the most important barriers towards online banking.

An empirical study conducted by Sohail and Shanmugham (2003) to examine the current trends in e-banking in Malaysia on a sample size of 300 revealed that digital accessibility, e-banking awareness and resistance from consumers are some of the factors that affected the usage of digital banking in Malaysia.

Hypothesis 4 (H4). The empathy aspect has a significant impact on customer satisfaction in Digital Banking.

The above hypothesis has been framed based on the works of the following researchers:

Nui Polatoglu and Ekin (2001) carried out an exploratory study in Turkey to examine the factors that affect consumers' and organizations' acceptance of digital banking. Data were collected from 114 respondents. Two-factor analysis and Cluster analysis were used to analyze the data and results show that internet banking reduces operational costs and leads to high customer satisfaction.

Bauer et al. (2005) measured the quality of e-banking web portals through an empirical study by constructing a model on the dimensions of cross-buying service quality, security and trust, responsiveness, transaction support, added-value and basic service quality. Through this study, the researchers classified all the dimensions into three different categories: core services, additional services and problem-solving services. Results of the study showed a strong tendency in favor of using web portals as a vital part of providing management solutions regarding e-banking.

Hypothesis $\mathbf{5}$ (H5). The responsiveness aspect has a significant impact on customer satisfaction in Digital Banking.

The above hypothesis has been framed based on the works of the following researchers:

Rijwani et al. (2017) performed a study on customers' satisfaction and the service quality of Indian banking services. The five SERVQUAL dimensions were used by the researchers to examine service quality. They analyzed the data through correlation, regression, reliability analysis and factor analysis to identify the effect of service quality on customer satisfaction. The sample size of the study was 384 respondents. The results of the study identified a direct relationship between service quality and customer satisfaction. Furthermore, it was determined that customer satisfaction was the least affected by reliability but highly dependent upon assurance.

Tharanikaran et al. (2017) scrutinized the level of customer satisfaction and service quality of electronic banking in the Batticaloa district of Sri Lanka. For the study, data were collected through a questionnaire from 231 respondents. To validate the constructs, unidimensionality, reliability and validity assessments were conducted by the researchers and to test the hypotheses, a one-sample t-test was performed. Results of the study 
revealed that there is a high degree of service quality and customer satisfaction in the Batticaloa district.

Toor et al. (2016) investigated the effect of e-banking on customer satisfaction. Data were collected from 264 respondents who are users of e-banking in different cities of Pakistan. The SERVQUAL model, correlation and multiple regression analysis were used to determine the significance level of all the variables for customer satisfaction in e-banking. Results of the study showed a positive relationship between service quality dimensions and customer satisfaction.

Jun and Palacios (2016) conducted an exploratory study to identify the key dimensions in mobile banking service quality by employing a critical incident technique. The findings of the study indicated that the key dimensions are classified into two categories: mobile banking customer service quality and mobile banking application quality.

Hypothesis 6 (H6). Tangibility, Reliability, Assurance, Empathy and Responsiveness have a significant impact on customer satisfaction in Digital Banking.

The above hypothesis has been framed based on the works of Parasuraman et al. (1988) and Zeithaml et al. (1990), who provided us with these five dimensions for the service sector.

Although the SERVQUAL model was developed in 1985, it is still widely used today due to its flexible and universal approach to defining five parameters that influence the overall perception of quality by customers. We believe that reliability, assurance, tangibility, empathy and responsiveness are appropriate metrics for assessing the highest level of risk with regard to customer satisfaction.

\section{Data and Methodology}

Service quality is a concept that has generated considerable interest and debate in the research literature due to the difficulties in both defining and measuring it, and there is no consensus on any of these issues (Jun and Palacios 2016; Awasthi et al. 2011; Lizarelli et al. 2021; Tumsekcali et al. 2021). The SERVQUAL model is one of the most influential service quality measurement instruments, which is still used in many applications and developments of the service quality fields (Ijadi Maghsoodi et al. 2019).

We started by searching for literature in popular databases such as WoS, Scopus, ScienceDirect, Google Scholar and others from 1988 to 2021 using the keywords: SERVQUAL AND Digitalisation OR SERVQUAL AND Banking. As a result, in March 2021, we selected 3707 relevant articles. After applying the PRISMA search strategy (preferred reporting elements for systematic reviews and meta-analysis), 56 literature sources were selected (Farrugia and Grima 2021).

In order to categorize and organize the findings and results, we reviewed the results, identified duplicates, and used the inclusion and exclusion criteria. We generated tables of articles $(n=56)$ based on their classification, allowing us to organize them. Manually comparing and contrasting search lists was performed.

By referring to the inclusion/exclusion criteria, we were able to eliminate studies that did not fit our review's objectives from the search and also discard repeated search items. Our search criteria were determined based on an analysis of the study objectives and a brainstorming session with peers to find the best words to describe the search. We set the search parameters at a high level and used the generic best-fit phrases, which led us to a number of sources. It was understood that if the initial search did not yield significant results, a more narrow syntax would be commissioned. We achieved the most relevant search by implementing a specific syntax, after which we narrowed it to digital banking services customer satisfaction.

We manually checked the results for duplications, removing 2884 articles and screening the remaining 823 using Braun and Clarke's (2006) thematic analysis. Manual screening was conducted to exclude any articles that were not relevant to our study's scope, resulting in 212 articles, and a second round brought this down to 158 articles. As soon as the quali- 
tative saturation of results was determined (other articles added no value), the repeated article citations were eliminated and we used the best 56 article citations. In this study, we searched and ranked 56 research articles based on their significance and relevance to the study objectives.

We use the SERVQUAL model provided by Parasuraman et al. (1988) and Zeithaml et al. (1990) to determine the impact intensity of digital banking service quality on customer satisfaction in Northern India, by subjecting it to the five dimensions of service quality suggested in this model; specifically, (1) reliability, (2) assurance, (3) tangibility, (4) empathy and (5) responsiveness. The conceptual framework is summarized in Figure 1.

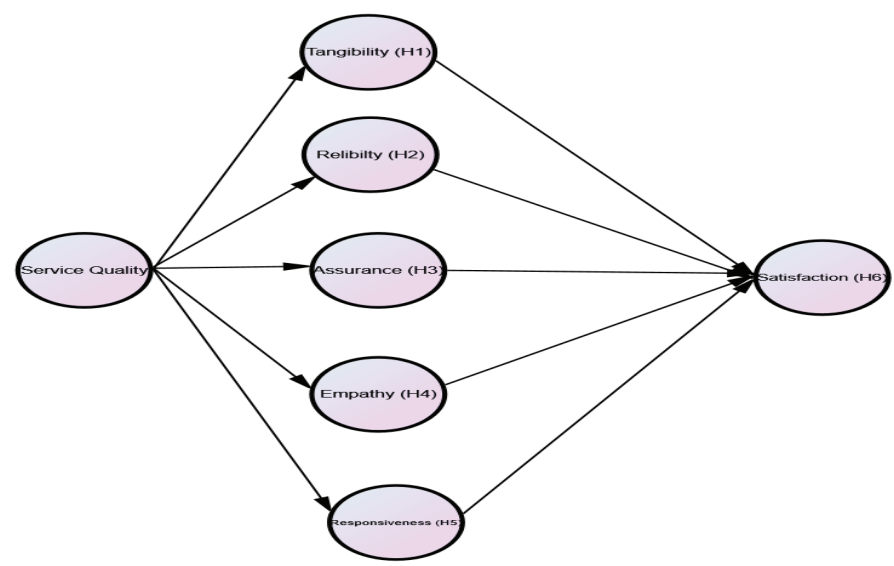

Figure 1. Conceptual framework. Source: Authors' compilation based on Parasuraman et al. (1988) and Zeithaml et al. (1990).

To collect data to examine the dimensions of the SERVQUAL model, we created a survey (Ijadi Maghsoodi et al. 2019; Awasthi et al. 2011; Zhou et al. 2021). The survey consisted of 25 statements determined after reviewing the literature on the five dimensions of the SERVQUAL model, as noted in Table 1, and demographic questions, specifically relating to the respondents' age, gender, occupation and qualification. The respondents were asked to respond to the 25 statements using a five-point Likert scale in which ' 5 ' $=$ Most satisfied/Most likely, '4' = Satisfied/likely, '3' = Neutral, '2' = Dissatisfied/unlikely, ' 1 ' = Most dissatisfied/Highly unlikely. We received 222 valid responses, which according to Hinkin (1995), is an ideal sample size based on the item-to-response ratio to carry out Structural Equation Modelling, ranging from as low as 1:4 to as high as 1:10 for each scale to be analyzed (i.e., 120-300 responses) (Deb and Lomo-David 2014; Hinkin 1995).

The data were collected through a structured survey targeting customers of different banks who are using banking services, between March and June 2021, in the Indian Northern Region. The survey was self-administered over social media such as LinkedIn`, Twitter@ and Facebook@; by verbal face-to-face meeting and over the phone; and online communication using Zoom $($, MS Teams $($ and Goto $($ ) applications to users of the banking services and products.

We inputted the data into a Microsoft Excel spreadsheet to determine the descriptive frequencies of the participant demographics. We then subjected the other data to Structural Equation Modelling using the Smart PLS (Partial Least Square) version 3 application to determine whether the variables (Tangibility, Reliability, Assurance, Empathy and Responsiveness) have a significant impact on customer satisfaction in digital banking in the Indian banking market.

The resultant 222 sample participants were fairly balanced between males (122) and females (100), with the largest number being between 26 and 40 years of age, followed by those between the age of 18 and 25 (59) and over 41 (28). The majority of respondents were 
self-employed (105), followed by those who were currently in employment (83), students (21) and others (13). Most of the participants held a post-graduate qualification (140), followed by those with an undergraduate qualification (66) and those with other skills and qualifications (16).

Table 1. Dimensions and sources.

\begin{tabular}{|c|c|}
\hline Dimensions & Source \\
\hline $\begin{array}{l}\text { Tangibility 1: Digital transformation provides an easy way to } \\
\text { do banking transactions to customers as per their needs. }\end{array}$ & \multirow{5}{*}{$\begin{array}{l}\text { (Chong et al. 2010; Amin 2016; } \\
\text { Zouari and Abdelhedi 2021) }\end{array}$} \\
\hline $\begin{array}{l}\text { Tangibility2: Digital banking provides convenient } \\
\text { banking services. }\end{array}$ & \\
\hline Tangibility 3: Digital banking facilities are visually appealing. & \\
\hline Tangibility 4: Digital banking facilities are modern. & \\
\hline $\begin{array}{l}\text { Tangibility 5: You are satisfied with the technological, } \\
\text { up-to-date equipment of the bank. }\end{array}$ & \\
\hline $\begin{array}{l}\text { Reliability 1: Digital banking provides accurate and } \\
\text { reliable information. }\end{array}$ & \multirow{5}{*}{$\begin{array}{l}\text { (Loonam and O'Loughlin 2008; } \\
\text { Kuisma et al. 2007; } \\
\text { Ozretic-Dosen and Zizak 2015) }\end{array}$} \\
\hline $\begin{array}{l}\text { Reliability 2: Digital banking provides timely updates and } \\
\text { maintenance of accounts. }\end{array}$ & \\
\hline $\begin{array}{l}\text { Reliability 3: Digital banking provides error-free transactions } \\
\text { as promised. }\end{array}$ & \\
\hline $\begin{array}{l}\text { Reliability 4: Digital banking has all the services available } \\
\text { when the customer wants it. }\end{array}$ & \\
\hline $\begin{array}{l}\text { Reliability 5: Digital banking performs the service right the } \\
\text { first time. }\end{array}$ & \\
\hline Assurance 1: You have confidence in the bank's services. & \multirow{5}{*}{$\begin{array}{l}\text { (Sohail and Shanmugham } 2003 \\
\text { Laforet and Li 2005; } \\
\text { Zhou et al. 2021) }\end{array}$} \\
\hline $\begin{array}{l}\text { Assurance 2: Digital banking provides ease in finding out } \\
\text { policy statements and notice statements. }\end{array}$ & \\
\hline $\begin{array}{l}\text { Assurance 3: The process of digital banking is easy } \\
\text { to remember. }\end{array}$ & \\
\hline $\begin{array}{l}\text { Assurance 4: You feel secure while making } \\
\text { transactions digitally. }\end{array}$ & \\
\hline $\begin{array}{l}\text { Assurance 5: Your digital banking site does not share your } \\
\text { personal information with other sites. }\end{array}$ & \\
\hline $\begin{array}{l}\text { Empathy 1: When you have a problem, the bank shows a } \\
\text { sincere interest in solving it. }\end{array}$ & \multirow{5}{*}{$\begin{array}{l}\text { (Nui Polatoglu and Ekin 2001; } \\
\text { Bauer et al. 2005) }\end{array}$} \\
\hline $\begin{array}{l}\text { Empathy 2: You receive personal attention from bank } \\
\text { employees if the need for a contract arises. }\end{array}$ & \\
\hline $\begin{array}{l}\text { Empathy 3: The employee of the bank understands your } \\
\text { specific needs. }\end{array}$ & \\
\hline $\begin{array}{l}\text { Empathy 4: You always receive details of your account } \\
\text { through SMS/email on your phone or mail. }\end{array}$ & \\
\hline Empathy 5: The bank compensates for a problem they create. & \\
\hline
\end{tabular}


Table 1. Cont.

\begin{tabular}{|c|c|}
\hline Dimensions & Source \\
\hline $\begin{array}{l}\text { Responsiveness 1: Digital banking provides quick } \\
\text { confirmation of the service ordered. }\end{array}$ & \multirow{5}{*}{$\begin{array}{l}\text { (Toor et al. 2016; Jun and } \\
\text { Palacios 2016; Rijwani et al. } \\
\text { 2017; Tharanikaran et al. 2017; } \\
\text { Tumsekcali et al. 2021) }\end{array}$} \\
\hline $\begin{array}{l}\text { Responsiveness 2: Digital banking can handle customer } \\
\text { complaints directly and immediately. }\end{array}$ & \\
\hline $\begin{array}{l}\text { Responsiveness 3: The bank's website provides appropriate } \\
\text { information to customers when a problem occurs. }\end{array}$ & \\
\hline $\begin{array}{l}\text { Responsiveness 4: Digital banking promptly responds to } \\
\text { requests and questions that are made by email or other means. }\end{array}$ & \\
\hline $\begin{array}{l}\text { Responsiveness 5: In digital banking, the bank quickly } \\
\text { resolves problems that you encounter with your } \\
\text { digital transactions. }\end{array}$ & \\
\hline $\begin{array}{l}\text { Customer Satisfaction 1: The bank's website provides precise } \\
\text { information that the user needs. }\end{array}$ & \multirow{5}{*}{$\begin{array}{l}\text { (Toor et al. 2016; Moraru and } \\
\text { Duhnea 2018) }\end{array}$} \\
\hline $\begin{array}{l}\text { Customer Satisfaction 2: The users are satisfied with the } \\
\text { accuracy of data in digital banking. }\end{array}$ & \\
\hline $\begin{array}{l}\text { Customer Satisfaction 3: Digital banking is user friendly and } \\
\text { easy to use. }\end{array}$ & \\
\hline $\begin{array}{l}\text { Customer Satisfaction 4: Digital banking provides up-to-date } \\
\text { information. }\end{array}$ & \\
\hline $\begin{array}{l}\text { Customer Satisfaction 5: The users are satisfied with the } \\
\text { security mechanism of digital banking }\end{array}$ & \\
\hline
\end{tabular}

\section{Results}

To determine the dominant and less important dimension/s of the SERVQUAL model that provide the highest level of risk with regard to customer satisfaction, we carried out a structured survey, which was sent out to Northern Indian banking customers, to which we received 222 valid responses. We subjected the data received to Structural Equation Modelling using the SmartPLS version 3 application software.

Results, as seen below, show reliability and validity since the solution has converged in eight iterations (default $=300$ iterations) (Henseler et al. 2009; Wong 2013; Garson 2016a). In addition, the data are free from multicollinearity issues (can occur in the structural or inner model, even in reflective models) since VIF (Variance Inflation Factor) is below the acceptable threshold of 4.0 (Garson 2016b). The data are also free from outliers. This is evaluated by examining the residuals in the partial least squares (PLS) output. A value of residuals in either the inner or outer model greater than 1.96, at a significance level of 0.05 , is considered as an outlier (Garson 2016a).

\subsection{Confirmatory Tetrad Analysis (CTA) Output}

It is imperative to understand before the analysis whether the model constructs are formative or reflective. Incorrect specifications of measurement models lead to biases in parameter estimation, thereby restricting the accuracy of the assessment of the relationships between the variables (Gudergan et al. 2008). In this context, a technique termed CTA is deployed. This evaluates the cause-effect relationships between the latent variable and its indicators. This technique works by forming tetrads for each variable, taking combinations of four indicators at a time, and then, computing the difference between the product of covariances of one pair to another. If all the tetrads for latent variables vanish, this implies that the model is reflective or the variable has effect indicators; otherwise, the model is formative and the variable has causal indicators (Bollen and Ting 2000). In SmartPLS-CTA output, the operational decision is made by examining the high and low 'Cladj.' columns, which imply confidence interval limits. If zero lies within the confidence limits for each 
tetrad of a latent variable in the model, the variable is reflective, or otherwise, it is formative (Garson 2016c). In this study, for all variables, the CTA analysis confirms that they are reflective. A sample CTA output for one variable ('Tangibility') is depicted in Table 2.

Table 2. CTA output for 'Tangibility'.

\begin{tabular}{ccc}
\hline Tangibility & CI Low adj. & CI Up adj. \\
\hline $\begin{array}{c}\text { 1: TANGIBILITY 1, TANGIBILITY 2, } \\
\text { TANGIBILITY 3, TANGIBILITY 4 }\end{array}$ & -0.160 & 0.069 \\
\hline $\begin{array}{c}\text { 2: TANGIBILITY 1, TANGIBILITY 2, } \\
\text { TANGIBILITY 4, TANGIBILITY 3 }\end{array}$ & -0.043 & 0.141 \\
\hline $\begin{array}{c}\text { 3 TANGIBILITY 1, TANGIBILITY 2, } \\
\text { TANGIBILITY 3, TANGIBILITY 5 }\end{array}$ & -0.054 & 0.226 \\
\hline $\begin{array}{c}\text { 4 TANGIBILITY 1, TANGIBILITY 3, } \\
\text { TANGIBILITY 5, TANGIBILITY 2 }\end{array}$ & -0.029 & 0.095 \\
\hline $\begin{array}{c}\text { 5: TANGIBILITY 1, TANGIBILITY 3, } \\
\text { TANGIBILITY 4, TANGIBILITY 5 }\end{array}$ & -0.175 & 0.187 \\
\hline
\end{tabular}

Source: Smart PLS output (authors' compilation).

\subsection{Explanation of Target Endogenous Variable Variance}

The coefficient of determination R2 for the endogenous variable 'Customer Satisfaction' is 0.783 . This means that the five latent variables (tangibility, reliability, assurance, empathy and responsiveness) explain $78.3 \%$ of the variance in 'Customer Satisfaction'.

\subsection{Inner Model Path Coefficients Sizes and Significance}

The inner model suggests that 'Reliability' has the strongest effect (0.859) on 'Customer Satisfaction' (see Figure 2). All path relations are statistically significant.

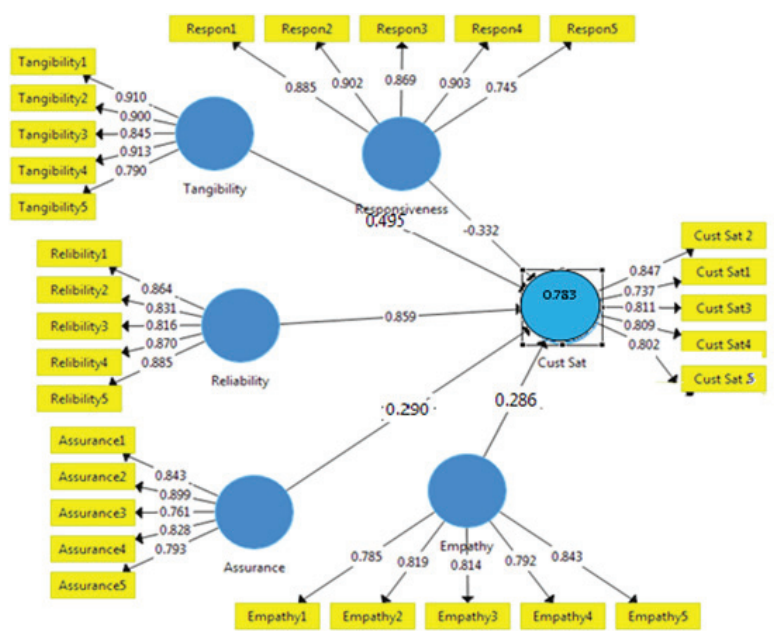

Figure 2. The inner model with path coefficients and coefficient of determination R2. Source: Smart PLS output (authors' compilation).

\subsection{Indicator Reliability}

These figures are computed by squaring the value of the outer loading for all indicators of each latent variable. For research design other than exploratory design, values close to 0.7 or higher are considered acceptable (Hulland 1999; Wong 2013). For all variables, the square of loadings of each of its indicators was computed and the indicator reliability is 
close to 0.7 . The 'Reliability' indicator for all variables (assurance, reliability, tangibility, responsiveness, empathy and customer satisfaction) has been presented in the below tables (Table 3).

Table 3. Summary of Reliability Indicators.

\begin{tabular}{|c|c|c|}
\hline Indicator & Outer Loadings & Indicator Reliability \\
\hline \multicolumn{3}{|c|}{ (a) Reliability Indicator for Assurance } \\
\hline Assurance 1 & 0.843 & 0.711 \\
\hline Assurance 2 & 0.899 & 0.808 \\
\hline Assurance 3 & 0.761 & 0.579 \\
\hline Assurance 4 & 0.828 & 0.686 \\
\hline Assurance 5 & 0.793 & 0.629 \\
\hline \multicolumn{3}{|c|}{ (b) The reliability indicator for Reliability } \\
\hline Reliability 1 & 0.864 & 0.746 \\
\hline Reliability 2 & 0.831 & 0.690 \\
\hline Reliability 3 & 0.816 & 0.665 \\
\hline Reliability 4 & 0.870 & 0.756 \\
\hline Reliability 5 & 0.885 & 0.756 \\
\hline \multicolumn{3}{|c|}{ (c) The reliability indicator for Tangibility } \\
\hline Tangibility 1 & 0.910 & 0.828 \\
\hline Tangibility 2 & 0.900 & 0.81 \\
\hline Tangibility 3 & 0.845 & 0.714 \\
\hline Tangibility 4 & 0.913 & 0.833 \\
\hline Tangibility 5 & 0.790 & 0.624 \\
\hline \multicolumn{3}{|c|}{ (d) The reliability indicator for Responsiveness } \\
\hline Responsiveness 1 & 0.885 & 0.783 \\
\hline Responsiveness 2 & 0.902 & 0.813 \\
\hline Responsiveness 3 & 0.869 & 0.755 \\
\hline Responsiveness 4 & 0.903 & 0.815 \\
\hline Responsiveness 5 & 0.745 & 0.555 \\
\hline \multicolumn{3}{|c|}{ (e) The reliability indicator for Empathy } \\
\hline Empathy 1 & 0.785 & 0.616 \\
\hline Empathy 2 & 0.819 & 0.670 \\
\hline Empathy 3 & 0.814 & 0.662 \\
\hline Empathy 4 & 0.792 & 0.627 \\
\hline Empathy 5 & 0.843 & 0.710 \\
\hline \multicolumn{3}{|c|}{ (f) The reliability indicator for Customer Satisfaction } \\
\hline Customer Satisfaction 1 & 0.737 & 0.543 \\
\hline Customer Satisfaction 2 & 0.847 & 0.717 \\
\hline Customer Satisfaction 3 & 0.811 & 0.657 \\
\hline Customer Satisfaction 4 & 0.809 & 0.654 \\
\hline Customer Satisfaction 5 & 0.802 & 0.643 \\
\hline
\end{tabular}

Source: Smart PLS output (authors' compilation).

\subsection{Internal Consistency Reliability and Convergent Validity}

Traditionally, internal consistency reliability and convergent validity have been assessed using Cronbach's alpha, and this coefficient can take values from 0 to 1 ; a value for a scale less than 0.6 is considered unsatisfactory (Malhotra 2019). Researchers also assess 'Composite Reliability', since Cronbach's alpha is deemed as a conservative measure. Similarly, to assess convergent validity, the Average Variance Extracted (AVE) for each latent variable is examined and should have a value greater than the acceptable minimum of 0.5 (Wong 2013; Hair et al. 2012).

Table 4 is a summary of the results for internal consistency reliability and convergent validity. Average Variance Extracted, calculated with the help of Cronbach's alpha, shows 
that both internal consistency reliability and convergent validity are confirmed because all values are more than 0.5 .

Table 4. Results summary.

\begin{tabular}{llll}
\hline & Cronbach's Alpha & Composite Reliability & $\begin{array}{c}\text { Average Variance } \\
\text { Extracted (AVE) }\end{array}$ \\
\hline Assurance & 0.739 & 0.884 & 0.793 \\
Empathy & 0.716 & 0.859 & 0.752 \\
Reliability & 0.798 & 0.861 & 0.756 \\
Responsiveness & 0.734 & 0.883 & 0.79 \\
Tangibility & 0.924 & 0.943 & 0.767 \\
Customer Satisfaction & 0.794 & 0.879 & 0.708 \\
\hline
\end{tabular}

Source: Smart PLS output (authors' compilation).

As is evident from the values in the table, both internal consistency reliability and convergent validity are confirmed.

\subsection{Discriminant Validity}

To establish discriminant validity, the Fornell-Larcker criteria (Fornell and Larcker 1981) are used. This suggests whether the square root of each latent variable's AVE is larger than other correlation values among other latent variables. The square root of AVE in every latent variable should be more than other correlation values among the latent variables. Table 5 shows that the latent variables satisfy the Fornell-Larcker criteria, and hence, discriminant validity can be assumed.

Table 5. Discriminant validity computations for each latent variable.

\begin{tabular}{lllllll}
\hline & Asr & CSat & Emp & Rel & Resp & Tang \\
\hline Asr & 0.826 & & & & & \\
\hline CSat & 0.497 & 0.802 & & & & \\
\hline Emp & 0.276 & 0.409 & 0.811 & & & \\
\hline Rel & 0.293 & 0.501 & 0.624 & 0.854 & & \\
\hline Resp & 0.816 & 0.361 & 0.005 & 0.095 & 0.863 & \\
\hline Tang & 0.724 & 0.369 & 0.51 & 0.655 & 0.787 & 0.873 \\
\hline
\end{tabular}

Source: Smart PLS output (authors' compilation). Note: Table cells contain the square root of AVE (diagonal elements) and correlation between latent variables in other cells. (Latent variables are abbreviated as Asr-Assurance; Emp-Empathy; Rel—Reliability; Resp-Responsiveness; Tan—Tangibility; CSat—Customer Satisfaction).

\subsection{Structural Path Significance in Bootstrapping}

The $\mathrm{T}$ statistics of the inner path model is shown in Table 6. At a confidence level of 0.05 , the path coefficients are significant if the T-statistics are larger than 1.96. As is evident from the table values, the T-statistics values are consistent with path coefficient findings.

Table 6. T-statistics of the inner model.

\begin{tabular}{ll}
\hline & T Statistics \\
\hline Reliability $\rightarrow$ Customer Satisfaction & 6.923 \\
Tangibility $\rightarrow$ Customer Satisfaction & 5.764 \\
Responsiveness $\rightarrow$ Customer Satisfaction & 3.605 \\
Empathy $\rightarrow$ Customer Satisfaction & 2.293 \\
Assurance $\rightarrow$ Customer Satisfaction & 2.709 \\
\hline Source: Smart PLS output (authors' compilation).
\end{tabular}

The same is valid for the outer model. All T-statistics values in the outer model are greater than the threshold of 1.96 . 


\subsection{Effect Sizes}

The analysis of effect sizes measures the change in R2 (effect on endogenous variables) arising from casual/exogenous factors (Cohen 1992). This describes three effect sizes: '0.02' as a small effect size, ' $0.15^{\prime}$ as a medium effect size and ' $0.35^{\prime}$ as a large effect size. This effect size, also termed as a change in $\mathrm{R} 2$ or simply as $\mathrm{f} 2$, is used to determine the statistical power or quantitative effect of one variable on another. The table below depicts the effect sizes for two endogenous variables 'Person-Organisation fit' and 'Job Satisfaction', indicating their influence (Brecht et al. 2012).

Table 7 shows that 'Reliability' has a stronger effect on the model, while 'Responsiveness' and 'Tangibility' have moderate effects and 'Empathy' and 'Assurance' have a small effect. The same was evident from the structural path coefficients as discussed before.

Table 7. Effect sizes.

\begin{tabular}{lccccc}
\hline & Reliability & Tangibility & Responsiveness & Empathy & Assurance \\
\hline $\begin{array}{l}\mathrm{f}^{2} \text { (Customer } \\
\text { Satisfaction) }\end{array}$ & 0.346 & 0.240 & 0.124 & 0.095 & 0.021 \\
\hline Source: Smart PLS output (authors' compilation).
\end{tabular}

\section{Discussion and Conclusions}

The purpose of this study is to determine the impact intensity of digital banking service quality on customer satisfaction in the banking sector in North India using the classic fivedimensional SERVQUAL model: specifically, reliability, assurance, tangibility, empathy and responsiveness. We hypothesize and aim to confirm that these five dimensions of the SERVQUAL model have a significant impact on customer satisfaction.

To confirm our hypotheses, we use confirmatory tetrad analysis (CTA) to evaluate the cause-effect relationships between the latent variable and its indicators. With the CTA technique, we formed tetrads for each dimension, taking a combination of four indicators at a time, and then computing the difference between the product of covariances of one pair on another; the results confirmed that all the dimensions of service quality are reflective. In addition, we also determined the dominant and less important dimension/s of the SERVQUAL model that provide the highest level of risk with regard to customer satisfaction. To reflect the strength in the relationship between the service quality dimensions and customer satisfaction, an inner model with path coefficients and coefficient of determination R2 was applied. As per the inner model, 'Reliability' has a more dominant and significant relationship (0.859) with customer satisfaction. This confirms $\mathrm{H} 2$, meaning that for customers in the new digital age, the ability to deliver services accurately, on time and reliably is assessed as dominant. This requires consistency in the implementation of services, respecting commitments and keeping promises to customers.

'Tangibility' (0.459) and 'Responsiveness' (0.332) have a less dominant relationship with customer satisfaction as compared to 'Reliability', but they still have a significant impact on customer satisfaction. This allows us to confirm H1 and H5. Tangibility relates to the appearance of the facilities, equipment, attitude of staff, materials, and information systems of the bank. This shows that digital-friendly services are considered very important in the new digital age but less important than 'Reliability'. The significance of 'Responsiveness', on the other hand, confirms that customers value the ability to resolve a problem quickly, handle customer complaints effectively, and the willingness to help and satisfy customers.

'Assurance' (0.290) and 'Empathy' (0.286) have a significant relationship with customer satisfaction. Therefore, we can confirm $\mathrm{H} 3$ and H4. Banks need to show credibility and ensure trust from customers, through professional services, excellent technical knowledge, a courtesy attitude and good communication skills. They also need to empathize with clients. However, these skills and attitudes are less important than the previous dimensions mentioned above (reliability, tangibility and responsiveness). 
Therefore, as noted above, the analysis reveals that customers in the northern region of India are genuinely satisfied with the service quality of digital banking. Overall, the results of the study proved the fact that 'Reliability' has a strong impact on customer satisfaction, followed by 'Tangibility' and 'Responsiveness'. Therefore, they are more important to risk managers and policymakers.

This study also suggests that all banks should provide accurate, reliable information, timely updates, maintenance of accounts, and error-free transactions while providing digital banking services. In addition, banks need to work on providing services that are easy, convenient, and visually appealing with error-free transactions to enhance tangibility and responsiveness. This is consistent with the findings of Loonam and O'Loughlin (2008), mentioned above, who have concluded that the most important factors for online banking services are trust, access, web usability and flexibility.

The findings that, in India, customers generally evaluate digital banking service quality based mainly on three dimensions ('Reliability', 'Tangibility' and 'Responsiveness') and give less importance to 'Assurance' and 'Empathy' are consistent with studies by Ozretic-Dosen and Zizak (2015), mentioned above, who found that management needs to improve banking services in these major dimensions, i.e., reliability, assurance and responsiveness, to ensure customer satisfaction.

Similarly, Raza et al. (2015) are also of the view that management of internet banking should focus more on creating websites that are visually appealing to attract new customers as well as to retain existing ones. Customers demand more dependable and consistent services from banks. They demand to feel comfortable, confident and assured. Conversely, the study conducted by Chong et al. (2010) in Vietnam showed that perceived utility trust and government support were all significantly related to intentions to utilize online banking. Contrary to this, perceived ease of use was not found to be relevant.

The findings by Dinçer et al. (2019) show that, in Turkey, the most important dimension is 'Responsiveness', whereas costs and earnings are the least important dimension. They also stressed that information technology infrastructure is the most important criterion in customer satisfaction and banks should invest in improving their technological infrastructure to satisfy the expectations of the customers.

Zhou et al.'s (2021) study on factors affecting service quality and loyalty intention in mobile banking in China showed that provision of a stable, secure and accurate mobile banking system, with fast response and efficient services (e.g., paying, transaction, credit card services, etc.), can ensure customers trust their mobile banking provider. Pakurár et al. (2019), on the other hand, found in their study of Jordanian banks that assurance, reliability, access, and employee competencies are the most important dimensions to ensure customer satisfaction followed by responsiveness, empathy and financial aspects; tangibility was the least important.

The authors' other conclusions discussed above confirm that the five dimensions of the SERVQUAL model are still relevant to identify the impact on customer satisfaction and, therefore, the risk of variance. However, the prevalence of each dimension differs depending on the preferences of customers in different countries. Banks should focus on enhancing consistency in service delivery and adherence to commitments, and keeping promises made to customers. Banks must concentrate on customer trust, primarily to raise awareness that funds are safe and available at the time and in the form that the customer chooses. To build trust, banks must minimize risk and provide safe, reliable, responsive, sustainable and always available services. The pace of digital banking adoption is growing steadily, and the need to scale reliable services has never been greater.

Customer satisfaction depends on a bank's ability to deliver the right content to the right people at the right time. The channels that banks use to communicate with customers and potential clients are advertising, SEO, drip campaigns, social media, etc. To meet customer needs, marketers must spend more time planning and producing educational written content, making the most of the latest visual storytelling techniques. 
The study suggests that all banks should provide accurate, reliable information, timely updates, maintenance of accounts, and error-free transactions while providing digital banking services. In addition, banks need to work on providing services that are easy, convenient and visually appealing with error-free transactions to enhance tangibility and responsiveness.

Finally, the government also plays a role in assisting banks in increasing digital banking acceptance. To increase the acceptance rate towards digital banking and to combat the resistance level of consumers, the government should lay down certain policies related to digital crimes and establish proper and clear arrangements for remedy or compensation of wrongdoing or grievances.

Our study is not without limitations. Although the response rate to our survey is satisfactory, respondents still cover only a subset of customers in India. For future research and discussion in the context of Indian customer satisfaction with digital banking, it would be beneficial to attract more customers from other regions of India. In addition to this research, it would be very interesting to study what factors influence the preferences of customers in different countries, for example, the level of wealth of the country, religion, etc.

Despite these limitations, this paper provides unique analytical evidence on customer satisfaction in the context of the banking sector in the digital age by taking a practical view of the situation of banks in Northern India. Our findings have practical implications for risk managers, banking practitioners, policymakers and marketing personnel. The SERVQUAL model can be similarly used in different regions and countries to help in the development of digital operations, systems and applications, which will ensure customer satisfaction and retention of clients as much as possible.

Author Contributions: B.K., S.K. were the principal researchers and prepared the first draft of the article. B.K., S.K. participated in collecting the data and statistical analysis of the study S.G., R.R.-A. Refined the draft into a publishable article and added valuable theoretical and methodological insights based on their knowledge and expertise regarding the topic. All authors have read and agreed to the published version of the manuscript.

Funding: This research was funded by Latvian Council of Science, grant number LZP-2020/2-0061, project DigiSMEs.

Data Availability Statement: Data are available from authors upon reasonable request.

Conflicts of Interest: The authors declare no conflict of interest.

\section{References}

Amin, Muslim. 2016. Internet Banking Service Quality and Its Implication on E-Customer Satisfaction and e-Customer Loyalty. International Journal of Bank Marketing 34: 280-306. [CrossRef]

Awan, Usama, Andrzej Kraslawski, and Janne Huiskonen. 2020. Progress from Blue to the Green World: Multilevel Governance for Pollution Prevention Planning and Sustainability. In Handbook of Environmental Materials Management. Edited by Chaudhery Mustansar Hussain. Cham: Springer, pp. 1-22. [CrossRef]

Awasthi, Anjali, Satyaveer S. Chauhan, Hichem Omrani, and Ariyo Panahi. 2011. A Hybrid Approach Based on SERVQUAL and Fuzzy TOPSIS for Evaluating Transportation Service Quality. Computers and Industrial Engineering 61: 637-46. [CrossRef]

Bauer, Hans H., Maik Hammerschmidt, and Tomas Falk. 2005. Measuring the Quality of E-banking Portals. International Journal of Bank Marketing 23: 153-75. [CrossRef]

Bollen, Kenneth A., and Kwok-fai Ting. 2000. A Tetrad Test for Causal Indicators. Psychological Methods 5: 3-22. [CrossRef]

Braun, Virginia, and Victoria Clarke. 2006. Using Thematic Analysis in Psychology. Qualitative Research in Psychology 3: 77-101. [CrossRef]

Brecht, Franziska, Andreas Eckhardt, Christian Berger, and Oliver Guenther. 2012. Corporate Career Presences on Social Network Sites: An Analysis of Hedonic and Utilitarian Value. In Proceedings of the SIGCHI Conference on Human Factors in Computing Systems. New York: Association for Computing Machinery, pp. 2441-50. [CrossRef]

Carrasco, Ramón A., Francisco Muñoz-Leiva, Juan Sánchez-Fernández, and Francisco J. Liébana-Cabanillas. 2012. A Model for the Integration of E-Financial Services Questionnaires with SERVQUAL Scales under Fuzzy Linguistic Modeling. Expert Systems with Applications 39: 11535-47. [CrossRef] 
Chingang Nde, Daniel, and Paul Lukong. 2010. Using the SERVQUAL Model to Assess Service Quality and Customer Satisfaction: An Empirical Study of Grocery Stores in Umeå. Available online: http:/ / urn.kb.se/resolve?urn=urn:nbn:se:umu:diva-35008 (accessed on 15 October 2021).

Chong, Alain Yee-Loong, Keng-Boon Ooi, Binshan Lin, and Boon-In Tan. 2010. Online Banking Adoption: An Empirical Analysis. International Journal of Bank Marketing 28: 267-87. [CrossRef]

Cohen, Jacob. 1992. A Power Primer. Psychological Bulletin 112: 155-59. [CrossRef]

Deb, Madhurima, and Ewuuk Lomo-David. 2014. An Empirical Examination of Customers' Adoption of m-Banking in India. Marketing Intelligence $\mathcal{E}$ Planning 32: 475-94. [CrossRef]

Dinçer, Hasan, Serhat Yüksel, and Luis Martínez. 2019. Analysis of Balanced Scorecard-Based SERVQUAL Criteria Based on Hesitant Decision-Making Approaches. Computers \& Industrial Engineering 131: 1-12. [CrossRef]

Farrugia, Andre, and Simon Grima. 2021. A Model to Determine the Need to Modernise the Regulation of the Principle of Utmost Good Faith. Journal of Financial Regulation and Compliance 29: 454-73. [CrossRef]

Fernández-Rovira, Cristina, Jesús Álvarez Valdés, Gemma Molleví, and Ruben Nicolas-Sans. 2021. The Digital Transformation of Business. Towards the Datafication of the Relationship with Customers. Technological Forecasting and Social Change 162: 120339. [CrossRef]

Fornell, Claes, and David F. Larcker. 1981. Evaluating Structural Equation Models with Unobservable Variables and Measurement Error. Journal of Marketing Research 18: 39-50. [CrossRef]

Garson, David G. 2016a. Analysis Residuals in Partial Least Squares: Regression and Structural Equation Models. Asheboro: Statistical Associates Publishers. Available online: http://www.statisticalassociates.com/pls-sem.htm (accessed on 9 September 2021).

Garson, David G. 2016b. Confirmatory Tetrad Analysis in Partial Least Squares: Regression and Structural Equation Models. Asheboro: Statistical Associates Publishers. Available online: http://www.statisticalassociates.com/pls-sem.htm (accessed on 9 September 2021).

Garson, David G. 2016c. Multicollinearity Analysis in Reflective Models in Partial Least Squares: Regression and Structural Equation Models. Asheboro: Statistical Associates Publishers.

Girlando, Alessandra, Simon Grima, Engin Boztepe, Sharon Seychell, Ramona Rupeika-Apoga, and Inna Romanova. 2021. Individual Risk Perceptions and Behavior. In Contemporary Studies in Economic and Financial Analysis. Edited by Simon Grima, Ercan Özen and Hakan Boz. Bingley: Emerald Publishing Limited, pp. 367-436. [CrossRef]

Grima, Simon, Murat Kizilkaya, Ramona Rupeika-Apoga, Inna Romānova, Rebecca Dalli Gonzi, and Mihajlo Jakovljevic. 2020. A Country Pandemic Risk Exposure Measurement Model. Risk Management and Healthcare Policy 13: 2067-77. [CrossRef] [PubMed]

Grima, Simon, Bahattin Hamarat, Ercan Özen, Alessandra Girlando, and Rebecca Dalli-Gonzi. 2021a. The Relationship between Risk Perception and Risk Definition and Risk-Addressing Behaviour during the Early COVID-19 Stages. Journal of Risk and Financial Management 14: 272. [CrossRef]

Grima, Simon, Murat Kizilkaya, Kiran Sood, and Mehmet ErdemDelice. 2021b. The Perceived Effectiveness of Blockchain for Digital Operational Risk Resilience in the European Union Insurance Market Sector. Journal of Risk and Financial Management 14: 363. [CrossRef]

Gudergan, Siegfried P., Christian M. Ringle, Sven Wende, and Alexander Will. 2008. Confirmatory Tetrad Analysis in PLS Path Modeling. Journal of Business Research Formative Indicators 61: 1238-49. [CrossRef]

Hair, Joe F., Marko Sarstedt, Christian M. Ringle, and Jeannette A. Mena. 2012. An Assessment of the Use of Partial Least Squares Structural Equation Modeling in Marketing Research. Journal of the Academy of Marketing Science 40: 414-33. [CrossRef]

Henseler, Jörg, Christian M. Ringle, and Rudolf R. Sinkovics. 2009. The Use of Partial Least Squares Path Modeling in International Marketing. In Advances in International Marketing. Edited by R. R. Sinkovics and P. N. Ghauri. Bingley: Emerald Group Publishing Limited, pp. 277-319.

Hinkin, Timothy R. 1995. A Review of Scale Development Practices in the Study of Organizations. Journal of Management $21: 23$. [CrossRef]

Hulland, John. 1999. Use of Partial Least Squares (PLS) in Strategic Management Research: A Review of Four Recent Studies. Strategic Management Journal 20: 195-204. [CrossRef]

Ijadi Maghsoodi, Abteen, Abbas Saghaei, and Ashkan Hafezalkotob. 2019. Service Quality Measurement Model Integrating an Extended SERVQUAL Model and a Hybrid Decision Support System. European Research on Management and Business Economics 25: 151-64. [CrossRef]

Japparova, Irina, and Ramona Rupeika-Apoga. 2017. Banking Business Models of the Digital Future: The Case of Latvia. European Research Studies Journal 20: 864-78. [CrossRef]

Jun, Minjoon, and Sergio Palacios. 2016. Examining the Key Dimensions of Mobile Banking Service Quality: An Exploratory Study. International Journal of Bank Marketing 34: 307-26. [CrossRef]

Karjaluoto, Heikki, Minna Mattila, and Tapio Pento. 2002. Factors Underlying Attitude Formation towards Online Banking in Finland. International Journal of Bank Marketing 20: 261-72. [CrossRef]

Kuisma, Tuire, Tommi Laukkanen, and Mika Hiltunen. 2007. Mapping the Reasons for Resistance to Internet Banking: A Means-End Approach. International Journal of Information Management 27: 75-85. [CrossRef]

Laforet, Sylvie, and Xiaoyan Li. 2005. Consumers' Attitudes towards Online and Mobile Banking in China. International Journal of Bank Marketing 23: 362-380. [CrossRef] 
Laidroo, Laivi, Ekaterina Koroleva, Agata Kliber, Ramona Rupeika-Apoga, and Zana Grigaliuniene. 2021. Business Models of FinTechs-Difference in Similarity? Electronic Commerce Research and Applications 46: 101034. [CrossRef]

Lau, Mei Mei, Ronnie Cheung, Aris Y. C. Lam, and Yuen Ting Chu. 2013. Measuring Service Quality in the Banking Industry: A Hong Kong Based Study. Contemporary Management Research 9: 263-282. [CrossRef]

Leal Filho, Walter, Anabela Marisa Azul, Luciana Brandli, Pinar Gökcin Özuyar, and Tony Wall, eds. 2020. Responsible Consumption and Production. Encyclopedia of the UN Sustainable Development Goals; Cham: Springer. [CrossRef]

Lizarelli, Fabiane L., Lauro Osiro, Gilberto M. D. Ganga, Glauco H. S. Mendes, and Guilherme R. Paz. 2021. Integration of SERVQUAL, Analytical Kano, and QFD Using Fuzzy Approaches to Support Improvement Decisions in an Entrepreneurial Education Service. Applied Soft Computing 112: 107786. [CrossRef]

Loonam, Mary, and Deirdre O'Loughlin. 2008. Exploring E-service Quality: A Study of Irish Online Banking. Marketing Intelligence E Planning 26: 759-80. [CrossRef]

Malhotra, Naresh K. 2019. Marketing Research: An Applied Orientation, 7th ed. Upper Saddle River: Pearson. Available online: https://www.pearson.com/content/one-dot-com/one-dot-com/us/en/higher-education/program.html (accessed on 14 September 2021).

Moraru, Andreea-Daniela, and Cristina Duhnea. 2018. E-Banking and Customer Satisfaction with Banking Services. Strategic Management 23: 3-9. [CrossRef]

Nui Polatoglu, Vichuda, and Serap Ekin. 2001. An Empirical Investigation of the Turkish Consumers' Acceptance of Internet Banking Services. International Journal of Bank Marketing 19: 156-65. [CrossRef]

Ozretic-Dosen, Durdana, and Ines Zizak. 2015. Measuring the Quality of Banking Services Targeting Student Population. EuroMed Journal of Business 10: 98-117. [CrossRef]

Pakurár, Miklós, Hossam Haddad, János Nagy, József Popp, and Judit Oláh. 2019. The Service Quality Dimensions That Affect Customer Satisfaction in the Jordanian Banking Sector. Sustainability 11: 1113. [CrossRef]

Parasuraman, A., Valarie A. Zeithaml, and Leonard L. Berry. 1988. SERVQUAL: A Multiple-Item Scale for Measuring Consumer Perceptions of Service Quality. Undefined 64: 12-40.

Pavia, Luke, Simon Grima, Inna Romanova, and Jonathan V. Spiteri. 2021. Fine Art Insurance Policies and Risk Perceptions: The Case of Malta. Journal of Risk and Financial Management 14: 66. [CrossRef]

Raza, Syed Ali, Syed Tehseen Jawaid, and Ayesha Hassan. 2015. Internet Banking and Customer Satisfaction in Pakistan. Qualitative Research in Financial Markets 7: 24-36. [CrossRef]

Rijwani, Parag, Ritesh Patel, and Nikunj Patel. 2017. Service Quality and Customer Satisfaction: Study of Indian Banks Using SERVQUAL. International Journal of Economic Research 14: 199-211.

Rupeika-Apoga, Ramona, and Stefan Wendt. 2021. FinTech in Latvia: Status Quo, Current Developments, and Challenges Ahead. Risks 9: 181. [CrossRef]

Sohail, M. Sadiq, and Balachandran Shanmugham. 2003. E-Banking and Customer Preferences in Malaysia: An Empirical Investigation. SSRN Scholarly Paper ID 2650354. Rochester: Social Science Research Network. [CrossRef]

Tharanikaran, Vadivelu, Sutha Sritharan, and Vadivelu Thusyanthy. 2017. Service Quality and Customer Satisfaction in the Electronic Banking. International Journal of Business and Management 12: 67. [CrossRef]

Toor, Areeba, Mudassir Hunain, T. Hussain, Shoaib Ali, and Adnan Shahid. 2016. The Impact of E-Banking on Customer Satisfaction: Evidence from Banking Sector of Pakistan. Journal of Business Administration Research 5: 27-40. [CrossRef]

Tumsekcali, Ecem, Ertugrul Ayyildiz, and Alev Taskin. 2021. Interval Valued Intuitionistic Fuzzy AHP-WASPAS Based Public Transportation Service Quality Evaluation by a New Extension of SERVQUAL Model: P-SERVQUAL 4.0. Expert Systems with Applications 186: 115757. [CrossRef]

Wong, Ken Kwong-Kay. 2013. Partial Least Squares Structural Equation Modeling (PLS-SEM) Techniques Using SmartPLS. Marketing Bulletin 24: 32.

Worku, G., A. Tilahun, and M. A. Tafa. 2016. The Impact of Electronic Banking on Customers' Satisfaction in Ethiopian Banking Industry (The Case of Customers of Dashen and Wogagen Banks in Gondar City). Journal of Business E Financial Affairs 5: 2-18. [CrossRef]

Zaidi, Syeda H., and Ramona Rupeika-Apoga. 2021. Liquidity Synchronization, Its Determinants and Outcomes under Economic Growth Volatility: Evidence from Emerging Asian Economies. Risks 9: 43. [CrossRef]

Zeithaml, Valarie A., Ananthanarayanan Parasuraman, and Leonard L. Berry. 1990. Delivering Quality Service: Balancing Customer Perceptions and Expectations. New York and London: Free Press and Collier Macmillan.

Zhou, Qingji, Fong Jie Lim, Han Yu, Gaoqian Xu, Xiaoyu Ren, Dan Liu, Xiangxin Wang, Xinda Mai, and Hong Xu. 2021. A Study on Factors Affecting Service Quality and Loyalty Intention in Mobile Banking. Journal of Retailing and Consumer Services 60: 102424. [CrossRef]

Zouari, Ghazi, and Marwa Abdelhedi. 2021. Customer Satisfaction in the Digital Era: Evidence from Islamic Banking. Journal of Innovation and Entrepreneurship 10: 9. [CrossRef] 


\title{
Triggers and Obstacles to the Development of the FinTech Sector in Poland
}

\author{
Agata Kliber ${ }^{1, *}$, Barbara Będowska-Sójka ${ }^{2}$, Aleksandra Rutkowska ${ }^{3}$ and Katarzyna Świerczyńska ${ }^{4}$ \\ 1 Department of Applied Mathematics, Poznań University of Economic and Business, al. Niepodległości 10, \\ 61-875 Poznań, Poland \\ 2 Department of Econometrics, Poznań University of Economic and Business, al. Niepodległości 10, \\ 61-875 Poznań, Poland; barbara.bedowska-sojka@ue.poznan.pl \\ 3 Department of Applied Mathematic, Poznań University of Economic and Business, al. Niepodległości 10 \\ 61-875 Poznań, Poland; aleksandra.rutkowska@ue.poznan.pl \\ 4 Department of Economic Journalism and Public Relations, Poznań University of Economic and Business, \\ al. Niepodległości 10, 61-875 Poznań, Poland; katarzyna.swierczynska@ue.poznan.pl \\ * Correspondence: agata.kliber@ue.poznan.pl; Tel.: +48-61-854-3875
}

Citation: Kliber, Agata, Barbara Będowska-Sójka, Aleksandra Rutkowska, and Katarzyna Swierczyńska. 2021. Triggers and Obstacles to the Development of the FinTech Sector in Poland. Risks 9: 30. https://doi.org/10.3390/risks9020030

Academic Editor: Ramona

Rupeika-Apoga

Received: 15 December 2020

Accepted: 22 January 2021

Published: 1 February 2021

Publisher's Note: MDPI stays neutral with regard to jurisdictional clai-ms in published maps and institutio-na affiliations.

Copyright: (C) 2021 by the authors. Licensee MDPI, Basel, Switzerland. This article is an open access article distributed under the terms and conditions of the Creative Commons Attribution (CC BY) license (https:// creativecommons.org/licenses/by/ $4.0 /)$.

\begin{abstract}
The article aims to show the opportunities for the formation of new FinTech startups in Poland and further development of the sector, as well as to identify the most critical threats. The study offers the descriptive and deductive analysis based on the literature review. The empirical part relies on the data from external databases as well as the dataset collected in a survey run among the FinTechs in Poland in January 2020. The paper reveals that Poland is a fast-growing FinTech market which satisfies various requirements such as the number of secure Internet servers, mobile telephone subscriptions, the available labor force, as well as growing tertiary education enrolment. The crucial obstacles to the development of the sector is the uncertainty about the availability of skilled workers in the future and the lack of proper legal regulations.
\end{abstract}

Keywords: FinTech; development; economic environment

\section{Introduction}

The term 'FinTech', which is an abbreviation from Financial Technology, refers to software and other modern technologies used by a business that provides automated and improved financial services. ${ }^{1}$ They introduce new financial products and offer them through disruptive technologies. FinTech is a good example of how innovation is ahead of regulation (Liu et al. 2020). Such entities began to flourish in the 1990s, together with the rapid increase of the internet, e-commerce businesses, and digitalization of banking and financial services. Some argue that also the Global Financial Crisis in 2008, in which many people lost their trust in traditional banking systems, became a driver of the development of this sector (Eddie 2020).

The FinTech sector develops worldwide, but the pace and the direction of this development are different in each country. According to the "Global FinTech Report" of PWC (2019), almost half of all firms in both financial services and technology, media and comunications (TMT) have fully incorporated FinTech-based products and services into their strategic operating models. Furthermore, more than half of banks and capital-markets companies have added emerging technologies solutions into commercial banking and personal loans. According to Deloitte report (Deloitte 2019), FinTechs have entered a new phase of their evolution from a formidable competitor to a trusted partner.

When it comes to geographical segmentation, China seems to be the FinTech-leader (PWC 2019): more than three-fourths of all products and services are supported with

1 https://www.FinTechweekly.com/fintech-definition. 
Insuretech, while two-thirds offer robo-advices. Brazil takes second place in the ranking. PWC report (PWC 2019) states that organisations in China and Brazil are more likely to fully embed FinTechs across their strategic operating model ( $58 \%$ and $55 \%$, respectively), compared with organisations in the developed economies such as the U.S. and Germany ( $37 \%$ and $36 \%$, respectively). This is mainly due to the legislation and regulations-in China, the regulators are keen to promote FinTech-related innovations, while the European FinTechs are struggling more with the legacy, complexity, and cost structures.

The report titled "New Financial Geographies of Asia" of Lai et al. (2020) shows that while the capital markets in Asia are fast-growing, the Western banks experience serious problems in the region. Asian investment banks have gained more importance not only on the continent but also globally. So far, Hong Kong, Singapore, and Tokyo have been considered well-established international financial centers. The rise of financial centers in China suggests that the global financial landscape may be significantly re-designed in the nearest future (Lai et al. 2020).

Contrary to that, Dealroom and Finch Capital (2019) show that the FinTech sector is more active in Europe than in Asia or the U.S., creating 150 billion euro in value. However, the regional reports demonstrate that the European market itself is also very diversified: FinTechs in smaller countries like Latvia, Lithuania, and Estonia are much more internationalized and diversified than those in larger countries (Laidroo et al. 2021).

This study is focused on the factors that support formation of new FinTech companies and the development of the whole FinTech sector in Poland. This is one of the biggest economies in the Central Europe, and the Polish market is also the biggest FinTech market in the Central and Eastern Europe, with an estimated value of 856 million euro (CEE Capital Market Leaders Forum 2019). It belongs to the group of post-communist countries which joined the European Union in 2004. When compared to the Western economies, it is characterized by higher speed of digitalization and a quicker adoption of financial innovations (GlobalData 2017). On the similar basis as the Asian tigers (Lai et al. 2020), the development of the FinTech sector seems to be not limited by the traditional perception of the financial system.

It is worth to note that the Polish FinTech market so far was mainly analysed by commercial analytic companies within technical reports (e.g., Flanders Investment and Trade (2018); Kliber et al. (2020); Microfinance Centre (2019)). To the best of the authors' knowledge, the only scientific publications about the Polish market include: Klimontowicz and Mitrega-Niestroj (2019), where the authors present the FinTech ecosystem, taxonomy of the Polish FinTech companies and the analysis of the financial market, Anielak (2019), who discussess innovativeness of Polish FinTechs, as well as Staszewska (2018) who analyses the interactions between the Polish FinTech and the banking sector. Thus the Polish FinTech sector has not been analysed thoroughly. Our article aims to fill this gap.

In the first step of our research, we provide an analysis of the publications that focus on the factors that support and accelerate FinTech start-ups' formation. Next, we analyse the Polish FinTech ecosystem concerning different criteria. Our analysis is based on the data obtained from the scientific databases and confronted with the results of the survey run among the companies from the Polish FinTech sector in January 2020 (see Kliber et al. (2020) for a detailed description of the survey results). Eventually, we identify the main obstacles that pose risk to the FinTech development. We analyse the statistical data and the responses from our survey to identify such threads in the Polish market. In the concluding section of our paper, we formulate policy implications.

We adopt descriptive and deductive approach in this study to address our main research goal, namely to identify obstacles and incentives for the FinTech growth in Poland. We apply a comparative analysis in order to assess the characteristics of the Polish market vs. other markets. We also apply a system analysis to identify the interactions between the economic, social, political and legal factors which all together create the environment for the FinTechs to operate. 
The main contribution of this paper is the creation of a methodological framework to assess FinTech sector growth potential. We chose parameters and provided measures which allow to approximate country performance. Based on this, we identified risks and opportunities for FinTech firms in Poland. Our implications can be applied by the policymakers as we provide a screenshot of political, social, economic, and legal conditions for the sector's further development and we systematise it in the context of other countries' performance. In future research, we plan to apply this method and provide a broader regional and World FinTech potential map.

It is not certain how the COVID-19 and the resulting recession will impact the FinTech sector. Some authors note that FinTech start-ups may struggle with access to funding. Knight and Wojcik (2020) say, however, that the pandemic has weakened incumbent financial institutions and stimulated the openness to digital finance solutions among consumers. Therefore, it is of the special importance to analyse the current situation of the sector and recognize its strengths and possible sources of risk in the economic and legal environment. These need to be improved to allow for the further development of this sector. Throughout the article, we try to defend the thesis that although Poland has a very good initial condition to support the formation of FinTech companies, there are obstacles that may restrain the development of the sector.

\section{Literature Review}

The literature focused on the development of FinTechs has been rising over a few years. First of all, the researchers are interested in the FinTech business models (Eickhoff et al. 2017; Laidroo et al. 2021; Lee and Shin 2018; Sannino et al. 2020). Liu et al. (2020) provide an overview of the 10-years history of research on the FinTechs topic, through the analysis of the 629 FinTech business model papers in the Web of Science database. The authors conclude that the most hot-topic in FinTech research are mobile payment, microfinance, peer-to-peer lending platform, and crowdfunding. They also suggest that the Blockchain and crowdfunding would dominate FinTech research in the nearest future.

There is a strand in the literature that discusses and analyses the interaction of FinTechs with banks and financial systems. FinTechs with the whole financial technology ecosystem have a disruptive impact on the financial services industry (Palmié et al. 2020). Bunea et al. (2016) analysed explicit mentions of competition from FinTech in the annual reports of the U.S. banks and found that there were no such remarks before 2016. The authors identified 14 banks that acknowledge being threatened by FinTech companies. The banks represented $3 \%$ of the banking sector by count but nearly a third of its assets. The results of Siek and Sutanto (2019) based on the quantitative analysis show that banks indeed have been disrupted by FinTechs since the emergence of such companies. Fintech were featured by superior value propositions and the concentration on customer satisfaction.

Another quantitative analysis of interrelationships between FinTechs and traditional institutions shows that finance services provided by the Internet tend to spill over first to the banking industry, then to the insurance industry, and finally to the securities industry (Chen et al. 2020).

In his paper, Anagnostopoulos (2018) argues that the competition between banks and FinTech has evolved into direct collaboration. Banks own legacy, financial expertise, infrastructure, and stable 'old' customer base, while FinTechs own agility, innovation, and future customer base. From the viewpoint of the banking sector, such an obstacle is the lack of clear regulations on IT security, while from the FinTechs side-the differences in culture and operational processes.

To summarize, the research shows that the traditional and new-finance co-exist and cooperate one with another, instead of competing (Bömer and Maxin 2018; Bunea et al. 2016; Siek and Sutanto 2019).

Eventually, there are papers in which authors discuss the factors that stimulate the growth of the FinTech sector, as well as the obstacles that prevent it. As this strand of the literature is crucial for our study, we present it in details in the following subsections. 


\subsection{Factors that Accelerate FinTech Formation and Development}

We base our analysis on the results of the studies focused on the determinants of the FinTech formation. First, we refer to the study of Haddad and Hornuf (2018), which investigated the economic and technological determinants inducing entrepreneurs to establish FinTechs. Authors analysed a panel dataset that consisted of 1177 observations from 2005 to 2015 and covered 107 countries (including 26 FinTech from Poland, which gave the country the rang no 30). The authors proved that well-developed capital market, already available technical base and supporting infrastructure is crucial for FinTechs formation. On the other hand, a more fragile financial sector is also an incentive, since FinTechs and traditional financial services might act complementary in some market segments, such as a high-risk market loans. Other factors enhancing the FinTech formation were the favorable regulations and a larger labor market.

A similar study was performed by Laidroo and Avarmaa (2019). The authors determined location-specific factors associated with FinTech establishment intensity over the period 2007-2012 using Porter's diamond framework. They confirmed that FinTech formation intensity is greater in countries with stronger financial system and already available technology. Moreover, the formation intensity tends to be higher in smaller than in big countries. Other important incentives mentioned by the authors were: high tertiary education rate, university-industry cooperation, overall ICT readiness, and greater financial development level. The authors comment that although lower financial development may support FinTechs development in some areas, the existing infrastructure is necessary for the wider development of their services. The authors note also the importance of the more developed legal environment for the FinTech formation rate.

Eventually, in the most recent study, Cojoianu et al. (2020) investigated the influence of the new regional knowledge creation in both the IT and financial services sectors on the development of the FinTech sector, taking additionally into account the lack of trust in financial services incumbents. They analysed 21 countries and 226 OECD regions from 2007 to 2014. The authors confirmed that the new knowledge created both in the incumbent IT sector, as well as in the financial services sector, supports the FinTech emergence, but the importance of each source changes together with the growth of the FinTech sector. On the other hand, the authors found no statistically significant relationship between the FinTech emergence and the level of trust in financial services incumbents.

In Table 1, we display the list of the factors that support FinTech formation-according to the aforementioned studies. We present the factors tested, the variables used to approximate the influence of these factors, and the relationship found (where " + " denotes positive, "-" negative, while " 0 " no relationship at all).

Table 1. Review of the factors that support FinTech formation.

\begin{tabular}{|c|c|c|c|}
\hline Study & Factors Tested & Proxy Used & Relationship \\
\hline \multirow[b]{4}{*}{ (Haddad and Hornuf 2018) } & $\begin{array}{l}\text { Well developed financial } \\
\text { market }\end{array}$ & GDP per capita, VCfinancing & + \\
\hline & Available technology & $\begin{array}{l}\text { Mobile telephone subscription, secure } \\
\text { Internet services }\end{array}$ & + \\
\hline & Fragile financial sector & Ease of access to loans & - \\
\hline & Regulation & $\begin{array}{l}\text { Regulation indicator from Fraser } \\
\text { Institute database (variable taking value } \\
\text { from } 0 \text { to } 10 \text {, where higher values } \\
\text { denote more market freedom) and } \\
\text { strength of legal rights indicator from } \\
\text { World Bank Doing Business database } \\
\text { (variable taking value from } 0 \text { to } 12 \text {, } \\
\text { where higher value denote higher } \\
\text { protection of borrowers' and lenders' } \\
\text { right by collateral and bankruptcy laws) }\end{array}$ & + \\
\hline
\end{tabular}


Table 1. Cont.

\begin{tabular}{|c|c|c|c|}
\hline Study & Factors Tested & Proxy Used & Relationship \\
\hline \multirow{5}{*}{ (Laidroo and Avarmaa 2019) } & $\begin{array}{l}\text { Strong financial and ICT } \\
\text { (information and } \\
\text { communication) services } \\
\text { clusters }\end{array}$ & $\begin{array}{l}\text { Dummy variable indicating whether } \\
\text { the mean ranking of the country in the } \\
\text { list of financial centres was below or } \\
\text { higher than } 10 \text {; ICT service exports as } \\
\% \text { of service exports. }\end{array}$ & + \\
\hline & Strong home demand & $\begin{array}{l}\text { Percentage of citizens at the age of } 15 \\
\text { years or older, who accessed their } \\
\text { bank account via mobile phone or the } \\
\text { internet; domestic market size index. }\end{array}$ & - \\
\hline & Developed factor conditions & $\begin{array}{l}\text { Tertiary education enrolment rates, } \\
\text { university-industry cooperation, } \\
\text { fixed-line availability, and overall } \\
\text { ICT readiness }\end{array}$ & + \\
\hline & $\begin{array}{l}\text { Crisis (trust in traditional } \\
\text { financial services) }\end{array}$ & $\begin{array}{l}\text { Dummy variable equal to } 1 \text { if the } \\
\text { country experienced a banking crisis } \\
\text { over } 2007-2017\end{array}$ & + \\
\hline & $\begin{array}{l}\text { Financial development } \\
\text { levels }\end{array}$ & $\begin{array}{l}\text { Financial freedom index (Heritage } \\
\text { Foundation), Combined indicators of } \\
\text { access to financing (based on GCI), } \\
\text { Financial development index (IMF), } \\
\text { Financial institutions index (IMF), } \\
\text { Financial markets index (IMF), } \\
\text { Stringency of capital requirements } \\
\text { (World Bank), Supervisory power of } \\
\text { regulatory authorities (World Bank), } \\
\text { Banking activity restrictions (World } \\
\text { Bank), Legal rights index } \\
\text { (World Bank) }\end{array}$ & + \\
\hline \multirow{5}{*}{ (Cojoianu et al. 2020) } & Knowledge in IT sector & $\begin{array}{l}\text { Sectional regional patent application } \\
\text { counts in the IT sector }\end{array}$ & + \\
\hline & $\begin{array}{l}\text { Knowledge in financial } \\
\text { sector }\end{array}$ & $\begin{array}{l}\text { Fractional count of patent applications } \\
\text { of asset managers, banks, insurance } \\
\text { companies and stock exchanges }\end{array}$ & + \\
\hline & IT sector productivity & $\begin{array}{l}\text { The ratio of the gross value added } \\
\text { (GVA) to total employment within } \\
\text { IT sector }\end{array}$ & + \\
\hline & Financial sector productivity & $\begin{array}{l}\text { The ratio of the gross value added } \\
\text { (GVA) to total employment within } \\
\text { financial sector }\end{array}$ & + \\
\hline & $\begin{array}{l}\text { Level of trust in financial } \\
\text { incumbents }\end{array}$ & $\begin{array}{l}\text { The percentage of people } \\
\text { answering "No"to the question in the } \\
\text { Gallup Annual Survey:"In this } \\
\text { country, do you trust financial } \\
\text { institutions or banks? }\end{array}$ & 0 \\
\hline
\end{tabular}

Note: Value: "+" in Relationship column denotes positive relationship, value: "-"—the negative one, while 0-lack of statistically significant relationship. 


\subsection{Obstacles and Risk Factors to FinTech Formation and Development}

Based on the review of the literature presented in the previous subsection, we can identify several obstacles to FinTech development. The most common are: a lack of clear regulations, a lack of technical base, limitations considering skilled workers, and a mistrust in financial innovation (translating into the demand problem).

The problem of regulation and trust in financial innovations are linked one to another. When it comes to regulation the fact is that after the global financial crisis in 2008, the policymakers had been focused on the safety in finance (Zavolokina et al. 2016). This increased the transparency, data visibility, and trust of the customers. As a result, the clients prefer to locate their wealth with more trustworthy banks, and the latter have access to a much larger group of customers than the FinTechs. As noted by Zetzsche et al. (2017) and Hansen (2012), the first and foremost asset of financial services providers is their clients' trust. On the other hand, FinTechs themselves create many challenges for regulators. The new regulations should increase the trust of the customers and also should support the development of FinTechs. The process of creating regulations is complex and demands cooperation between the legislators and the FinTechs.

The other problem is the technical base. As already noted, the lower stage of financial development may accelerate FinTechs' expansion. However, as the sector expands, the infrastructure base supports the wide and full development of FinTech services.

Another crucial source of risk is the availability of qualified staff. The new knowledge created in the incumbent IT sector and the financial services sector is beneficial for the FinTech formation (Cojoianu et al. 2020). The knowledge creation depends on the qualified staff. For instance, Brown et al. (2019) analyse the impact of Brexit on small and medium enterprises, including FinTechs, and note the danger of the possible shortage of highly-skilled workforce, which is crucial for FinTech development. In line with this need, Sung et al. (2019) explores specifically the availability and opportunities for Fintech education and retraining in the UK.

\section{Data and Research Methods}

In our research, we apply both inductive and deductive methods, together with comparative and system analysis. The theoretical analysis of the factors that support FinTech growth and formation was based on the literature review including scientific articles, technical papers and press releases. In this part of the article we applied mostly the inductive method and comparative analysis.

In the empirical part of the paper we analyse the external quantitative data gathered during empirical research conducted by the World Bank, UNESCO, Statistics Poland, as well as through Gallup questionnaire. Yet, the data are confronted with the internal ones obtained through the survey conducted among Polish FinTechs in January 2020. The survey was run by Quantify in cooperation with QuantFin Foundation. We obtained responses from 48 companies. This part of analysis is based on deductive methods, namely descriptive statistical methods and comparative analyses. The calculations were performed using R.

Various definitions of FinTech can be found in the literature. Our definition of FinTech is consistent with the one used in Tirmaste et al. (2019) and Rupeika-Apoga et al. (2020), and is as follows: companies that provide financial services and have a clear, and generally innovative, information technology component in their business model. In consequence, our sample includes not only the startups but also some institutions of longer history. Such definition was used in order to obtain the consistent results with our partners from Estonia, Latvia, Lithuania and Russia, since the survey was run in cooperation. Hence, all the questions were structured in such a way that the results are comparable across the 
countries. ${ }^{2}$ The questions were based on the questionnaire used in Ankenbrand et al. (2018) and refered to the business model canvas of Osterwalder and Pigneur (2010). The model includes nine blocks representing the important parts of any business, i.e., key partners, key activities, key resources, value proposition, customer relationships, channels, customer segments, revenue streams, and cost structure (Osterwalder and Pigneur 2010). The questions in the survey addressed the first eight ones. Apart from that, we included sentiment questions, which are crucial for this paper and allowed us to confront the values of the indicators obtained from external databases with the opinion of the FinTechs. We asked companies to assess the challenges for their business on a scale from 1 (not pressing) to 10 (extremely pressing). The challenges comprised: finding customers, access to finance, costs of production or labour, availability of skilled staff, regulation, and expansion to international markets. The questions were based on the European Central Bank (2018) survey. The last part of the survey tackled the problem of the relationships of FinTechs with banks, as well as their projections on the future interrelationships. The proposed scenarios were taken from Basel Committee on Banking Supervision (2018).

The companies have filled the questionnaire online or via telephone interviews. The respondents of the survey were the managers or decision-makers. Most of the questions were closed-one, yet, in some of them, we asked for the opinion. Interested readers can find a technical description of the survey and its results in Kliber et al. (2020).

The adopted research method has the following advantages. First of all, we find in the literature the respective factors that have been identified by independent research groups based on quantitative analysis performed on different set of data and countries. Thus, we can suppose that their results are fairly robust. Next, we use the data from external databases to verify the position of Poland with respect to the identified factors. Based on the values of the indicators, we divide them into the ones that support or hamper the startup formation and sector development. Lastly, we confront the findings with the internal data obtained directly from the companies representing the sector. What is interesting, in some cases the sentiment of the respondents contradicts the external data. Therefore, we can say that the assessment of the opportunities and threads is a complex task and that the external data may not be sufficient enough to obtain a complete view of the internal situation of the sector.

\section{Overview of the FinTech Sector in Poland}

Poland is the biggest FinTech market in Central and Eastern Europe, with an estimated value of 856 million Euro (CEE Capital Market Leaders Forum 2019). The capital of Poland, Warsaw, is also a financial technology hub in the region and home to nearly $45 \%$ of startups in the country. Klimontowicz and Mitrega-Niestroj (2019), who divide Polish FinTech sector into three groups of: banks (and their FinTech accelerators), interbank and non-banks' entities (after Widawski and Brakoniecki (2016)) state that the non-banking FinTech sector alone reached net profit from EUR 10.5 to 14 million in 2017. The Polish FinTechs serve both individual customers and enterprises. Among the enterprises, the most important are financial institutions and small and medium-size companies (SME) (Klimontowicz and Mitrega-Niestroj 2019).

To identify the field of activity of Polish FinTechs we used the following classification. ${ }^{3}$ We divide the FinTechs into eight groups, i.e.,

- Payment;

- Analytics;

- Banking infrastructure;

2 The results of the analogous surveys run for Latvia and Estonia can be found respectively in (Rupeika-Apoga et al. 2020; Tirmaste et al. 2019) (our survey is the modification of the surveys presented in the reports for the Polish market), while the comparison of the FinTechs in the CEE in Laidroo et al. (2021).

3 This classification is similar to that used in IFZ FinTech Study 2018 (Ankenbrand et al. 2018). Our classification is also compatible with the one used in FinTech Report Estonia (Tirmaste et al. 2019) and FinTech Study Latvia (Rupeika-Apoga et al. 2020), and the same as the one applied in (Kliber et al. 2020). 
- Distributed ledger technology;

- Deposit and lending;

- Investment management;

- InsureTech;

- Accountech.

The payment group encompasses the companies dealing with mobile and online payments, mobile transfers and other form of payments. In the field of analytics we include enterprises that deal with data and business analytics including big data, machine learning, artificial inteligence used for automated advice, as well as chatbots. The companies from banking infrastructure are all those software companies in financial sector that prepare the user interface, enhance processing and produce infrastructure technology. Distributed ledger sector comprises cryptocurrency and blockchain technologies. In the group of deposit and lending we include crowdinvesting, crowdlending and invoice trading. According to our criteria, investment management sub-sector deals with robo-advising, social trading, hybrid models and advice-supported digital investing. InsureTech are companies that apply softwware technologies in insurance, while Accountech are the same for accounting.

At the beginning of 2020, we identified 233 FinTech companies in Poland. The source of our data were: Crunchbase and Cashless databases and the expert knowledge of our business partners: Quantfin and Quantify. Most of the FinTechs belonged to the payments sector $(28.3 \%)$. The deposit and lending field was the second largest $(22.7 \%) .17 .6 \%$ of the enterprises were associated with banking infrastructure. Investment management and analytics were of almost the same size: $9.9 \%$ and $9.4 \%$, respectively. The distributed ledger technologies subsector was relatively small, encompassing $5.2 \%$ of firms, while the smallest number of companies were classified as InsureTech and Accountech ( $3.4 \%$ each group).

In our study, we dealt with a subsample of the whole population (i.e., 233 companies). This subsample covered 48 companies that agreed to take part in our survey (the list of the participants can be found in the Appendix A). It reflected the distribution of the companies across the identified fields quite well: three main groups comprised companies dealing with payment $(33.3 \%)$, deposit and lending $(20.8 \%)$, and banking infrastructure $(18.8 \%)$. The share of analytic companies was slightly larger than in the whole population (10.4\% vs. 9.4\%). The investment management sector was slightly unrepresented $(6.3 \%$ as compared to $9.5 \%$ in the population), while the Accountech-overrepresented $(6.3 \%$ vs. $3.4 \%)$. InsureTech and distributed ledger sector were the smallest groups ( $2.1 \%$ eachwhich means that we had only one respondent from each of the groups). In Table 2, we present the comparison of the companies in the whole population versus the one included in the sample. We run the chi-square Pearson's test and obtained $p$-value exceeding 0.8 . Therefore we can suppose that the sample represents the population quite well, at least when the distribution across the FinTech types is considered.

Table 2. Comparison of the sample and population data.

\begin{tabular}{ccc}
\hline & Population & Sample \\
\hline Analytics & $9.4 \%$ & $10.4 \%$ \\
Investment management & $9.9 \%$ & $6.3 \%$ \\
Payment & $28.3 \%$ & $33.3 \%$ \\
Deposit and lending & $22.7 \%$ & $20.8 \%$ \\
Banking infrastructure & $17.6 \%$ & $18.8 \%$ \\
Distributed ledger & $5.2 \%$ & $2.1 \%$ \\
technology & $3.4 \%$ & $6.3 \%$ \\
Accountech & $3.4 \%$ & $2.1 \%$ \\
InsureTech & &
\end{tabular}

Note: To test whether the sample is representative, we run the chi-square Pearson's test. The $p$-value exceeded 0.8 . 
The distribution of the sample by the activity type is presented in Figure $1 .{ }^{4} \mathrm{We}$ emphasize that these companies operate in more than one sector. The classification relies heavily on the information found on the companies' websites or in other FinTech reports. Moreover, some companies did not indicate any of the pre-defined classes and chose to classify themselves using their classification.

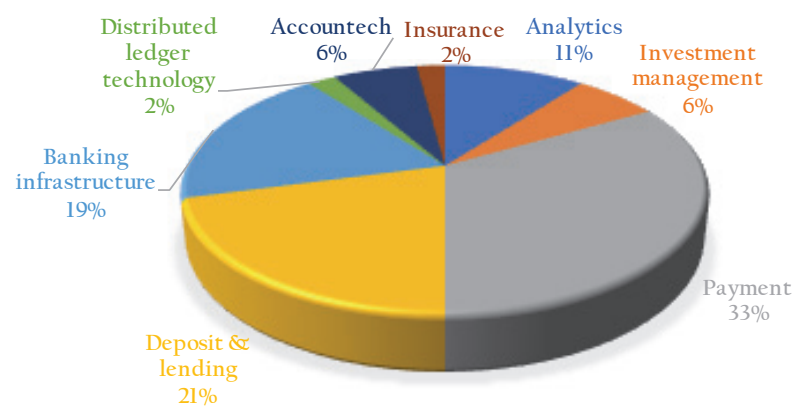

Figure 1. Field of activity of companies which completed the survey.

The FinTech sector in Poland is still a relatively young one- $-15 \%$ of our respondents were still under development (i.e., in a testing phase). The majority of our respondents were present on the market for 5 to 10 years ( $44 \%$ of the firms) or for 1 to 5 years $(35 \%)$. The "mature" companies running their business from 10 to 15 years represent the lowest share $(6 \%)$ in the group (see Figure 2, left panel).
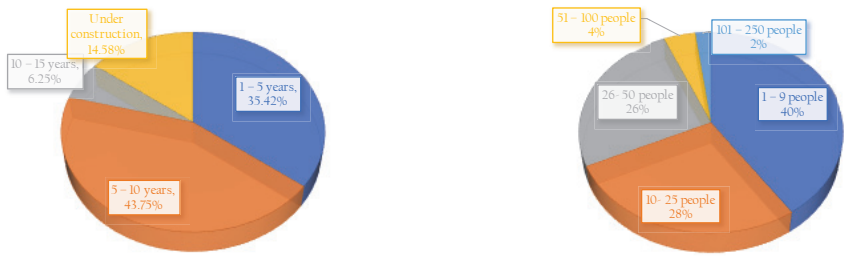

Figure 2. Maturity and size of FinTech companies.

In Figure 3, we present the maturity of companies across their fields of activity. We find that FinTechs which have been existing on the market for the longest time, are from the payment and analytic sectors. However, there are no analytical companies, as well as no banking-infrastructure ones in the under construction group. The payment companies are present in each maturity set. Accountech, investment management, and InsureTech companies belong to the group of the youngest ones (either under construction or up to 5 years on the market).

At the moment of writing this article, the FinTech sector in Poland has been dominated by small companies: enterprises of 1 to 9 employees constituted almost $40 \%$ of the sample (see Figure 2 right panel and Table 3). FinTechs that employ 10 to 25 people constitute $27.1 \%$ of the sample, and the ones that engage from 26 to 50 people $-25 \%$.

Table 3 presents the size of the FinTechs across their activity. The smallest companies ( 1 to 9 employees) were most often present in payment, deposit and L lending, insurance, and investment management. The banking infrastructure sector was represented by larger firms (from 10 to 25 employees). In analytics, enterprises employing from 26 to

4 The survey allowed the respondents to choose more than one option as an area of activity. 
50 people dominated. The largest companies belonged only to banking infrastructure or payment groups.

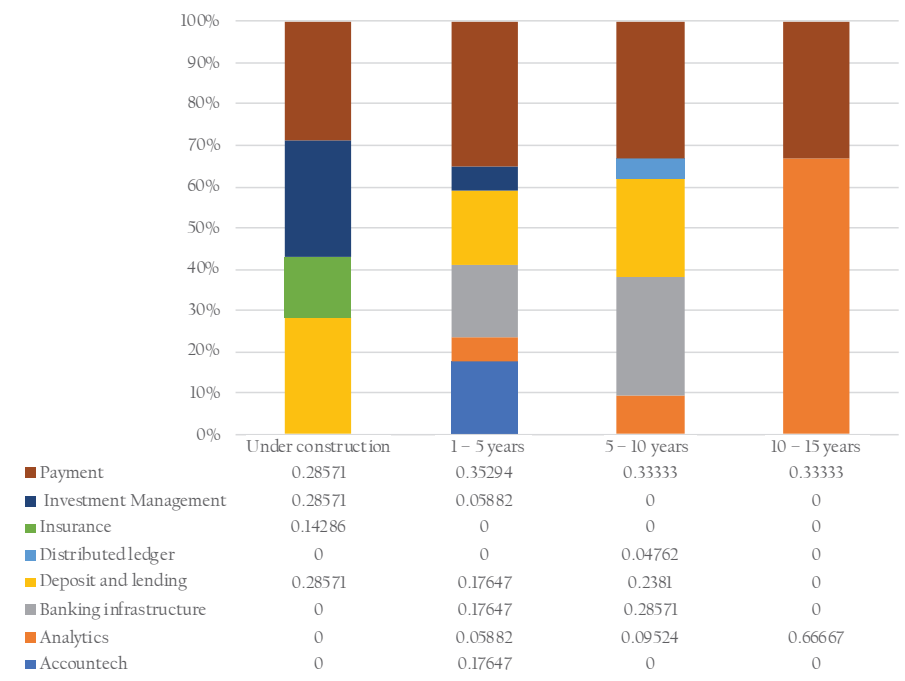

Figure 3. Maturity of companies by field of activity.

Table 3. Number of employees versus the field of activity.

\begin{tabular}{|c|c|c|c|c|c|c|}
\hline \multirow[t]{2}{*}{ Field of Activity } & \multicolumn{6}{|c|}{ Number of Employees } \\
\hline & $1-9$ & $10-25$ & $26-50$ & $51-100$ & $101-250$ & No Answer \\
\hline Accountech & $2.1 \%$ & $4.2 \%$ & - & - & - & - \\
\hline Analytics & $2.1 \%$ & $2.1 \%$ & $6.3 \%$ & - & - & - \\
\hline $\begin{array}{c}\text { Banking } \\
\text { Infrastructure }\end{array}$ & $4.2 \%$ & $6.3 \%$ & $4.2 \%$ & $2.1 \%$ & $2.1 \%$ & - \\
\hline $\begin{array}{l}\text { Deposit and } \\
\text { lending }\end{array}$ & $8.3 \%$ & $6.3 \%$ & $4.2 \%$ & - & - & $2.1 \%$ \\
\hline Distributed ledger & - & - & $2.1 \%$ & - & - & - \\
\hline Insurance & $2.1 \%$ & - & - & - & - & - \\
\hline $\begin{array}{l}\text { Investment } \\
\text { Management }\end{array}$ & $4.2 \%$ & - & $2.1 \%$ & - & - & - \\
\hline Payment & $16.7 \%$ & $8.3 \%$ & $6.3 \%$ & $2.1 \%$ & - & - \\
\hline Total & $39.6 \%$ & $27.1 \%$ & $25.0 \% \%$ & $4.2 \%$ & $2.1 \%$ & $2.1 \%$ \\
\hline
\end{tabular}

Source: FinTechs in Poland: Insights, Trends and Perspectives: (Kliber et al. 2020).

The Polish FinTechs are not very internationalized. The employees of the majority $(87.5 \%)$ were working in Poland. Only four companies indicated that a part of their workers operated from abroad (in these cases the ratio of workers from Poland was: $98 \%, 90 \%, 10 \%$, and $2 \%)^{5}$

The trends in the workforce suggest that the FinTech sector in Poland is still expanding. Although most of our respondents $(54.2 \%)$ did not note a change in the number of employees between 2018 and 2019, only 6.3\% reported a moderate decmidrule. In the rest of the cases, the companies reported either moderate $(22.9 \%)$ or large $(16.7 \%)$ growth.

5 The lack of internalization is visible also when we analyse the country of registration of the FinTechs. 46 companies from our sample were registered in Poland, one in the Czech Republic, and one in Belgium. Most of the Polish FinTechs focused their business on the Polish market (77\% of the respondents), and only $33 \%$ were oriented on international clients. 
To sum up, the FinTech sector in Poland is still growing. The micro and small enterprises dominate the market. Start-ups constitute a substantial share of the business. The most mature companies are from the analytic group, while the largest deal with payment or banking infrastructure. Therefore, we find it important, to investigate whether Poland satisfies the condition to support further formation of the new FinTechs companies, which in turn will translate into the growth and development of the whole sector in the country.

\section{Factors That Support FinTech Formation and Development}

In this section, we identify triggers and opportunities for the FinTech sector development in Poland. The analysis is done with respect to the factors identified in the literature and specifier in Table 1. We discuss them and illustrate them with the statistical data from the external scientific databases and primary data from our survey.

In the group of factors that accelerate the FinTech growth, we include the stage of development of the financial system, the very secure banking system unwilling to give loans to risky enterprises but willing to cooperate with the FinTechs, education level (high tertiary education enrolment rate, high rate of technical students), as well as the available technology (knowledge in the IT sector) and the openness to financial innovation.

\subsection{Stage of Development of the Financial System in Poland}

One of the crucial factor which is supportive for FinTech formation and development is the adequate level of the financial system development. It is approximated inter alia by the number of commercial bank branches and bank accounts per 1,000,000 (see: Figure 4), by the GDP per capita, ease of access to loans, as well as indices of financial development.

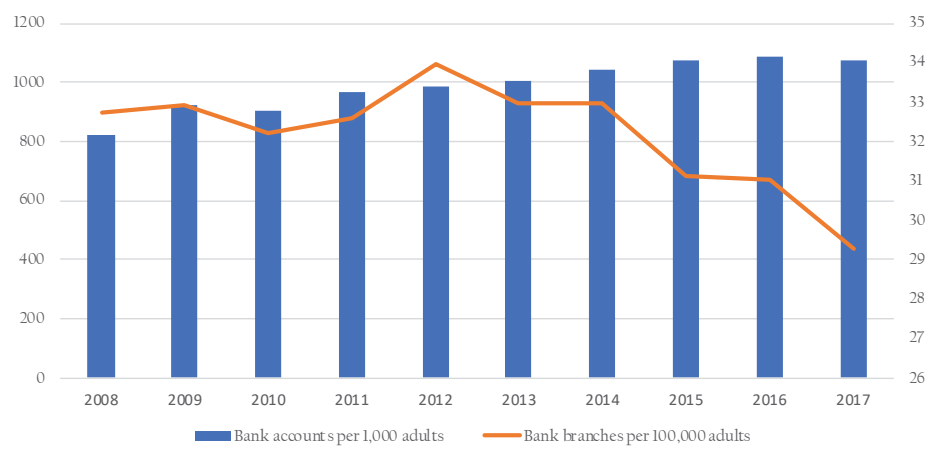

Figure 4. Number of bank accounts and bank branches per 1,000,000 in Poland over the period 2011-2017 (World Bank: Financial Development database)

The crucial feature of the financial system in Poland is the well-grounded banking system which follows the German approach to financing. The main source of financing of the companies is the bank credit. Bank transfers have been still the most-used payment method accounting for 50\% of all payments in 2019 (JPMorgan 2019a). This is, inter alia, the consequence of legal solutions that require business payments to be executed via bank transfer.

However, there are some characteristics in the Polish financial market, in particular in terms of consumer behavior, which makes it somehow more promising to FinTech development. It seems that there are sharp differences between consumers' habits and approaches in Germany and Poland. The report of J.P. Morgan shows that German consumers are featured by the conservative approach to spending, and Germany's e-commerce sector is highly influenced by habits formed in the pre-internet era (JPMorgan 2019b). On contrary, Polish consumers are one of Europe's early adopters, eager to migrate to digital-only payment options and to launch the contactless technology (GlobalData 2017). Mobile payment 
systems have been relatively popular. Both card payments and digital wallets had been growing in popularity fast, with forecasts of $25 \%$ and $33 \%$ of the compound annual growth rate, respectively (JPMorgan 2019a). These tendencies have even strengthened during the outbreak.

Table 4 shows trends in e-commerce in various European countries. Within the group, Poland has a rather moderate position. E-commerce market value and mobile commerce market size are relatively low when compared to other European countries. Mobile commerce has only $11 \%$ share of overall e-commerce sales. The internet access is second lowest within the group of countries included in the reports. The popularity of smartphones is a little below the average. The number of cards per person is comparable to Italy but higher than in France or Germany. The predicted growth rate of the e-commerce segment is two-digit. All these features favor strong market potential to develop. Bank transfers which are Poland's most-used payment method might be easily proxied by e-payments soon.

Table 4. E-commerce payments trends in European countries.

\begin{tabular}{ccccccc}
\hline & E-Comm & M-Comm & Internet & SPHN & Cards & GR \\
\hline Austria & 9.1 & 0.7 & 88 & 65.0 & 1.51 & 8 \\
Belgium & 10 & 1.5 & 89 & 69.7 & 1.95 & 8.5 \\
Czechs & 4.4 & 2.4 & 85 & 67.3 & 1.11 & 16 \\
Denmark & 15.4 & 4.9 & 97 & 78.2 & 1.57 & 10.5 \\
Finland & 8.5 & 2.8 & 94 & 76.0 & 2.3 & 11 \\
France & 81.7 & 17.2 & 88 & 67.8 & 0.94 & 10.5 \\
Germany & 73 & 19.7 & 91 & 71.0 & 0.52 & 7.3 \\
Ireland & 7 & 2.9 & 83 & 71.0 & 1.37 & 8.6 \\
Italy & 21.2 & 7 & 73 & 68.5 & 1.09 & 14 \\
Luxembourg & 0.74 & 0.14 & 98 & 70.5 & 4.35 & 8 \\
Netherlands & 22.5 & 4.5 & 96 & 71.0 & 0.18 & 11 \\
Norway & 10.9 & 4.3 & 99 & 76.1 & 2.92 & 13 \\
Poland & 9.9 & 1.1 & 78 & 66.5 & 1.03 & 10 \\
Portugal & 4.3 & 0.43 & na & 68.0 & 2.66 & 12 \\
Spain & 30.3 & 11.5 & 87 & 69.5 & 1.64 & 13.5 \\
Sweden & 12 & 4.9 & 97 & 74.0 & 1.89 & 9 \\
Switzerland & 10.1 & 2.7 & 91 & 73.5 & 1.95 & 7.5 \\
UK & 178.5 & 91 & 95 & 70.8 & 2.48 & 9
\end{tabular}

Note: Table is based on J.P.Morgan's Payment reports (JPMorgan 2019c). E-comm denotes e-commerce market value, $\mathrm{M}$-comm denotes mobile commerce market size (both in billions of euro), Internet denotes internet penetration (in \%), SPHN is for smartphones' penetration (in \%), Cards denotes number of cards per capita, and GR denotes the predicted e-commerce compound annual growth rate 2017-2021.

\subsection{FinTechs and Banks}

Together with the rapid development of financial innovations, a discussion about the possible threat that FinTechs pose to the established banking sector has emerged. However, as we pointed out in Section 2 of this article, the worldwide research shows that the traditional and new-finance co-exist and cooperate one with another, instead of competing (Bömer and Maxin 2018; Bunea et al. 2016; Siek and Sutanto 2019). Based on the analysis of 14 case-studies of FinTech-bank cooperation in Germany, Bömer and Maxin (2018) identified three main reasons why such collaboration is profitable for FinTechs. To begin with, it enables FinTechs to enter the market. Next, cooperation with a bank increases the FinTechs' profits. Finally, banks enable new FinTech products.

The situation in Poland resembles the one observed worldwide. The authors of the "FINTECH in Poland" market survey (Flanders Investment and Trade 2018) indicate that with respect to the banking sector, Poland is a regional leader in high-tech pioneering solutions. Figure 1 shows the activities of the Polish FinTechs, which operate in various areas (payment, deposit and lending, banking infrastructure, investment management). They are already prepared to support banks with customer relationships, offering better or 
more personalized products. In the future Fintechs might be able to replace banks entirely. The results of another international survey on mobile banking conducted by ING in 2015 (ING 2015), show that when the number of users of mobile banking is considered, Poland is the third country in Europe; $60 \%$ of smartphone users in Poland had already used mobile banking or expected to use it. Only the Netherlands and the UK show higher engagement in mobile banking services (67\% and 63\%, respectively).

One of our survey question was How do you see that FinTechs change traditional banks? The answers show that FinTechs do not perceive themselves as competitors. They rather tend to collaborate with the traditional banks. The majority of respondents (73\%) claim that traditional banks will unavoidably endorse new technologies, modernize, and digitalize their services. More than half $(60 \%)$ claim that new business providing specialized services would emerge, $44 \%$ of respondents expect the role of traditional banks to be restricted to offer commoditized services only. In such scenario direct customer relationships will be handled by other entities (FinTechs). For a minority of respondents traditional banks would become either irrelevant $(17 \%)$, or disappear $(19 \%)$. Then new technology-driven firms will be created in their place.

When the cooperation with banks is considered only $17 \%$ of FinTechs' managers stated that they do not have any common interests with banks. Among those who collaborate, the majority create new IT solutions, offer and aggregate bank products. They sell analytical tools, mobile applications, or programs responding to the challenges of banks related office issues. Naturally, FinTechs themselves use bank products such as traditional bank accounts. Some also interact with banks indirectly through leasing companies or brokerage houses.

Our results corroborate the findings of Staszewska (2018), who noted that FinTechs are eager to cooperate with banks (and vice-versa). Obviously, the FinTechs cannot yet compete with well-settled banks when the convenience and security is taken into account. So far, as everywhere in the world the role of Polish FinTechs is to "disrupt" the financial sector and change relations among the market participants in the near future. So far most FinTechs in Poland collaborate with banks, either as customers or as supporters. They are linked through friendly cooperation and derive mutual benefits.

\subsection{Trust in Financial Incumbents}

Although Cojoianu et al. (2020) showed that the level of trust in financial incumbents is not a necessary factor supporting FinTech formation and development, other researchers claim that trust is the most important factor that may encourage or discourage clients to put their money into a financial institution (Hansen 2012; Zetzsche et al. 2017). In the case of Poland, as we already said, most of the FinTechs collaborate with banks. What is important, Polish citizens trust banks more than the citizens of Western European countries. Although in 2009 the decrease of the level of trust in banks was sharper in Poland than in the global market, already a year prior to the COVID pandemic, it was significantly higher than worldwide (Piotrowski 2020).

Taking the above into account, we can formulate conclusion that the high level of trust in banks is a factor supporting the formation of new FinTechs that plan to cooperate with banks, as well as the future development of the sector (especially the subsector classified as banking infrastructure).

\subsection{Factor Conditions-Trends in the Education}

When it comes to the availability of qualified staff, we observe a growing trend of tertiary educational attainment. Analyzing the data from the Ministry of Science and Higher Education, we can see that Computer Science, Economics as well as Finance and Accounting have been ranked among the most popular fields of study for over 10 years.

Table 5 presents data collected by the ministry on recruitment to state and private universities in the last 10 years. As it is easy to observe, that Computer Science has been an unquestionable leader for 9 years, being the first among the most popular fields of study. Economics also has a stable 4-6 positions, and Finance and Accounting ranks 6-10 
depending on the year. As one can see in the Figure 5, the percentage share of all candidates for the three analyzed fields ranged from $12 \%$ to $18 \%$ of all accepted candidates It is worth noting that not the entire ranking looks so stable. For instance, Construction has dropped from the first place in 2011/2012 to the 9th in recent years, while Education has dropped out from the top 10 most popular fields of study.

Table 5. Selected results of recruitment for higher education in 2011-2021. Showing the place in the popularity ranking and the number of candidates for Computer Science, Economics, Finance and Accounting field of study

\begin{tabular}{|c|c|c|c|c|c|c|c|}
\hline $\begin{array}{l}\text { Academic } \\
\text { Year }\end{array}$ & $\begin{array}{c}\text { Total No. of } \\
\text { New } \\
\text { Students }\end{array}$ & $\begin{array}{c}\text { Computer } \\
\text { Science } \\
\text { Rank }\end{array}$ & $\begin{array}{c}\text { Candidates No. } \\
\text { for Computer } \\
\text { Science }\end{array}$ & $\begin{array}{l}\text { Economy } \\
\text { Rank }\end{array}$ & $\begin{array}{l}\text { Candidates No. } \\
\text { for Economy }\end{array}$ & $\begin{array}{c}\text { Finance and } \\
\text { Accounting } \\
\text { Rank }\end{array}$ & $\begin{array}{c}\text { Candidates No. } \\
\text { for Finance and } \\
\text { Accounting }\end{array}$ \\
\hline $2011 / 2012$ & 555,439 & 3 & 29,888 & 6 & 21,523 & 7 & 13,610 \\
\hline $2012 / 2013$ & 549,443 & 1 & 30,639 & 6 & 20,202 & 8 & 14,729 \\
\hline $2013 / 2014$ & 476,809 & 1 & 31,782 & 6 & 17,298 & 6 & 16,138 \\
\hline $2014 / 2015$ & 462,681 & 1 & 30,309 & 4 & 16,061 & 7 & 15,535 \\
\hline $2015 / 2016$ & 446,012 & 1 & 35,137 & 6 & 15,649 & 6 & 15,512 \\
\hline $2016 / 2017$ & 436,316 & 1 & 38,285 & 7 & 15,459 & 8 & 14,873 \\
\hline $2017 / 2018$ & 429,114 & 1 & 42,434 & 4 & 17,938 & 7 & 15,014 \\
\hline $2018 / 2019$ & 416,153 & 1 & 42,759 & 4 & 18,773 & 10 & 16,275 \\
\hline $2019 / 2020$ & 424,328 & 1 & 32,680 & 6 & 17,143 & 9 & 17,642 \\
\hline $2020 / 2021$ & 428,609 & 1 & 33,687 & 6 & 16,708 & 7 & 19,998 \\
\hline
\end{tabular}

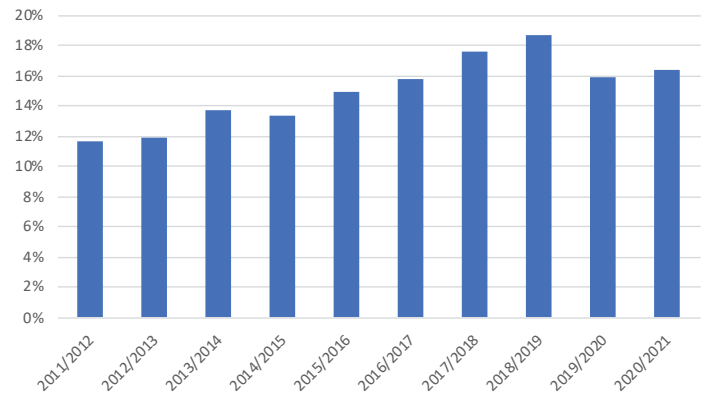

Figure 5. Number of candidates for Computer Science, Economics and Finance and Accounting as a percentage of all new admissions to higher education.

The constant and very high interest in these fields of science should promise a large number of qualified employees for the FinTech industry. However, as we show in Section 6, one of the high-risk factors identified by our respondents is the availability of the skilled workers. We discuss the possible reason for this discrepancy in Section 6.2.

\subsection{Available Technology and the Openness to Financial Innovation}

Another very important factor supporting the FinTech formation is available technology (Cojoianu et al. 2020; Haddad and Hornuf 2018; Laidroo and Avarmaa 2019). It is usually approximated with the secure Internet services or fixed-line availability. In Figure 6, we present the enormous growth of the number of secure Internet servers in Poland over the period 2011-2019. We note, that the cloud servers (e.g., Azure, AWS) are located outside of Poland, which can be a factor of data storage cost, yet we assume that this is not an obstacle per se. Thus, we can assume that the technology already available in Poland is a factor contributing to the FinTech sector development. 


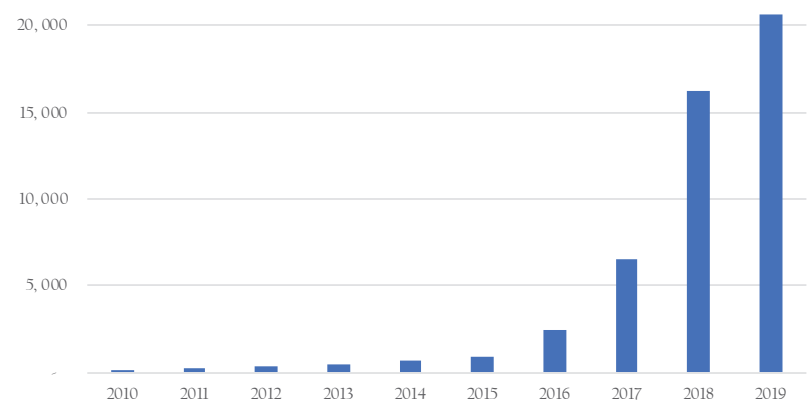

Figure 6. Secure Internet server in Poland (World Bank database).

\subsection{Triggers Behind the Sector Development Identified by the FinTechs}

In the previous subsections, we outlined the opportunities for FinTech formation, referring to the factors identified in the literature. In our survey we also asked the companies to identify the factors that can be considered triggers behind the sector development. Figure 7 presents the answers given by our respondents. The most frequently chosen ones were digitalization of financial services, expansion of FinTech beyond traditional financial services and rising number of payment options at retailers.

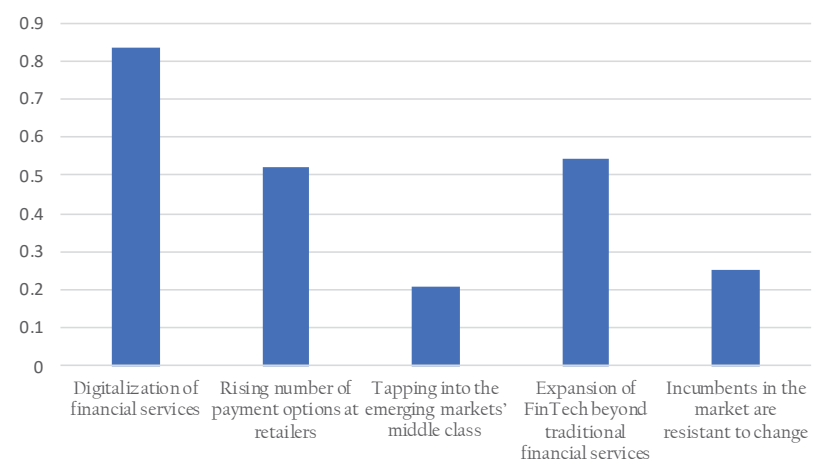

Figure 7. Triggers behind FinTech development.

Additional answers provided by our respondents were:

- Innovation;

- Regulations favoring open banking;

- Customer-orientation (FinTechs put emphasis on user experience and quality improvement);

- Qualification (FinTechs gather highly qualified staff).

Figure 8 shows the distribution of answers by maturity (already running versus under construction). Since the sample of the companies under construction is much smaller, we express the answers in the form of percentage-i.e., what share of the group chose the given option (each could have been chosen more than once). Thus, we are able to compare the opinions of the companies who already operate on the market and those, who are planning to enter it. We note some discrepancies: the companies that already operate chose digitalization of financial services and rising number of payment options at retailers most frequently, while the new companies see their strength in the fact that incumbents in the market are resistant to change. 


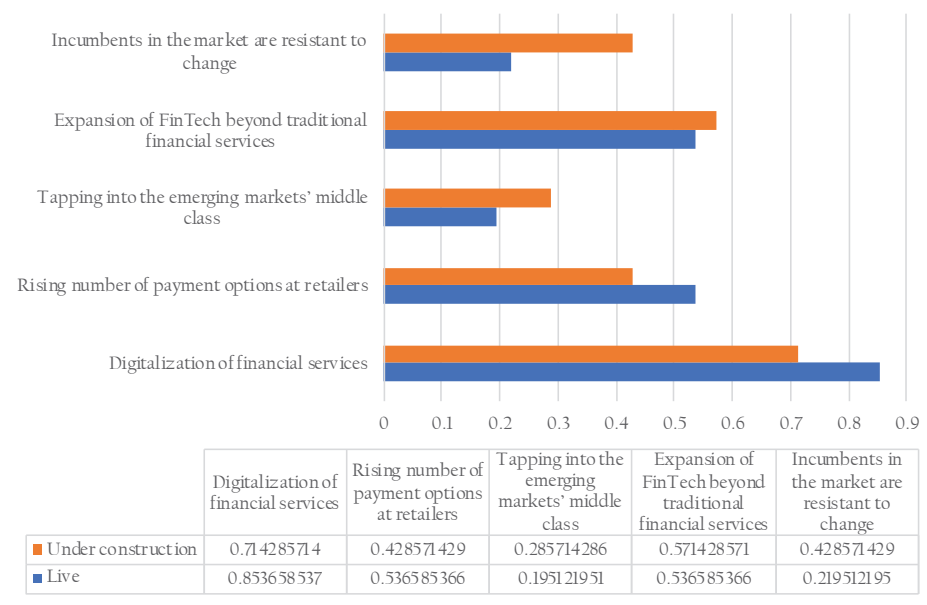

Figure 8. Triggers behind FinTech development-distribution of answers across the maturity of the companies.

Thus, we can conclude that the companies themselves see the opportunities for their development in the future development of the financial system, the openness of customers to innovation, but also the reluctance of the incumbents to be innovative themselves. Therefore, the FinTech can fill up the demand from the customers' side.

\subsection{Positive Trends in Legislation}

Some credit, in terms of financial openness, should be given to institutional efforts. A government institution that plays the role of the financial market supervisor and takes part in the respective legislative works is The Polish Financial Supervision Authority (Urząd Komisji Nadzoru Finansowego, further: the KNF). Its two main initiatives are Special Task Force for Financial Innovation in Poland, and Innovation Hub. The goal of the first one is to identify obstacles in the institutional framework. The second one (the $\mathrm{Hub}$ ) provides institutional support for companies from the FinTech sector. It helps, among others, with interpreting the regulations, obtaining licenses, and maintaining adequate client protection. All FinTech start-ups who plan to introduce their innovative products into the financial market under the KNF supervision and seek institutional support can qualify for the Innovation Hub Programme.

\section{Challenges for the FinTechs' Growth in Poland}

When it comes to the challenges and risk factors that can possibly hamper FinTech formation and sector development in Poland, the most important ones are: regulations, possible home demand problems, factor conditions (problems with finding qualified stuff, which translates into the education and university-industry cooperation-see Table 1), and problems with financing.

One of the questions in our survey tackled the specific problems that the FinTech encounter (see Figure 9 and Table 6). The most pressing ones appeared to be the home demand problem, i.e., finding customers. The companies ranked the risk of finding skilled staff and inadequate regulations equally high, but slightly lower than the customerfinding. As a high-risk factor, the FinTechs pointed also increasing production costs and expansion to international markets (which can be associated with home demand problems). The enterprises worried less about access to finance and competition. In the open-answer question, they also enumerated the high cost of data (8 points on the 1 to 10 scale), problems with the large organizations' attitude towards FinTechs (10 points), and once again - the regulations ( 9 points). 


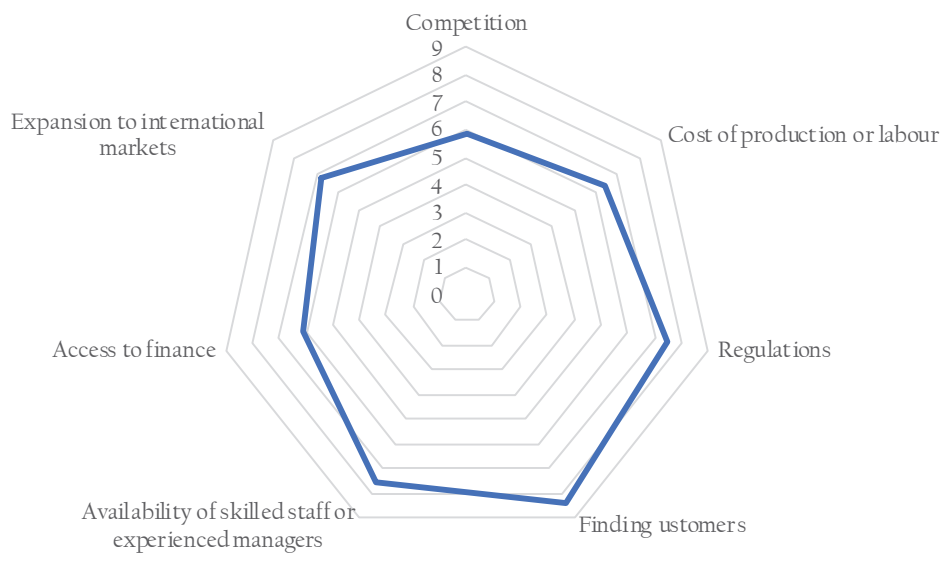

Figure 9. Specific problems and their pressure (means).

Table 6. Specific problems and their pressure-by FinTech type.

\begin{tabular}{ccccccc}
\hline & Accountech & Analytics & Banking Infr. & Dep. and Lend. & Inv. Manag. & Payment \\
\hline Competition & 4.67 & 5.00 & 6.00 & 7.10 & 4.67 & 5.81 \\
Finding customers & 9.67 & 8.60 & 7.44 & 9.00 & 7.00 & 8.56 \\
Access to finance & 6.00 & 5.40 & 6.11 & 7.50 & 7.33 & 5.13 \\
Cost of production/labour & 6.67 & 6.40 & 7.11 & 6.30 & 4.67 & 6.88 \\
Availability of staff & 7.00 & 8.60 & 7.89 & 7.60 & 7.00 & 7.38 \\
Regulation & 4.67 & 8.00 & 8.11 & 8.30 & 8.33 & 7.25 \\
Expansion to international markets & 7.67 & 7.20 & 7.56 & 7.00 & 6.33 & 6.38 \\
\hline
\end{tabular}

Source: FinTechs in Poland: Insights, Trends and Perspectives: (Kliber et al. 2020).

We further compared the answers across the six largest FinTech types to check whether the problems were valued equally by each group (Table 6). There are some differences in the answers. Accountech, payment, and deposit and lending firms ranked the risk of finding customers the highest, as compared to other FinTechs. Accountechs were not concerned about the regulations and competition as much as other groups. The competition was also ranked as a relatively low risk-factor by investment and management. The whole sector, however, was approximately equally worried about the possibility to find competent staff.

\subsection{Home Demand Problems}

As already stated, the respondents of our survey pointed out home demand as one of the most pressing ones. However, we note that the companies from investment management as well as banking infrastructure rated it lower than e.g., the Accountech or Deposit and Lending ones.

In Figure 10, we display the change in mobile phone usage for payment and money transfer between the 2014 and 2017. The number of people using mobile to pay bills increased almost four times, while those using mobile to send money-almost twice.

In Section 5.1, we mentioned also that Polish consumers are one of the Europe's early adopters of financial innovations. It is worth to stress the early (pre-pandemic) success of BLIK payments. BLIK is a Polish FinTech that uses the domestic automatic clearing houses $(\mathrm{ACH})$ to enable instant payments and mobile transfers. The initiative was launched in 2015 as a joint venture of the six largest Polish banks, while at the moment of writing this paper, it covers all major banks and payment institutions in Poland. According to Baba et al. (2020), during the second quarter of 2020, BLIK executed over 1 million transactions per day and was available to 13.1 million registered users. Therefore, it seems that the home demand should not constitute a big thread for the FinTechs from the payment sector as well. 


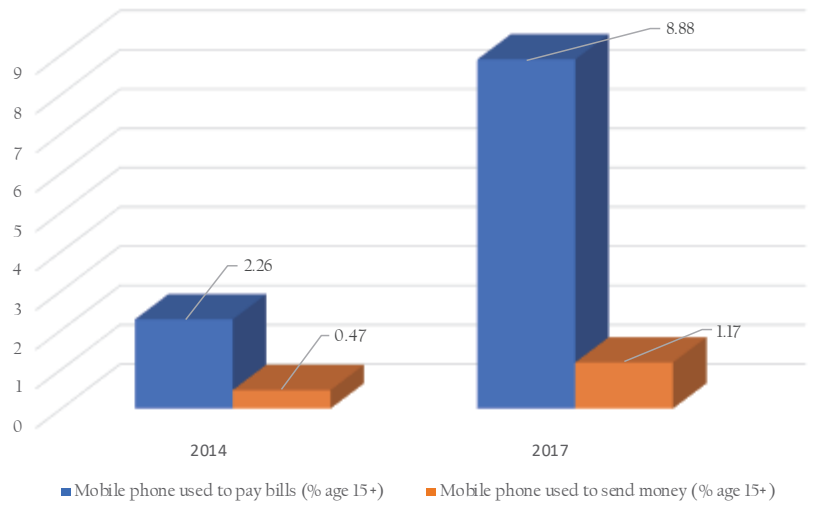

Figure 10. Mobile phone usage for payment and money transfer: 2014 vs. 2017 (source: World Bank Financial Development database).

\subsection{Knowledge and Talent}

Poland struggles with the issues related to innovation and talent retention. In terms of funding R\&D Poland is among laggard Community economies, spending only half of the European Union average (see Table 7). At the same time, the dynamic index of technicians and researchers in R\&D growth is a bit better for Poland (1.03 and 1.10) than for the Community on the whole (1.01 and 1.04); yet taking into account that Poland should be still catching up to the leaders, it seems quite moderate result to support innovative sectors development.

Table 7. Research and technology indicators.

\begin{tabular}{ccccc}
\hline Year & $\begin{array}{c}\text { Scientific and Technical } \\
\text { Journal Articles }\end{array}$ & $\begin{array}{c}\text { Technicians in R\&D (Per } \\
\text { Mln People) }\end{array}$ & $\begin{array}{c}\text { R\&D Expenditure (\% of } \\
\text { GDP) }\end{array}$ & $\begin{array}{c}\text { Researchers in R\&D (Per } \\
\text { Mln People) }\end{array}$ \\
\hline 2011 & $25,735.0$ & 359.8 & 0.7 & 1675.1 \\
2012 & $27,969.6$ & 420.6 & 0.9 & 1752.7 \\
2013 & $30,026.1$ & 384.7 & 0.9 & 1873.1 \\
2014 & $31,773.3$ & 438.5 & 0.9 & 2064.0 \\
2015 & $33,116.4$ & 443.6 & 1.0 & 2171.6 \\
2016 & $34,838.7$ & 399.8 & 1.0 & 2320.8 \\
2017 & $34,675.7$ & 415.3 & 1.0 & 3019.1 \\
2018 & $35,662.6$ & NA & 1.2 & 3106.1 \\
\hline
\end{tabular}

Source: Scientific and technical journal articles: National Science Foundation, the rest of indicators: UNESCO.

Based in the Global Competitiveness Report, Poland is ranked 59th World economy in terms of Innovation and sophistication factors, placing it below European and North American regional average. In particular, Poland is ranked poorly for the universityindustry collaboration in R\&D and government procurement of advanced technology products. Slight trend of improvement can be noticed for the innovation capacity, company soundings on R\&D, and PCT patents applications. Moreover, the fact that Poland is especially badly rated for both keeping (rank 89) and attracting talents (rank 113) appears to by an obstacle for any innovative sector to flourish.

According to Global Entrepreneurship Monitor data for 2019, the extent to which training in creating or managing SMEs is incorporated within the education and training system at primary and secondary levels is actually getting worse in Poland, compared to previous years (indices value 2.16 in 2019, 3.07 in 2013). However, it is getting better in higher education such as vocational, college, business schools, etc. (4.57 in 2019). Moreover, the extent to which social and cultural norms encourage or allow actions leading to new 
business methods or activities that can potentially increase personal wealth and income are considered very low in Poland. This means that despite the relatively decent education system (see Section 5.4), the potential for sophisticated branches may be retained by lack of highly qualified stuff, institutional weakness, social values, and R\&D policy.

\subsection{IT and Financial Sector Productivity}

Interestingly, the value of Financial Development Index by IMF for Poland is currently at the similar level as in the 1980s (0.47 in 2018), after a temporary deterioration in the 1990s and 2000s. This places Poland far behind the leaders such as Switzerland (0.96) or UK (0.90), but also below the European average value of the index, 0.52 . The evaluation of Financial Institutions Index for Poland is higher than the value of Financial Markets Index (respectively 0.59 and 0.32 ).

The capacity of Polish firms to export service related to finance and ICT may approximate the conditions of the sectors and their productivity. According to WDI data, Poland improved its performance in terms of high technology exports (7\% in 2011 to $11 \%$ in 2019) as a share of manufactured exports. As such it is closer to the European Union regional average of $16 \%$. In terms of ICT goods, these remain consequently around $7 \%$ of total goods export since 2011, which is above the mean value in European Union (5\% in 2018). However, a sneak peak of the WDI data on insurance and financial services exports indicates that these are only $2 \%$ in commercial services exports, which is less than $7 \%$ average in the UE. Thus, we can consider that both financial sector internal and export performance need improvement to better accommodate FinTechs.

\subsection{Regulations}

We note that most of the companies ranked the regulations as one of the highest risk factors. Yet, only $37.5 \%$ of them admitted that the current regulations restrict their activities. FinTechs criticized the imprecision of the regulations, denoted their ambiguity and the fact that they are often out-of-date (the regulations are backward, not taking into account rapidly changing reality-as one of the respondents wrote). The companies complained also about the unnecessary bureaucracy (e.g., the companies from the payment sector, who struggled to acquire the status of a payment institution). Some sectors were more affected by the lack of regulations-for instance, the leasing companies that were struggling for the regulation that would make it possible to sign leasing contracts online. Those enterprises that offer complementary services to banks, reported that the legislators very often neglect the existence of the FinTechs. In yet another question, FinTechs from the sector of analytics, banking infrastructure, deposit and lending, as well as payment admitted that they felt subject to relatively high compliance regimes, as compared to their competitors (for details see the report (Kliber et al. 2020)). All the respondents would appreciate it if the legislators consult them before implementing further modifications to the existing law.

In Table 1, we presented the proxies used in the literature, to describe the state of the regulations favouring FinTech formation and development. According to the Fraser Institute data for 2018 (data for 2019 and 2020 are not available at the moment of writing this report), the value of the Regulation indicator for Poland amounts to 7.32, while Legal system and property rights-to 5.99. The value of the first index is comparable to the one obtained by Hungary (7.42), but evidently lower than the scores of the Czech Republic, as well as small Baltic Republics (in each case higher than 8). Furthermore, when it comes to the Legal system and property rights-Poland stays behind the other CEE economies, for which the analogous variable exceeds 6 (Hungary and the Slovak and Czech Republics) or even 7 (Baltic republics). Yet another indicator used in the literature is legal rights from the World Bank database, which describes the degree of protection of the lender and borrower in the case of bankruptcy. The value of the index reached by Poland has not changed since 2014 and amounts to 7, which is the same value as the one reached by the Czech Republic, Slovakia and Estonia, higher than Lithuania (6), but lower than Latvia and Hungary (9). 
The complexity and uncertainty of the regulatory environment hinder FinTech development in Poland (KNF 2018). This was confirmed by the respondents of our survey (one of them said that they will contribute to the ongoing dialogue on the introduction of legal regulations).

Polish authorities undertake legislative and regulatory activities to mitigate these risks. So far, Poland has implemented European FinTech directives on Payment Services Directive (PSD2), Anti-Money Laundering and Counter-Terrorist Financing (AML/CTF), and the Markets in Financial Instruments Directive (MiFID II). Other Community regulations, such as eIDAS ${ }^{6}$ are directly applied in all Member states and require supervision. There are plans to introduce new legal measures for the FinTech sector, such as regulatory sandbox, artificial intelligence, and distributed processing technologies in the supervision of the financial sector (KNF 2020b).

Postulates for regulatory agenda include decreasing formalities, limiting over regulation, and clarifying the rules for new entities. It is required to recognize and secure non-banking FinTech entities' presence on the market by enabling them to access basic needs such as maintaining bank accounts (for instance, sometimes banks refuse to open bank accounts for cryptocurrency trading platform organizers).

Entrepreneurs in Poland face the problems of lengthy procedures and stale writtenform requirements. Lack of new regulations related to registering accessibility, data processing, or digital identity implies the use of outdated legal solutions (KNF 2020b). For instance, business information offices should be allowed to outsource using modern technological solutions and to enable creditors to send payment requests electronically in all cases (email, SMS, MMS). Moreover, there is a need to create an institutional framework to prevent identity theft, which hampers FinTech industry development (KNF 2020a).

The KNF Working group identifies numerous needed changes in the legal environment of FinTech (Kliber et al. 2020). We may divide them into new rules, amendments, and a need for interpretation. Some issues require to be regulated, e.g., new instruments for start-up funding, the publication of interpretation and review of rules for the KNF, or legal advice for new trans-border PSP. The amendments to existing rules, according to the KNF Working group, should cover, for instance, the substitution of written form with a digital form of documents, the taxation of crypto-assets, or tokenization of bills, cheques, or bills of exchange. Eventually, practice change is required in areas related to the length of getting a license for payment service processing, robo-advice, creation of new securities, etc. In reference to the answers from the survey, we can conclude that not only the FinTechs see the need for future regulations change.

\subsection{Access to Capital}

Haddad and Hornuf (2018) show that access to financing is a crucial factor that encourages the FinTech formation and used it as a proxy for the financial market development. As noted in Lai et al. (2020), well-functioning capital and venture capital markets are crucial to entrepreneurship, the high-tech industry as well as innovation. For these reasons we decided to describe this aspect of the Polish market.

First of all, venture capital (VC) market of Poland is perceived as "inexperienced" (Palmer 2020). In 2019, there were 130 active VC firms in Poland (Krzysztofiak-Szopa et al. 2019). The majority of Polish venture capital investment comes from Polish Development Fund (PFR) Ventures, as well as from government programmes such as the National Center for Research and Development (NCBR) (Palmer 2020). It is estimated that about $52 \%$ of funds available on the market comes from the state, while $56 \%$ of Polish VCs mostly uses government support (Krzysztofiak-Szopa et al. 2019). There are just between five to seven $\mathrm{VC}$ teams that are experienced in managing more than two funds, while the other are younger ones, with nano-VC dominating, and have done only a few investments to date (Krzysztofiak-Szopa et al. 2019; Palmer 2020).

6 eIDAS Regulation is Regulation (EU) 910/2014 on electronic identification and trust services for electronic transactions in the internal market. 
For the companies in our research sample, the main capital source is own capitalsee Figure 11. Only seven companies do not mention it, while three respondents refused to answer this question. In addition, business angels, individual investors and venture capital funds are other identified sources, that provided access to capital for the Polish startups.

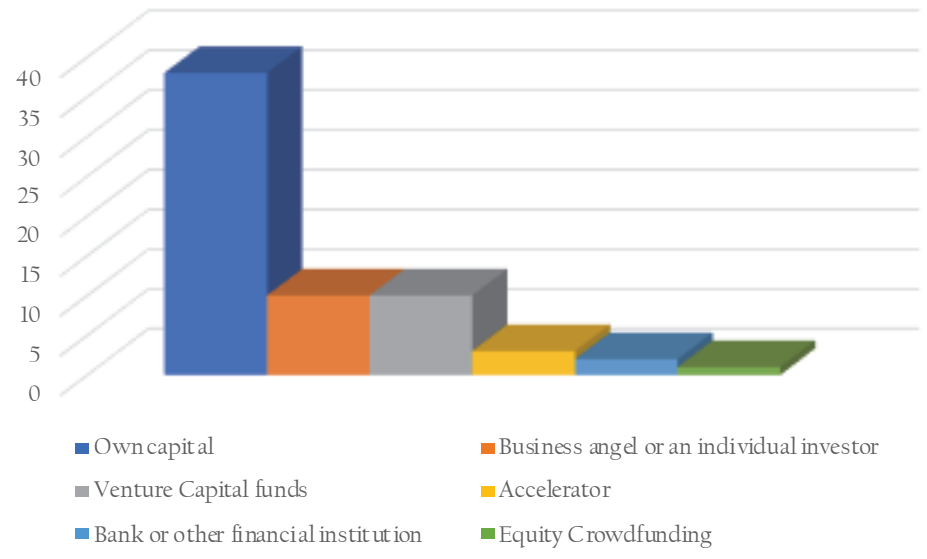

Figure 11. Sources of capital for Polish FinTechs.

The distribution of responses reflects the situation of the start-up financing in the Polish market. Although there are almost 350,000 angel investors in Europe, only a few hundred are present in Poland. Equity crowdfunding has not been very popular among Polish companies (in 2015 only one campaign took place), but this situation has been gradually changing (Eukowski and Zygmanowski 2019). The reason for the relatively low popularity of the alternative sources of founding among Polish companies are a lack of knowledge of equity crowdfunding by entrepreneurs from one side, and unfavourable legal conditions from the other one (Kozioł-Nadolna 2018). However, as Łukowski and Zygmanowski (2019) show, the companies from the technology and finance sectors are the early and eager adopters of this form of financing.

Although the respondents of our survey marked access to capital as less relevant risk factor, we should bear in mind that most of the FinTechs in Poland are startups or young companies, and especially during the crisis time a problem of raising capital to start a new business may appear.

\subsection{Suggestions for Policy Makers}

When we asked our respondents what kind of policy implemented by the state entities might enable their future development, the majority indicated special regulations from the Polish government (65\%). Slightly fewer respondents pointed to sandboxes (56\%) and just behind them tax reliefs ( $46 \%$ ) as possible stimulus for a sector development. The survey enabled choosing more than one answer.

In Figure 12, we present the suggested changes of policy indicated by the FinTechs across the fields. What we observe, is that the special regulations have been chosen most frequently, and by each group (apart from the InsureTech that chose the option other). Regulatory sandboxes have been the second popular option chosen. This result once again confirms the need for proper legislation to enable the full development of the FinTech services. 


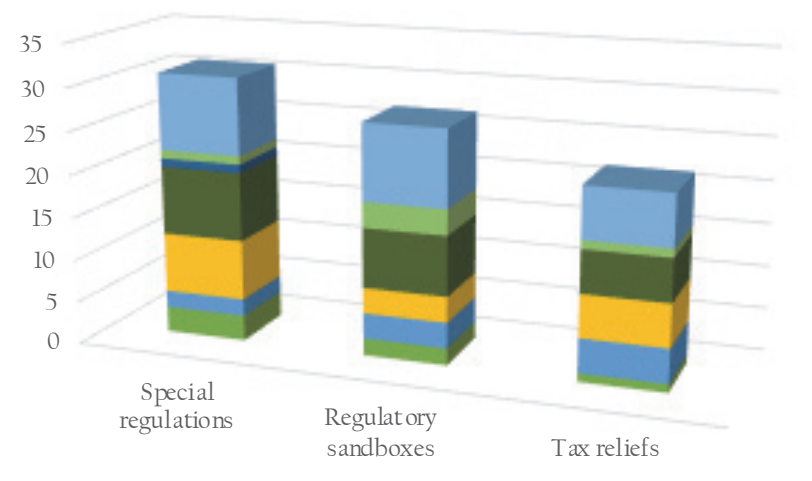

\begin{tabular}{|l|c|c|c|}
\cline { 2 - 4 } \multicolumn{1}{c|}{} & Special regulations & $\begin{array}{c}\text { Regulat ory } \\
\text { sandboxes }\end{array}$ & Tax reliefs \\
\hline - Payment & 9 & 9 & 6 \\
\hline - Investment Management & 1 & 3 & 1 \\
\hline - Insurance & 0 & 0 & 0 \\
\hline - Distributed ledger & 1 & 0 & 0 \\
\hline - Deposit and lending & 8 & 7 & 5 \\
\hline - Banking infrastructure & 7 & 3 & 5 \\
\hline - Analytics & 2 & 3 & 4 \\
\hline - Accountech & 3 & 2 & 1 \\
\hline
\end{tabular}

Figure 12. Expected government support—by field.

The companies mentioned also other kind of possible support, such as:

- Providing various sources of financing for start-ups;

- Intensifying the dialogue with developing companies from the FinTech industry;

- An active regulatory and organizational support, as well as the adoption of interesting solutions offered by FinTechs (FinTechs are en mass too small organizations to successfully promote good ideas by themselves).

It is worth to note that the above insights are in line with the KNF recommendation mentioned in Section 6.4 of this report, and the answers given to the question about the specific problems (see Table 6). Analytics, deposit, and lending, banking infrastructure, as well as investment management companies chose regulations one of the most burning issues. The mean value in these groups was equal at least 8.00 , while in the payment sector it was 7.25. Only among the Accountech companies, it was relatively low (4.67). All the results show that there is a demand for clear regulations, and providing them is decisive for the future development of FinTech.

\section{Discussion and Conclusions}

In the paper, we present the stage of the development of the Polish FinTech sector and identify the main opportunities and challenges to the formation of new companies. The conclusions are formulated based on the literature review and the results of the survey run among the Polish FinTech sector in January 2020. Haddad and Hornuf (2018) documents that FinTech startups formation need not be left to chance, but active policies can influence the emergence of this new sector. Thus, the survey aimed to identify the most pressing issues for improvement.

We summarize our findings in Table 8. We refer to the factors identified in Table 1 and divide them into ones that support and pose a threat to the FinTech development in Poland.

To summarize, Poland is a fast-growing market for FinTechs. It satisfies the requirements mentioned in various studies, such as the number of secure Internet servers, mobile 
telephone subscriptions, the available labor force, as well as growing tertiary education enrolment rate (Haddad and Hornuf 2018; Laidroo and Avarmaa 2019). Moreover, we observe positive trends in education, such as the constantly rising interest in IT, economics, and finance. As an opportunity for sector growth, we also recognize the fact that banks are not treated as competitors by the Polish FinTech sector. There is a collaboration that is profitable to both sides. The respondents expect that the banks will be adopting new technologies more eagerly soon, and they will modernize and digitalize. They also assume future partnerships with banks.

The results of our survey reveal, however, that there are also conditions that are not satisfied. Most importantly, the study demonstrates that regulations are the main obstacle for FinTech development. The companies consider them ambiguous, imprecise and requiring too much bureaucracy. FinTechs claimed that the rules are backward, neither follow the rapidly changing reality nor take the existence of the FinTechs into account. Another risk factor for the FinTech development is the availability of highly-skilled workers (which may stem from the fact that Poland is especially badly rated when it comes to keeping and attracting talents), and the availability of customers. Additionally, Poland lacks strong university-industry cooperation, which was underlined by our respondents in the open-answer questions. The companies mentioned the problems with access to the funds by startups as well.

Table 8. Factors supporting and posing the risk to FinTech formation and development in Poland.

\begin{tabular}{|c|c|c|}
\hline Category & Opportunities & Risk Factors \\
\hline Financing system & $\begin{array}{l}\text { Well developed banking system, } \\
\text { openness to financial innovations }\end{array}$ & $\begin{array}{l}\text { Venture capital financed } \\
\text { mainly by government }\end{array}$ \\
\hline $\begin{array}{l}\text { FinTechs versus } \\
\text { banks }\end{array}$ & Mutual cooperation & Legislation favours banks \\
\hline $\begin{array}{l}\text { Available } \\
\text { technology }\end{array}$ & $\begin{array}{l}\text { Increasing number } \\
\text { of mobile phone subscription, } \\
\text { and of secure internet services }\end{array}$ & $\begin{array}{l}\text { Smartphones penetration below EU average, } \\
\text { cloud servers located outside of Poland }\end{array}$ \\
\hline $\begin{array}{l}\text { Level of trust } \\
\text { in financial incumbents }\end{array}$ & $\begin{array}{l}\text { Trust in banking system } \\
\text { above average }\end{array}$ & $\begin{array}{l}\text { The overconfidence may result in the } \\
\text { improper assessment of real risks }\end{array}$ \\
\hline Home demand & $\begin{array}{l}\text { Openness to financial } \\
\text { innovations }\end{array}$ & $\begin{array}{l}\text { Problems with } \\
\text { finding customers }\end{array}$ \\
\hline Education & Positive trends in education & Weak university-industry cooperation \\
\hline Regulations & Innovation Hub, sandboxes & $\begin{array}{l}\text { Regulations not sufficient for FinTechs; } \\
\text { high level of bureaucracy }\end{array}$ \\
\hline $\begin{array}{l}\text { Knowledge in } \\
\text { IT and financial } \\
\text { sector }\end{array}$ & $\begin{array}{l}\text { Increasing number } \\
\text { of students in IT, } \\
\text { finance and economics }\end{array}$ & $\begin{array}{l}\text { Poland is badly rated for both } \\
\text { keeping and attracting talents }\end{array}$ \\
\hline $\begin{array}{l}\text { IT and } \\
\text { financial sectors } \\
\text { productivity }\end{array}$ & $\begin{array}{l}\text { Improved performance } \\
\text { of high technology exports } \\
\text { as a share of manufactured exports }\end{array}$ & $\begin{array}{l}\text { ITC goods exports: only } 2 \% \text { in } \\
\text { commercial services exports, } \\
\text { (EU average: } 7 \% \text { ) }\end{array}$ \\
\hline Crisis & $\begin{array}{l}\text { Increased demand for } \\
\text { FinTechs services }\end{array}$ & Weaker opportunities for start-up financing \\
\hline
\end{tabular}

Some policy implications can be formulated based on the presented analysis. First of all, there is still a need to improve current legislation to make the process more innovationoriented. However, the regulatory changes should be preceded by the debate with the sector itself. Sandboxes are considered a good incentive for development by the majority of the FinTechs. Lastly, especially in a crisis time, tax reliefs would significantly support the sector. Moreover, the government should support the collaboration between the industry and the academic environment, since currently, it is quite scarce. Eventually, since one of the major 
concerns of the FinTech sector is the possible problem with the access to qualified staff, there is a need to further support and enhance the creation of technically-oriented degree courses at the universities, to provide an adequate number of highly-skilled workers in the market.

In the end, the results of our study enable us to provide policy implications for FinTech managers. First of all, they could initiate the cooperation with universities, for instance through focused guest lectures, and in this way enhance the formation of further skilled staff (we note that the IT labour market is at the moment one of the most competitive ones, characterized by the lowest unemployment rate and the shortest time to find a job). It should also be profitable for FinTechs to sustain cooperation with banks, whom the Polish citizens trust. Eventually, to prevent home demand problems, the companies may follow the consumers' trends and adapt their offer accordingly.

Finally, we would like to outline that our research has some limitations. First of all, our sample covered 48 companies out of 233 , and thus the obtained responses do not reflect the view of the whole population. The subsector of InsureTech, as well as Distributed Ledger, was underrepresented, and hence we should be aware of the possible bias when we formulate the conclusions for the whole sector. The second limitation is the fact that the survey was run just before the COVID pandemic outbreak. The environment and the demand for the FinTech services and the sentiment of the companies might have changed. Moreover, some legal solutions that FinTechs had hoped for, have been already implemented. The current situation-the crisis-is an opportunity itself for the companies from the Distributed Ledger or Payments sectors. On the other hand, the overall crisis may be harmful to others. The VC financing, which in the Polish case has been mostly supported by the government, may be limited in the future. It would restrain the development of new companies. The FinTechs outside the payment-related sector may also suffer, especially those that support the tourism or travelling sectors. Thus, the current conditions may affect and reshape the FinTech sector in Poland.

In future research, we plan to run the next round of the survey among the FinTechs in Poland and verify how the results changed in the after-pandemic economic environment. Ideally, such surveys could be repeated in the future (also across different countries), to monitor the rapidly developing Fintech environment, support its development, successfully monitor risk sources and formulate recommendations for state authorities.

Author Contributions: Conceptualization: B.B.-S. and A.K.; methodology: B.B.-S. and A.K.; formal analysis: B.B.-S., A.K., A.R. and K.Ś.; investigation, B.B.-S., A.K., A.R. and K.Ś.; data curation: A.K. and A.R.; writing-original draft preparation: B.B.-S. and A.K.; writing-review and editing: B.B.-S., A.K., A.R. and K.Ś.; visualization: A.K. and A.R.; funding acquisition, A.K. All authors have read and agreed to the final version of the manuscript.

Funding: This research was funded by the National Science Center through the project NCN MINIATURA 2019/03/X/HS4/01025 as well as Regional Initiative for Excellence programme of the Minister of Science and Higher Education of Poland, years 2019-2022, grant No. 004/RID/2018/19, financing 3,000,000 PLN.

Institutional Review Board Statement: Not applicable.

Informed Consent Statement: Not applicable.

Data Availability Statement: Data is available from authors upon reaasonable request.

Acknowledgments: We would like to thank Quantify and Quantfin for the help with obtaining the data, as well as all the respondents of our survey. We thank anonymous Referees for detailed reviews and suggestions. Eventually, we would like to thank the participants of the (virtual) International Conference on Finance and Economic Polity (ICOFEP) 2020 for the fruitful comments and discussion.

Conflicts of Interest: The authors declare no conflict of interest.

\section{Appendix A. List of the Participants of the Survey}

The FinTechs who participated in our survey were: AssetLife, BanqUP, Beesfund, Bee-Tech, BillTech, Blik, Braintri (Neontri), Brutto.pl, BSS PolandSA, Centreo, Coderion, 
Comperia, Currency One, Digital Teammates, Empirica, ePortfel24.pl, Faktorama, Find Funds, FinPack, Greencash, hiPRO, HOTPAY, Identt, Jakdojade, Let's Pay (PerceptusSA), Monevia, NicePay (1PayPolandSp. zo.o.), NuDelta, Payholding, PaymentTechnology, PDU, Scanye, SCFO, SportBonus, Squaber, Star Funds, Storyous, Straal, Taxxo (Columb Technologies S.A.), Tpay (Ferbuy), Trefix, Urban.one, Velochron, VoiceLab, WWWASH, Ybanking, zbiletem.pl, zrzutka.pl.

\section{References}

Anagnostopoulos, Ioannis. 2018. Fintech and regtech: Impact on regulators and banks. Journal of Economics and Business $100:$ 7-25. [CrossRef]

Anielak, Karolina. 2019. Fintech as a source of financial innovations on the Polish financial services market. Zeszyty Naukowe SGGW w Warszawie-Problemy Rolnictwa Światowego 19: 162-71. [CrossRef]

Ankenbrand, Thomas, Andreas Dietrich, and Denis Bieri. 2018. IFZ FinTech Study 2018: An Overview of Swiss FinTech. Lucerne: Lucerne University of Applied Sciences and Art, Institute of Financial Services Zug IFZ.

Baba, Chikako, Cristina Batog, Enrique Flores, Borja Gracia, Izabela Karpowicz, Piotr Kopyrski, James Roaf, Anna Shabunina, Rachel Elkan, and Xin Cindy Xu. 2020. Fintech in Europe: Promises and Threats. IMF Working Paper 20/241. Available online: https:/ / www.imf.org/en/Publications/WP/Issues/2020/11/13/Fintech-in-Europe-Promises-and-Threats-49859 (accessed on 26 January 2021).

Basel Committee on Banking Supervision. 2018. Sound Practices-Implications of FinTech Developments for Banks and Bank Supervisors. Available online: https://www.bis.org/bcbs/publ/d431.htm (accessed on 26 January 2021).

Bömer, Max, and Hannes Maxin. 2018. Why fintechs cooperate with banks-Evidence from Germany. Zeitschrift für die Gesamte Versicherungswissenschaft 107: 359-86. [CrossRef]

Brown, Ross, Jose Liñares-Zegarra, and John O. S. Wilson. 2019. The (potential) impact of Brexit on UK SMEs: Regional evidence and public policy implications. Regional Studies 53: 761-70. [CrossRef]

Bunea, Sinziana, Benjamin Kogan, and David Stolin. 2016. Banks versus fintech: At last, it's official. Journal of Financial Transformation 44: 122-31.

CEE Capital Market Leaders Forum. 2019. FinTech in the CEE Region. Available online: https://paga.org.pl/wp-content/uploads/20 19/12/ fintech-in-the-cee-region.pdf (accessed on 26 January 2021).

Chen, Rongda, Huiwen Chen, Chenglu Jin, Bo Wei, and Lean Yu. 2020. Linkages and spillovers between internet finance and traditional finance: Evidence from china. Emerging Markets Finance and Trade 56: 1196-210. [CrossRef]

Cojoianu, Theodor F., Gordon L. Clark, Andreas G.F. Hoepner, Vladimir Pažitka, and Dariusz Wojcik. 2020. Fin vs. tech: Are trust and knowledge creation key ingredients in fintech start-up emergence and financing? Small Business Economics. [CrossRef]

Dealroom and Finch Capital. 2019. The State of European FinTech. Available online: https://blog.dealroom.co/wp-content/uploads/ 2019/10/The-State-of-European-Fintech-2019.pdf (accessed on 26 January 2021).

Deloitte. 2019. Fintech by the Numbers. Available online: https://www2.deloitte.com/ (accessed on 26 January 2021).

Eickhoff, Matthias, Jan Muntermann, and Timo Weinrich. 2017. What Do FinTechs Actually Do? A Taxonomy of FinTech Business Models. Paper presented at Thirty Eight International Conference on Information Systems 2017, Seoul, Korea, December 10-13. Available online: https://www.researchgate.net/publication/320215812_What_do_FinTechs_actually_do_A_Taxonomy_of_ FinTech_Business_Models (accessed on 26 January 2021)

European Central Bank. 2018. Survey on the Access to Finance of Enterprises in the Euro Area-October 2018 to March 2019. Available online: https://www.ecb.europa.eu/stats/ecb_surveys/safe/html/index.en.html (accessed on 26 January 2021).

Flanders Investment and Trade. 2018. FinTech in Poland. Available online: https://www.flandersinvestmentandtrade.com (accessed on 26 January 2021).

GlobalData. 2017. Payments Landscape in Poland: Opportunities and Risks to 2021. London: GlobalData.

Haddad, Christian, and Lars Hornuf. 2019. The emergence of the global fintech market: Economic and technological determinants. Small Business Economics 53: 81-105. [CrossRef]

Hansen, Torben. 2012. Understanding trust in financial services the influence of financial healthiness, knowledge, and satisfaction. Journal of Service Research 15: 280-95. [CrossRef]

ING. 2015. Mobile Banking 2015: Changing Face of Payments in the Digital Age. Available online: https://think.ing.com/reports/ mobile-banking-2015-changing-face-of-payments-in-the-digital-age (accessed on 26 January 2021).

JPMorgan. 2019a. Global Payments Trends Report-Poland Country Insights. Available online: https://www.jpmorgan.com (accessed on 26 January 2021)

JPMorgan. 2019b. J. P. Morgan Global Payment Trends. E-Commerce Payments Trends: Germany. Available online: https://www. jpmorgan.com (accessed on 26 January 2021).

JPMorgan. 2019c. Payment Insights. Available online: https:/ / www.jpmorgan.com (accessed on 26 January 2021).

Kliber, Agata, Barbara Będowska-Sójka, Aleksandra Rutkowska, Katarzyna Świerczyńska, and Wojciech Zdunkiewicz. 2020. FinTechs in Poland: Insights, Trends and Perspectives. Technical Report. Available online: https://www.researchgate.net/publication/3417 26862_FinTechs_in_Poland_Insights_Trends_and_Perspectives (accessed on 26 January 2021). [CrossRef] 
Klimontowicz, Monika, and Krystyna Mitrega-Niestroj. 2019. Fintechs as alternative financial market players. Paper presented at 16 th Annual International Scientific Conference on European Financial Systems, Krakow, Poland, June 15-16. pp. $282-89$.

KNF. 2018. Report on the Activities of the KNF and the KNF Board in 2018. Available online: https://www.knf.gov.pl/knf/en/ komponenty/img/ANNUAL\%20REPORT\%20OF\%20THE\%20ACTIVITIES\%202018_66983.pdf (accessed on 26 January 2021).

KNF. 2020a. Propozycje Barier w Rozwoju Rynku Fintech. Available online: https://www.knf.gov.pl/knf/pl/komponenty/img/ Propozycje_barier_25_02_2020.xls (accessed on 26 January 2021)

KNF. 2020b. Proposal of Regulatory Changes. Available online: https://www.knf.gov.pl/knf/pl/komponenty/img/Projekt_zmian_ regulacyjnych_MF_i_UKNF_dot_FinTech_68816.pdf (accessed on 26 January 2021)

Knight, Eric, and Dariusz Wojcik. 2020. Fintech, economy and space: Introduction to the special issue. Environment and Planning A: Economy and Space 52: 1490-97. [CrossRef]

Kozioł-Nadolna, Katarzyna. 2018. Crowdfunding a model otwartej innowacji. Charakterystyka modeli i platform crowdfundingowych w Polsce. In Crowdfunding w Polsce. Edited by A. Pluszyńska and A. Szopa. Cracow: Wydawnictwo Uniwersytetu Jagiellońskiego, pp. 71-90.

Krzysztofiak-Szopa, Julia, Monika Wisłowska, and Michał Kulbacki. 2019. The Golden Book of Venture Capital in Poland. Warsaw: Startup Poland. Available online: https://www.omgkrk.com/wp-content/uploads/2019/07/The-Golden-Book-of-Venture-Capitalin-Poland-2019.pdf (accessed on 26 January 2021).

Lai, Karen P. Y., Fenghua Pan, Martin Sokol, and Dariusz Wójcik. 2020. New financial geographies of Asia. Regional Studies 54: 143-48. [CrossRef]

Laidroo, Laivi, and Mari Avarmaa. 2019. The role of location in fintech formation. Entrepreneurship \& Regional Development 1-18.

Laidroo, Laivi, Ekaterina Koroleva, Agata Kliber, Ramona Rupeika-Apoga, and Zana Grigaliuniene. 2021. Business Models of FinTechsDifference in Similarity? Working Paper (Under Review, available upon request).

Lee, Eddie. 2020. The Global Financial Crisis Gave Birth to FinTech. What Will COVID-19 Recession Bring? Available online: https:/ / e27.co/the-global-financial-crisis-gave-birth-to-fintech-what-will-covid-19-recession-bring-20200403/ (accessed on 26 January 2021).

Lee, I., and Y. J. Shin. 2018. Fintech: Ecosystem, business models, investment decisions, and challenges. Business Horizons 61: 35-46. [CrossRef]

Liu, Jiajia, Xuerong Li, and Shouyang Wang. 2020. What have we learnt from 10 years of fintech research? A scientometric analysis. Technological Forecasting and Social Change 155: 120022. Available online: http://www.sciencedirect.com/science/article/pii/S004 0162519321869 (accessed on 26 January 2021). [CrossRef]

Łukowski, Michał, and Piotr Zygmanowski. 2019. The role of crowdfunding in reducing the equity gap in Poland. Ruch Prawniczy, Ekonomiczny i Socjologiczny 81: 185-201. [CrossRef]

Microfinance Centre. 2019. The FinTech Market in Poland. Available online: https://mfc.org.pl/wp-content/uploads/2020/03/ POLAND_FINTECH-CASE-STUDY_FEB2020.pdf (accessed on 26 January 2021)

Osterwalder, Alexander, and Yves Pigneur. 2010. Business Model Generation: A Handbook for Visionaries, Game Changers, and Challenges. Hoboken: John Wiley \& Sons.

Palmer, Maija. 2020. Poland's Venture Capital: Inexperienced However, Not "toxic" Sifted. January 13. Available online: https: / / sifted.eu/articles/poland-vc-market/ (accessed on 26 January 2021).

Palmié, Maximilian, Joakim Wincent, Vinit Parida, Umur Caglar. 2020. The evolution of the financial technology ecosystem: An introduction and agenda for future research on disruptive innovations in ecosystems. Technological Forecasting and Social Change 151: 119779. Available online: http:/ / www.sciencedirect.com/science/article/pii/S0040162519310595 (accessed on 26 January 2021). [CrossRef]

Piotrowski, Dariusz. 2020. Trust in the banking sector in Poland in comparison to global trends. Economics and Law 19: 319-32. doi:10.12775/EiP.2020.022. [CrossRef]

PWC. 2019. Crossing the Lines: How FinTech is Propelling FS and TMT Firms Out of Their Lanes. Global FinTech Report. Available online: https://www.pwc.com/gx/en/industries/financial-services/assets/pwc-global-fintech-report-2019.pdf (accessed on 26 January 2021).

Rupeika-Apoga, Ramona, Inna Romānova, and Simon Grima. 2020. FinTech Study Latvia 2020. Available online:: https://www. researchgate.net/publication/345904763_FINTECH_STUDY_LATVIA_2020 (accessed on 26 January 2021). [CrossRef]

Sannino, Giuseppe, Ferdinando Di Carlo, and Manuela Lucchese. 2020. CEO characteristics and sustainability business model in financial technologies firms. Management Decision 58: 1779-1799. [CrossRef]

Siek, Michael, and Andrew Sutanto. 2019. Impact analysis of fintech on banking industry. Paper presented at IEEE 2019 International Conference on Information Management and Technology (ICIMTech), Jakarta, Indonesia, August 19-20; vol. 1, pp. 356-61.

Staszewska, Aniela. 2018. Fintech in poland: Fintech start-ups versus traditional banking in Poland. Przedsiębiorstwo E Finanse 3: 105-13.

Sung, Anna, Kelvin Leong, Paolo Sironi, Tim O'Reilly, and Alison Mcmillan. 2019. An exploratory study of the fintech (financial technology) education and retraining in UK. Journal of Work-Applied Management 11: 187-98. Available online: http://hdl.handle. net/10034/623594 (accessed on 26 January 2021). [CrossRef] 
Tirmaste, Kersti, Liina Voolma, Laivi Laidroo, Mari-Liis Kukk, and Mari Avarmaa. 2019. FinTech Report Estonia. Available online: https://old.taltech.ee/public/m/majandusanaluusi-ja-rahanduse-instituut/FinTech_Report_Estonia_2019_final.pdf (accessed on 26 January 2021).

Widawski, Paweł, and Miłosz Brakoniecki. 2016. FinTech w Polsce. Bariery i Szanse Rozwoju. Available online: http:/ / fintechpoland. com/wp-content/uploads/2020/01/FinTech_w_Polsce_bariery_i_szanse_rozwoju.pdf (accessed on 26 January 2021).

Zavolokina, Liudmila, Mateusz Dolata, and Gerhard Schwabe. 2016. The FinTech phenomenon: Antecedents of financial innovation perceived by the popular press. Financial Innovation 2: 1-16. [CrossRef]

Zetzsche, Dirk, Ross P. Buckley, Douglas W. Arner, and Janos N. Barberis. 2017. From fintech to techfin: The regulatory challenges of data-driven finance. SSRN Electronic Journal. Available online: https://papers.ssrn.com/sol3/papers.cfm?abstract_id=2959925 (accessed on 26 January 2021). [CrossRef] 

MDPI

St. Alban-Anlage 66

4052 Basel

Switzerland

Tel. +41 616837734

Fax +41 613028918

www.mdpi.com

Risks Editorial Office

E-mail: risks@mdpi.com www.mdpi.com/journal/risks

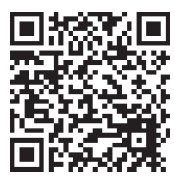



MDPI

St. Alban-Anlage 66

4052 Basel

Switzerland

Tel: +41 616837734

Fax: +41 613028918 